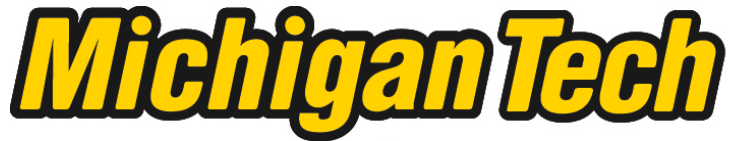 \\ Michigan Technological University Create the Future Digital Commons @ Michigan Tech
}

\section{DEVELOPMENT OF PRACTICAL APPLICATIONS FOR REPRAP STYLE 3-D PRINTERS IN ENGINEERING}

Benjamin T. Wittbrodt

Michigan Technological University

Follow this and additional works at: https://digitalcommons.mtu.edu/etds

Part of the Materials Science and Engineering Commons Copyright 2014 Benjamin T. Wittbrodt

\section{Recommended Citation}

Wittbrodt, Benjamin T., "DEVELOPMENT OF PRACTICAL APPLICATIONS FOR REPRAP STYLE 3-D PRINTERS IN ENGINEERING", Master's Thesis, Michigan Technological University, 2014.

https://doi.org/10.37099/mtu.dc.etds/962

Follow this and additional works at: https://digitalcommons.mtu.edu/etds

Part of the Materials Science and Engineering Commons 


\title{
DEVELOPMENT OF PRACTICAL APPLICATIONS FOR REPRAP STYLE 3-D PRINTERS IN ENGINEERING
}

\author{
Benjamin T. Wittbrodt
}

\begin{abstract}
A THESIS
Submitted in partial fulfillment of the requirements for the degree of MASTER OF SCIENCE

In Materials Science and Engineering
\end{abstract}

MICHIGAN TECHNOLOGICAL UNIVERSITY

2014

(C) 2014 Benjamin T. Wittbrodt 
This thesis has been approved in partial fulfillment of the requirements for the Degree of MASTER OF SCIENCE in Materials Science and Engineering.

Department of Materials Science and Engineering

\author{
Thesis Advisor: $\quad$ J oshua M. Pearce \\ Committee Member: $\quad$ Paul G. Sanders \\ Committee Member: J J ohn Irwin
}

Department Chair: $\quad$ Stephen L. Kampe 
To all those who had to listen to the words 3-D printing from me every day for 3 years 
Table of Contents:

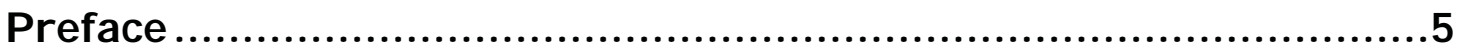

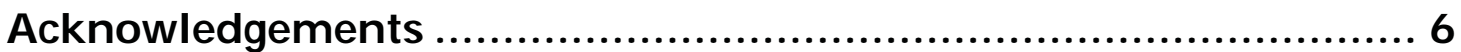

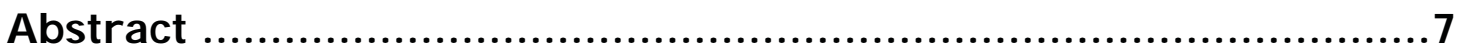

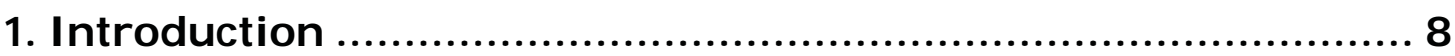

2. Life-Cycle Economic Analysis of Distributed

Manufacturing with Open-Source 3-D Printers ........................ 11

3. Distributed Manufacturing with 3-D Printing:

A Case Study of Recreational Vehicle Solar

Photovoltaic Mounting Systems ........................................... 38

4. Total Cost Evaluation of Low-Weight Tension-Based

Photovoltaic Flat-Roof Mounted Racking ...............................56

5. 3-D Printing Solar Photovoltaic Racking in

Developing World ........................................................... 77

6. The Effects of PLA Color on Material Properties

of 3-D Printed Components .................................................. 93

7. Future Work ................................................................... 111

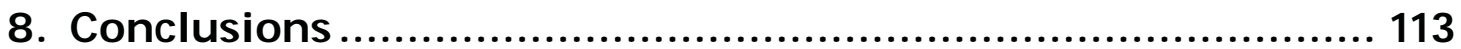

Appendix .......................................................................... 114 


\section{Preface:}

Included in this work is a selection of previously published, or submitted, work completed by the author of this thesis.

The list of previous work include:

Ch. 2: B. T. Wittbrodt, A. G. Glover, J . Laureto, G. C. Anzalone, D. Oppliger, J . L. Irwin, J . M. and Pearce, Life-Cycle Economic Analysis of Distributed Manufacturing with Open-Source 3-D Printers, Mechatronics 23 (2013) 713726.

Wittbrodt: Data collection, writing. Glover: Data analysis, writing. Laureto: Data analysis, writing. Anzalone: Writing. Oppliger: Writing. Irwin: Writing. Pearce: Writing, Review.

Ch. 3: Distributed Manufacturing with 3-D Printing: Recreational Vehicle Solar Photovoltaic Mounting. Co-Authors: J. Laureto, B. M. Tymrak, J . M. Pearce

Wittbrodt: Data collection, writing. Laureto: Data collection, writing. Tymrak: Analysis, writing. Pearce: Writing, review.

Ch. 4: Total Cost Evaluation of Low-Weight Tension-Based Photovoltaic FlatRoof Mounted Racking. Co-Author: J. M. Pearce

Wittbrodt: Data collection, design, analysis, writing. Pearce: Writing, review.

Ch. 5: RepRap 3-D Printing of Solar Photovoltaic Racking for Renewable Energy Deployment in the Developing World. Co-Author: J . M. Pearce Wittbrodt: Data collection, design, analysis, writing. Pearce: Writing, review.

Ch. 6: The Effects of PLA Color on Material Properties of 3-D Printed Components. Co-Author: J . M. Pearce

Wittbrodt: Data collection, design, analysis, writing. Pearce: Writing, review. 


\section{Acknowledgements:}

I would like to thank Dr. Paul Sanders, and Dr. J ohn Irwin for taking the time to serve as my committee members.

I would also like to send my sincerest thanks to my undergraduate and graduate research advisor Dr. J oshua Pearce for his continued patience, encouragement, guidance, enthusiasm, and support over these last 2 and one-half years that we have been working together. His experience in this field have proven to be invaluable in my development in a researcher and my exposure to the 3-D printing and open-source community. 


\begin{abstract}
:
The current rise in popularity of consumer level 3-D printers introduces a need to understand the application and material property capabilities of the technology. Presented here is data demonstrating the ability for the average U.S. consumer to recuperate the cost of a 3-D printer within one year of ownership. Additionally, using a consumer level 3-D printer, multiple photovoltaic (PV) racking systems were printed and produced with much lower cost compared to commercially available aluminum racking. Additionally, mechanical testing on 3-D printed components showed a temperature dependence on both percent crystallinity and ultimate tensile strength. Conclusions are drawn using the information to describe the potential uses and applications of RepRap (Self Replicating Rapid Prototyper) style 3-D printers and their validity as an engineering tool.
\end{abstract}




\section{1- Introduction}

Although 3-D printing technology has been prevalent in the industrial setting for over 30 years, the large cost of entry has been prohibitive for small businesses, education, and the home setting [1]. In 2006, Dr. Adrian Bowyer set out to create a low-cost 3-D printer designed to replicate a portion of parts to construct a new printer, thus introducing the RepRap (Self-Replicating Rapid-Prototyper) [2]. Additionally, RepRap was founded on the idea of decentralized development of 3-D printing technology [3], [4], and therefore all hardware and software are freely available. A sizable community has subsequently developed and, in the 8 years following its creation, RepRap is the number one at-home 3-D printer [5].

RepRap's popularity has facilitated the introduction of 3-D printing into many previously undiscovered notions about the consumption and manufacturing of goods [6], [7]. For example, the RepRap project allows for the decentralization of the manufacturing process from large plants to digital files on an individual's computer [8], allowing for the rapid manufacturing of customized goods, decreases both cost to the end user and the environment [9]. The large cost of photovoltaiv (PV) racking components has begun to encroach on the price of the modules themselves causing making the technology more expensive than necessary opening an opportunity for 3-D printing to be used to decrease that cost. Additionally, the nature of the 3-D printing process can change the properties of the material that it prints, compared to a traditional injection molded piece. Consumer level 3-D printers have been demonstrated to produce comparable parts, in terms of strength, to commercial grade 3-D printers [10]. For the 3-D printing technology to be used in real world engineering applications these changes in material properties must be characterized.

The goal of this thesis, is to expand the use of the RepRap 3-D printer in three main ways: 1) quantifying the reduced at-home costs of consumer goods, 2) reducing balance of cost for PV systems, and 3) obtain real-world data about the material properties to expand the sophistication of 3-D printed products. In Chapter 2 I will complete the first economic analysis of RepRap home ownership by presenting easily 
printed items and compare the electricity and printing material cost to the purchase price of a comparable item. Chapter 3 will present a novel photovoltaic (PV) racking system aimed at small-scale recreational vehicle (RV) applications. This system is analyzed for a direct replacement of commercial aluminum racking components analyzing the strength of the material and the response to expected wind loads. Chapter 4 will provide an alternative racking solution for commercial rooftops with PV modules. Chapter 5 focuses on sustainable long-term development by providing a comparable, small scale, PV racking system tested throughout winter months and under real-world conditions. Chapter 6 focuses on characterizing the material properties of 3-D printed PLA and determining relationships between colors and printing temperature to ultimate tensile strength and percent crystallinity. Chapter 7 consists of future work suggestions to lead the further development of at home 3-D printers. Chapter 8 includes all conclusions drawn from this work and summarizes data collected and the importance of the work.

\subsection{References}

[1] S. Bradshaw, A. Bowyer, and P. Haufe, The intellectual property implications of low-cost 3D printing, ScriptEd 7(1) (2010) 5- 31.

[2] R. Jones, P. Haufe, E. Sells, P. Iravani, V. Olliver, C. Palmer, and A. Bowyer, RepRap - the replicating rapid prototyper, Robotica 29(01) (2011) 177191.

[3] J . M. Pearce, Building Research Equipment with Free, Open-Source Hardware, Science 337(6100) (2012) 1303- 1304.

[4] M. Zschoch, The Success of Open Source, Can. J . Polit. Sci. Can. Sci. Polit. 40(01) (2007) 250- 252.

[5] J . Moilanen and T. Vaden, Manufacturing in motion: first survey on 3D printing communit, [Online] Available: http:/ / surveys.peerproduction.net/ 2012/ 05/ manufacturing-in-motion/ . [Accessed: 21-Nov-2014].

[6] C. Anderson, Makers: The New Industrial Revolution, Crown Business (2012). 
[7] N. Hopkinson and P. Dickens, Rapid prototyping for direct manufacture, Rapid Prototyp. J . 7(4) (2001) 197- 202.

[8] C. Mota, The Rise of Personal Fabrication, in Proceedings of the 8th ACM Conference on Creativity and Cognition, New York, NY, USA, (2011) 279288.

[9] M. Kreiger and J . M. Pearce, Environmental Impacts of Distributed Manufacturing from 3-D Printing of Polymer Components and Products, in Symposium D/ G - Materials for Sustainable Development-Challenges and Opportunities 1492 (2013) 85- 90.

[10] B. M. Tymrak, M. Kreiger, and J. M. Pearce, Mechanical properties of components fabricated with open-source 3-D printers under realistic environmental conditions, Mater. Des. 58 (2014) 242- 246. 


\section{2 - Life-Cycle Economic Analysis of Distributed Manufacturing with Open-Source 3-D Printers ${ }^{1}$}

\subsection{Introduction}

The technological development of additive manufacturing and 3-D printing has been substantial, fueling rapid growth in commercial rapid prototyping as it has proven useful for both design and small-batch production [1-8]. There has been speculation by the Economist that these technical advances could result in a 'third industrial revolution' governed by mass-customization and digital manufacturing following traditional business paradigms [9]. However, the recent development of open-source 3-D printers makes the scaling of mass-distributed additive manufacturing of high-value objects technically feasible at the individual or household level [10-18]. These 3-D printers are self-replicating rapid prototypers (RepRaps), which manufacture approximately half of their own mechanical components ( $57 \%$ self replicating potential, excluding fasteners, bolts and nuts) from sequential fused deposition of a range of polymers and use common hardware $[11,19,20]$. The RepRap is a mechatronic device consisting of a combination of printed mechanical components, stepper motors for 3-D motion and extrusion, and a hot-end for melting and depositing sequential layers of polymers; all of which is controlled by an open-source micro-controller such as the Arduino [21,22]. The extruder intakes a filament of the working material (polyactic acid (PLA), acrylonitrile butadiene styrene (ABS), and high-density polyethylene (HDPE) among other materials [23,24]), melts it using resistive heating, and extrudes it through a nozzle. RepRaps have been proposed and demonstrated to be useful for standard prototyping and engineering [19], education [25], customizing scientific equipment [26], chemical reactionware [27], electronic sensors [28], wire embedding [29], tissue engineering [30] and appropriate technology-related product manufacturing for sustainable development [14]. Despite this wide array of applications, RepRaps are relatively simple mechatronic devices. Historically, mechatronics has been relatively isolated as specialist discipline, but now the advent

1 The material contained in this chapter was previously published in Mechatronics 
of the RepRap with its inherent open-source nature offers the potential for widespread proliferation of mechatronics education and participation. However, in order for this technology to become as ubiquitous as are common 2-D electronic printers, the RepRap must be economically viable for the standard household.

This study reports on the life-cycle economic analysis (LCEA) of RepRap technology for an average U.S. household. A new low-cost RepRap is described and the costs of materials and time to construct it are quantified. The costs for a selection of open-source printable designs that a typical family might purchase are quantified for print time, energy, and filament consumption and compared to low and high market prices for similar products. The results of this life-cycle economic analysis, the developmental trends including environmental impact, and comparison with commercial 3-D printers are discussed and conclusions are drawn about the future of distributed manufacturing.

\subsection{Material and Methods}

A new variant of the Prusa Mendel RepRap shown in Figure 2.1 was used to print the physical parts for an LCEA analysis. The RepRap bill of materials (BOM) and printed parts list are shown in Appendix A and B, respectively. The capital cost ( $\mathrm{C}_{\text {RepRap}}$ ) of the RepRap was calculated by summing the individual costs of the BOM and the necessary printed components. The printers have an approximately cubic build envelope with sides $18 \mathrm{~cm}$ in length with a print rate of $60 \mathrm{~mm} / \mathrm{s}$ (although the printers are capable of $120 \mathrm{~mm} / \mathrm{s}$ ). The RepRap used here had a $0.5 \mathrm{~mm}$ diameter nozzle, $0.1 \mathrm{~mm}$ positioning accuracy and used 0.2 or $0.25 \mathrm{~mm}$ layer thickness, depending on the detail necessary for the print. 


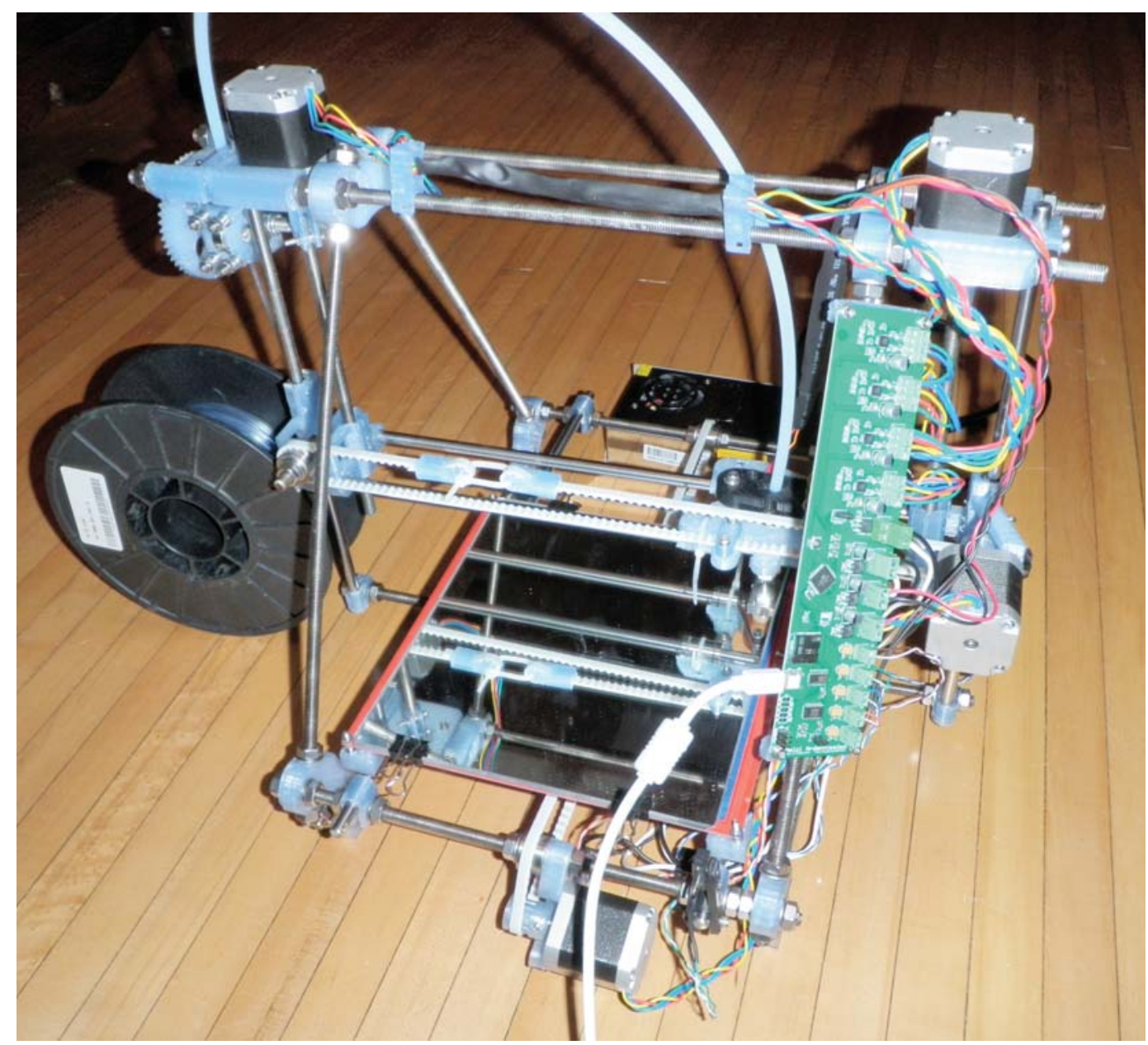

Figure 2.1: A new variant of the Prusa Mendell RepRap and open-source 3-D printer capable of fabricating about half of its own parts. In the picture all the translucent blue parts were printed on an identical mechatronic machine.

The growth rate of open-source designs was determined by recording the date and posted item number on Thingiverse. Twenty open-source designs were selected from over 100,000 items in the Thingiverse repository [31], which met the following criteria: 1) printable in PLA with existing RepRap technology, 2) have a commercially available direct substitute, and 3) are likely to be purchased or owned by an average American household.

\subsection{Calculations}


The high and low commercial costs for each product were found using a Google Shopping search in February 2013 from conventional brick and mortar retailers, excluding shipping costs. It should be noted that shipping for low-value products often dominated total cost, but was nevertheless ignored to ensure conservative estimates of return. Operating costs for the RepRap-produced products $\left(\mathrm{O}_{\mathrm{p}}\right)$ were calculated using energy and filament consumption as measured and described below, applying the U.S. average electric rate of $\$ 0.1174 / \mathrm{kW}-\mathrm{hr}$ [32] and the average cost of PLA [33] as follows:

\section{$\mathrm{O}_{\mathrm{p}}=\mathrm{EC}_{\mathrm{e}}+\mathbf{1 0 0 0 m}_{\mathrm{f}} \mathrm{C}_{\mathrm{f}}[\mathrm{US} \$ /$ part $]$}

(1)

where $\mathrm{E}$ is energy use in $\mathrm{kW}-\mathrm{hr}, \mathrm{C}_{\mathrm{e}}$ is the average U.S. electric rate in $\mathrm{US} \$, \mathrm{~m}_{\mathrm{f}}$ is the filament mass consumed in grams $\left(\mathrm{m}_{\mathrm{f}}\right.$ also includes any support material that needed to be printed for a specific part), and $\mathrm{C}_{\mathrm{f}}$ is the cost of the filament in US $\$ / \mathrm{kg}$. The total cost of a RepRap produced product is:

$$
\mathbf{P}_{\text {RepRap }}=\Sigma \mathbf{O}_{\mathbf{p}}+\Sigma A \quad[\mathrm{US} \$ / \text { product }] \quad \text { (2) }
$$

where A represents the cost of individual non-printed components in \$US.

Prints were made with PLA using with a bed temperature of $65^{\circ} \mathrm{C}$ and extruder temperature of $190^{\circ} \mathrm{C}$. Both the layer height and infill percentages are shown in Table 1 as they varied for the item being printed (e.g products such as the garlic press that require increased mechanical strength were printed with $100 \%$ fill, while lightly-loaded products like the spoon holder were printed with $10 \%$ fill).

Energy use was measured during extrusion with a multimeter ( $\pm 0.005 \mathrm{~kW}$-hr) for each part during printing. Energy required for pre-heating the stage was measured 10 times and averaged. Filament use is estimated by the open-source slicing software, Cura [34] and then verified by massing $( \pm 0.05 \mathrm{~g})$ on a digital scale. The avoided costs $\left(\mathrm{C}_{\mathrm{a}}\right)$ for a product is the difference between the cost to print with the RepRap, which includes a factor for failed prints (determined from Appendix B by measuring the bad prints on a new RepRap with a user performing initial prints for parts for another RepRap). The percent change is given by:

\section{$\left(P_{\text {RepRap }}-\mathbf{P}_{\mathbf{c}}\right) / \mathbf{P}_{\text {RepRap }} \times 100 \%=C_{a} / P_{\text {RepRap }} \mathbf{1 0 0} \%$ [percent]}

for the low $\left(\mathrm{P}_{\mathrm{c}-\text { low }}\right)$ and high $\left(\mathrm{P}_{\mathrm{c}-\text { high }}\right)$ retail costs respectively. The simple payback time 
$\left(\mathrm{t}_{\mathrm{pb}}\right)$ of the RepRap is given by:

$$
\left.\mathbf{t}_{\mathrm{pb}}=\mathbf{C}_{\text {RepRap }} / \Sigma \mathbf{C}_{\mathbf{a}}=\mathbf{C}_{\text {RepRap }} / \Sigma\left(\mathbf{P}_{\text {RepRap }}-\mathbf{P}_{\mathrm{c}}\right) \quad \text { [years }\right]
$$

where $\mathrm{C}_{\text {RepRap }}$ is the cost of the RepRap and the sum is taken over a collection of products avoided for purchasing by 3-D printing. The approximate return on investment (R) for a RepRap in percent following [35] can be given by:

$$
t_{p b}=\left(1-e^{R T}\right) / R \quad \text { [years] }
$$

(5)

where $T$ is the lifetime of the RepRap in years and assumed to be at least 3 years. The durability of the machine has yet to be proven in longer-term real-world testing, however it is clear that a large portion of the machine can be printed, and therefore replaced when parts wear out. In the same way, the RepRap can be upgraded.

\subsection{Results and Discussion}

\subsubsection{Growth of Open-source Designs}

The growth rate of open-source designs is shown in Figure 2 as a function of time. It should be noted that this is the total number of designs and a high estimate for those listed on Thingiverse as this includes designs that were deleted by users or by Makerbot Industries, the host of the site, for any form of content restrictions (e.g. weapons, pornography, etc.). Thingiverse, however, is not the only repository of open-source designs as they are also stored on Google Sketchup 3-D Warehouse, 123D Content, 3Dvia, Shapeways 3-D parts database, Appropedia, Github and the GrabCAD library. Thus the data in Figure 2 should be indicative of the growth rate not the total number of open-source designs. As can be seen from Figure 2.2 the growth has been rapid and can be fit with an exponential growth function. As of J une 6, 2013 there were over 101,150. 


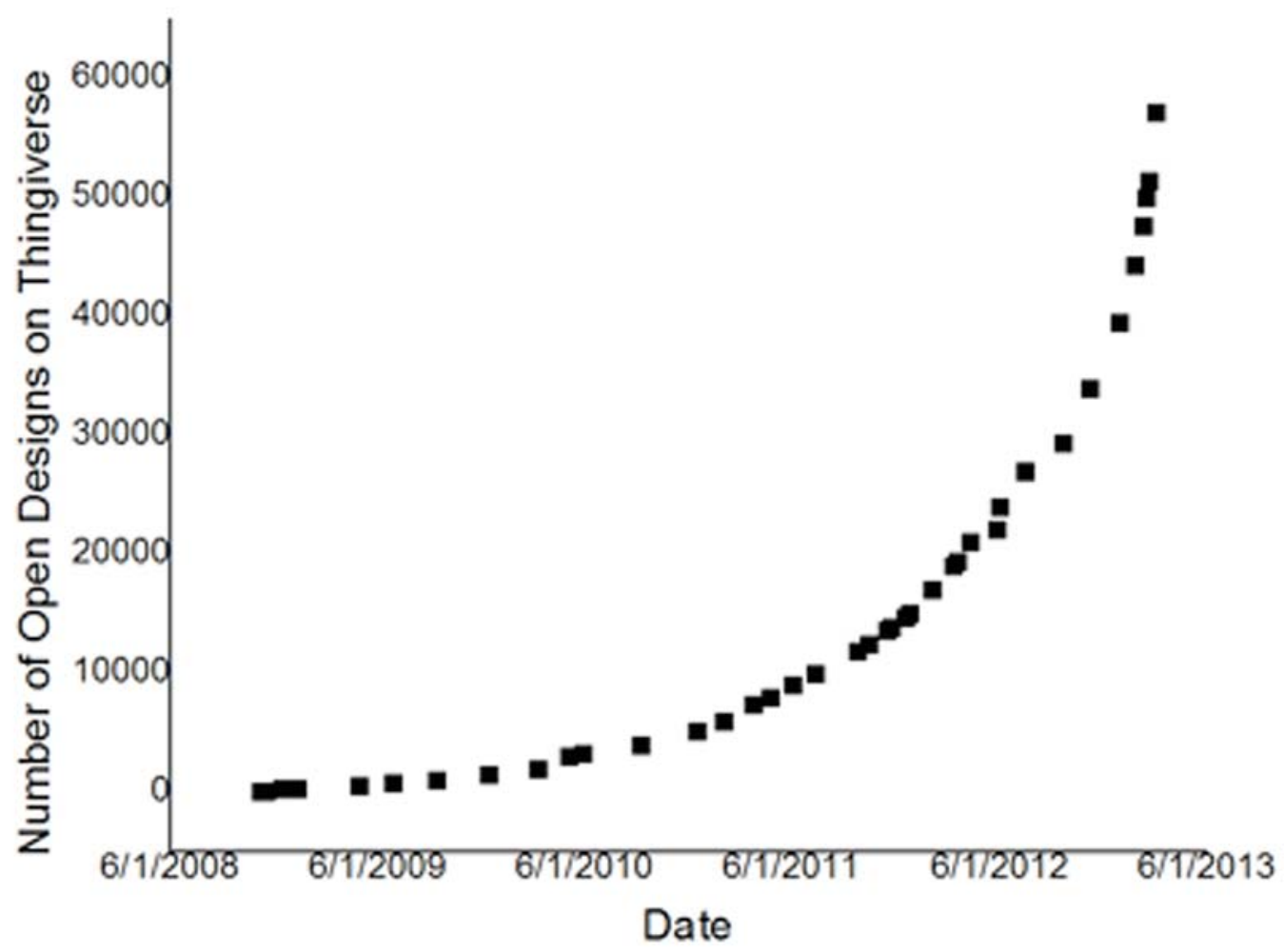

Figure 2.2: The approximate number of open-source designs on Thingiverse, which can be printed on an open-source 3-D printer, as a function of date.

\subsubsection{Open-source 3-D Printing Fabrication Times and Energy Use}

Of these 100,000 designs the 20 designs were chosen (or less than $0.02 \%$ of those available only on one repository) for analysis and are listed along with their Thingiverse thing number in Table 2.1. The designs can be downloaded from www.thingiverse.com/ thing:[thing number]. In addition Table 2.1 quantifies both the Cura sliced theoretical PLA filament length, mass, and estimated print time along with the experimentally verified mass, energy consumed in $\mathrm{kW}$-hrs and print times. 
Table 2.1: Selected open-source designs that are printable on a RepRap with both Cura slicing simulations and experimentally measured values of energy, mass and print time.

\begin{tabular}{|c|c|c|c|c|c|c|c|c|c|c|c|c|c|c|c|}
\hline \multirow[b]{2}{*}{ Product } & \multirow[b]{2}{*}{ Thing: } & \multicolumn{6}{|c|}{ Cura Slicing Simulaticn Estimates } & \multicolumn{2}{|c|}{$\begin{array}{c}\text { All } \mathrm{kWh} \\
\text { experimental }\end{array}$} & \multicolumn{6}{|c|}{ Experimentally Measured Values } \\
\hline & & Meters & $\begin{array}{c}\text { Mass } \\
\text { (g) }\end{array}$ & Infill & $\begin{array}{l}\text { Layer } \\
\text { height } \\
(\mathrm{mm})\end{array}$ & $\begin{array}{c}\text { Nozzle } \\
\text { diameter } \\
(\mathrm{mm})\end{array}$ & $\begin{array}{l}\text { Estimated } \\
\text { Print Time }\end{array}$ & $\mathrm{kWh} / \mathrm{g}$ & $\mathrm{kWh} / \mathrm{hr}$ & $\begin{array}{c}\text { Actual Print } \\
\text { Time }\end{array}$ & $\begin{array}{l}\text { Time } \\
(\min .)\end{array}$ & $\mathrm{kWh}$ & Mass (g) & $\mathrm{kWh} / \mathrm{g}$ & $\mathrm{kWh} / \mathrm{hr}$ \\
\hline iPhone 5 dock & 33338 & 5.87 & 53.2 & 0.5 & 0.25 & 0.5 & $1: 35: 00$ & 0.0053 & 4.2442 & $2: 04: 30$ & 124.50 & 0.28 & 46.2 & 0.0061 & 3.2386 \\
\hline iPhone 4 dock & 6931 & 2.65 & 24.02 & 0.3 & 0.25 & 0.5 & $0: 45: 15$ & 0.0042 & 3.1823 & $0: 56: 26$ & 56.43 & 0.1 & 19.5 & 0.0051 & 2.5517 \\
\hline iPhone 5 case & 43279 & 1.05 & 9.51 & 1 & 0.2 & 0.5 & 0:23:00 & 0.0042 & 2.5043 & $0: 33: 27$ & 33.45 & 0.04 & 7.5 & 0.0053 & 1.7220 \\
\hline Jewelry Organizer & 45003 & 2.8 & 25.39 & 0.1 & 0.25 & 0.5 & $0: 48: 00$ & 0.0032 & 2.4000 & $0: 58: 30$ & 58.50 & 0.08 & 19.63 & 0.0041 & 1.9692 \\
\hline Wall Plate & 47956 & 2.16 & 19.59 & 0.2 & 0.2 & 0.5 & $0: 41: 00$ & 0.0036 & 2.4585 & $0: 46: 15$ & 46.25 & 0.07 & 15.7 & 0.0045 & 2.1795 \\
\hline Shower Curtain Ring x 12 & 42667 & 4.72 & 42.68 & 0.1 & 0.25 & 0.5 & $1: 28: 00$ & 0.0056 & 3.9273 & $1: 44: 36$ & 104.60 & 0.24 & 33.6 & 0.0071 & 3.3040 \\
\hline Shower Head & 40903 & 10.01 & 90.72 & 0.5 & 0.25 & 0.5 & 2:16:00 & 0.0030 & 2.8588 & 2:48:04 & 168.07 & 0.27 & 71.32 & 0.0038 & 2.3134 \\
\hline Key Hanger ( 3 hooks) & 44482 & 2.41 & 21.85 & 0.1 & 0.25 & 0.5 & $0: 47: 00$ & 0.0037 & 2.4511 & $0: 54: 21$ & 54.35 & 0.08 & 17.03 & 0.0047 & 2.1196 \\
\hline iPad Stand & 46887 & 2.11 & 17.99 & 0.1 & 0.2 & 0.5 & 0.53 .00 & 0.0056 & 2.7170 & $0: 51: 20$ & 51.33 & 0.1 & 11.24 & 0.0089 & 2.8052 \\
\hline Orthotic & 47208 & 5.48 & 49.01 & 1 & 0.25 & 0.5 & $1: 35: 00$ & 0.0027 & 1.9705 & 1:29:58 & 89.97 & 0.13 & 39.08 & 0.0033 & 2.0808 \\
\hline iPhone Tripod & 47944 & 1.82 & 16.47 & 0.1 & 0.25 & 0.5 & $0: 36: 00$ & 0.0049 & 3.2000 & $0: 44: 44$ & 44.73 & 0.08 & 12.88 & 0.0062 & 2.5753 \\
\hline Paper Towl Holder & 44068 & 9.47 & 85.84 & 0.25 & 0.25 & 0.5 & $2: 48: 00$ & 0.0036 & 2.6571 & 3:24:05 & 204.08 & 0.31 & 63.44 & 0.0049 & 2.1873 \\
\hline Pierogi mold & 17545 & 2.63 & 23.86 & 0.15 & 0.25 & 0.5 & 0:39:00 & 0.0029 & 2.5846 & $0: 50: 00$ & 50.00 & 0.07 & 18.9 & 0.0037 & 2.0160 \\
\hline Spoon holder & 22000 & 1.6 & 14.5 & 0.1 & 0.25 & 0.5 & $0: 30: 00$ & 0.0041 & 2.8800 & $0: 35: 24$ & 35.40 & 0.06 & 11.6 & 0.0052 & 2.4407 \\
\hline \multicolumn{2}{|c|}{ Totals } & 72.16 & 647.46 & & & & $21: 14: 15$ & & & $24: 57: 58$ & 1497.96 & 2.61 & 508.63 & & \\
\hline \multicolumn{2}{|c|}{ Averages } & & & & & & & 0.0043 & 2.9456 & & & & & 0.0056 & 2.5078 \\
\hline
\end{tabular}

For both the simulation and the experimental results energy use per mass and energy use per time values are shown and graphed in Figures 2.3 and 2.4 respectively. As can be seen in Figures 2.3 and 2.4 there is a linear correlation with energy use and both mass printed and time to print with an $\mathrm{R}^{2}$ of 0.85 and 0.9 , respectfully. Cura overestimated the mass due to a difference in measured density (1269 kg/ m³) with Curas default setting of (1300 kg/ m³). In addition, the diameter of the filament used in Cura was $2.98 \mathrm{~mm}$ while the measured diameter was about 2.8mm. This difference existed because the Cura slicing diameter was used as a printing quality variable and altered to obtain high-quality prints and complete surface uniformity. As can be seen in Table 1 the actual printing time was about $12 \%$ longer than Cura estimated, due to retraction time and non-extrusion movement time of the printer. This was to ensure high-quality prints, but could be reduced for a highly-tuned printer. The total print time for the 20 products was just under 25 hours and used about $500 \mathrm{~g}$ of filament. Energy use was minimal at $0.1 \mathrm{~kW}$-hr per hour of printing and $0.01 \mathrm{~kW}$-hr for the bed and extruder to be heated. The average deposition rate was $0.3 \mathrm{~g} / \mathrm{min}$ and ranged from 0.2 to $0.4 \mathrm{~g} / \mathrm{min}$. This factor of two range existed because of the need for support, varying infill percentage, and 
geometric complexity of the print model.

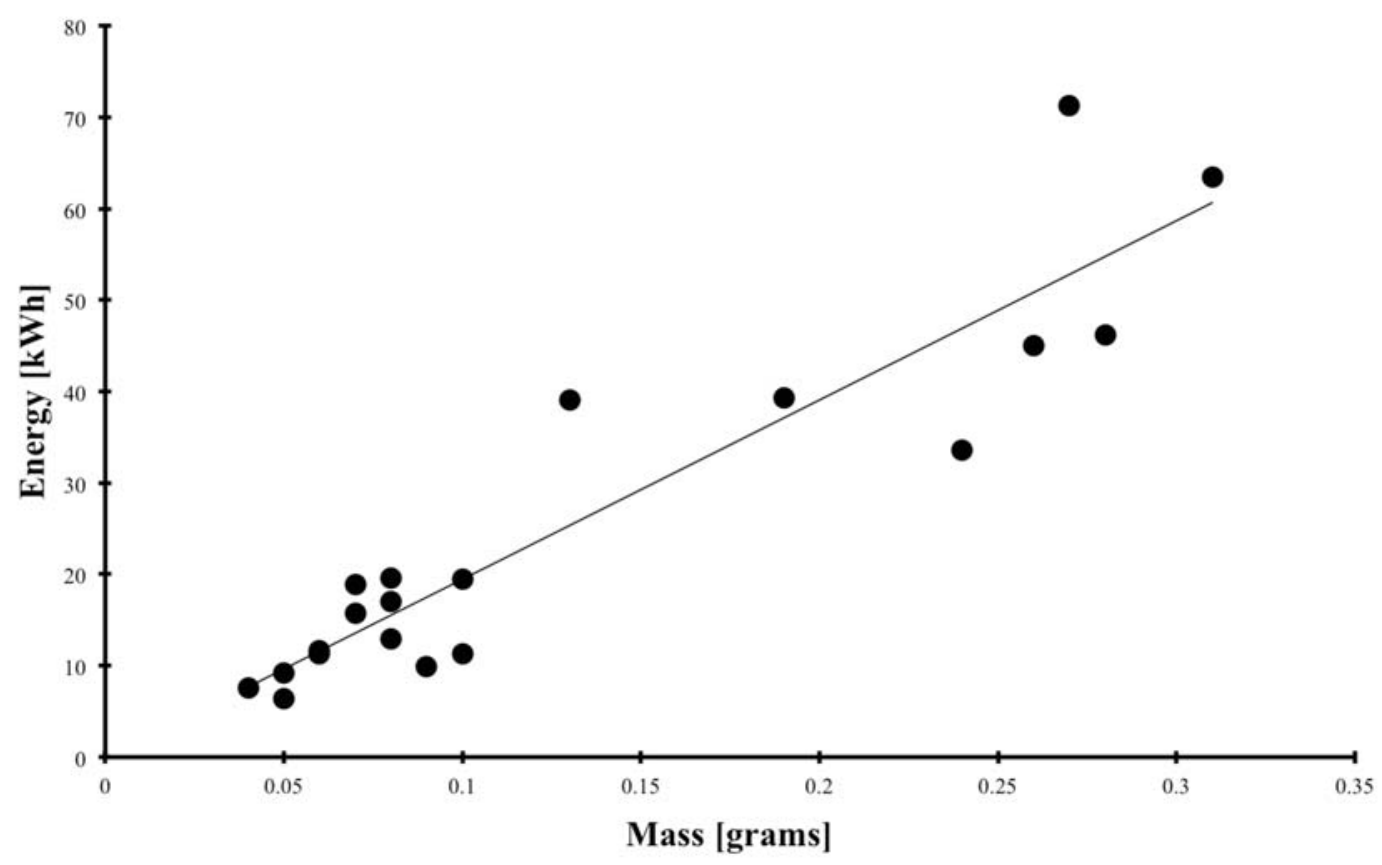

Figure 2.3: Electrical energy consumption in killowatt-hours as a function of mass in grams of filament deposited including support material. 


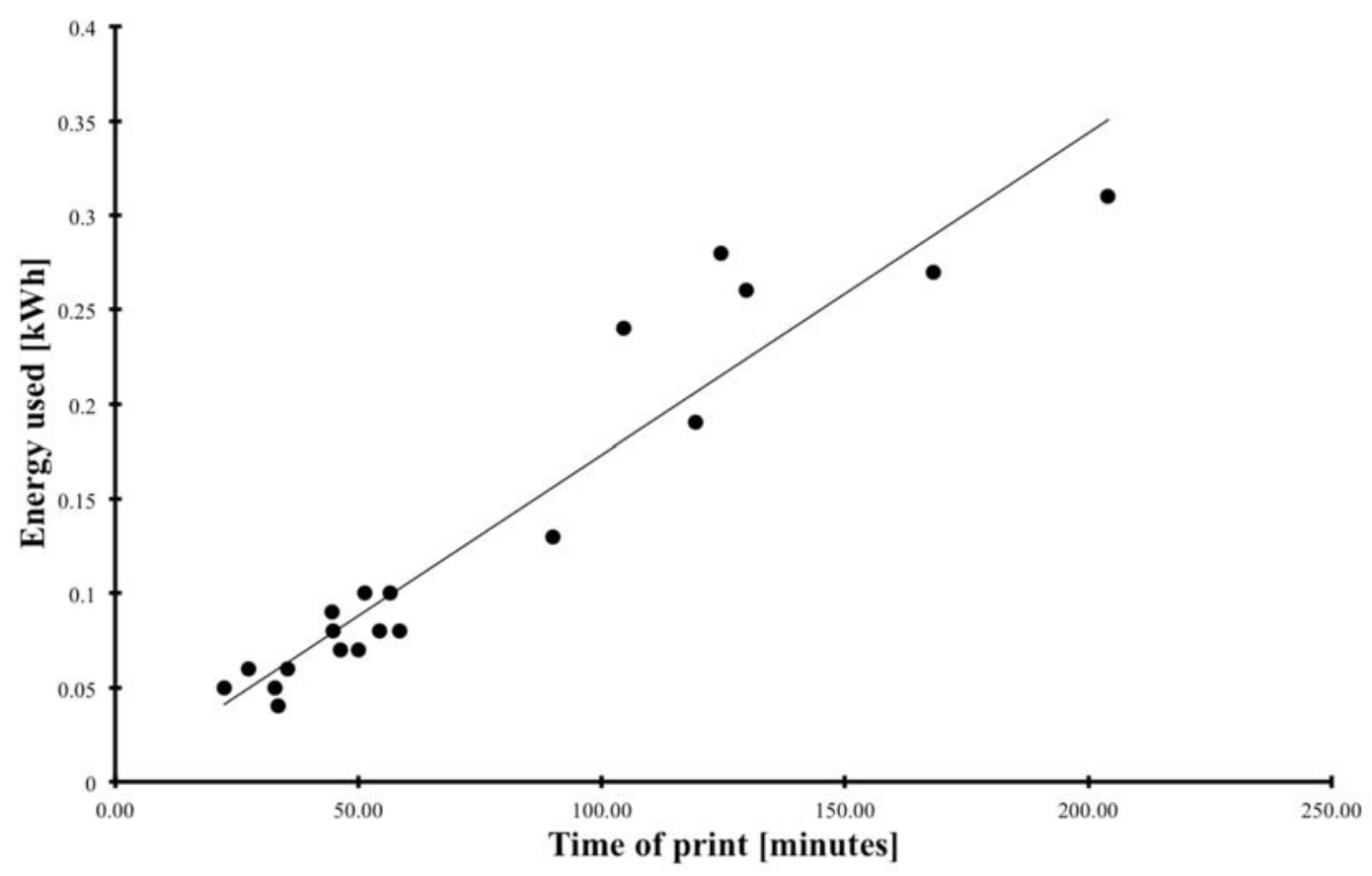

Figure 2.4: Electrical energy consumption in killowatt-hours as a function of printing time in minutes.

\subsubsection{Distributed Production Costs with Open-source 3-D Printing}

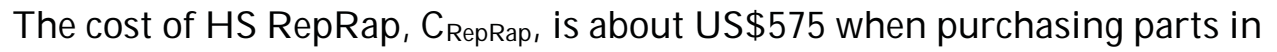
single printer quantities and the printed parts (shown in detail in Appendix A). This cost is low comparable with other in-home office equipment products, although it demands investment of approximately 24 hours for one person with modest technical competence to assemble once the BOM has been procured (see Appendix B). Commercial versions of fully-assembled open-source 3-D printers are available ranging from US $\$ 2,199$ from Trinity Labs [36], US\$1,725 from Aleph Objects [37], US \$1,400 from Type A Machines [38], and Printrbot LC for US\$799 [39]. Many other open-source 3-D printers are now on the market [40]. It should also be noted there are less sophisticated RepRap-like commercial products like the Printrbot Jr for US $\$ 399$ with a significantly smaller build volume (4 inch ${ }^{3}$ ) [39]. These less expensive small 3-D printers can be used as 'RepStraps' to help manufacture the printed parts for a full scale RepRap. The RepRap parts can be printed in 
approximately 21 hours, but a print failure rate of $20 \%$ could lead to longer print times as detailed in Appendix B. These values from Appendix B will be used as the inputs in the LCEA below.

An economic evaluation is shown in Table 2.2 for all twenty products, including printing costs, high and low retail costs, and the percent change in the high and low cases. As can be seen in Table 2, there are substantial cost savings for distributed manufacturing over purchasing from online retailers. The total cost for printing the 20 selected products was about $\$ 20$ including energy and feedstock costs. On average the products cost less than one dollar a piece to print. In comparison, online retail costs ranged from of $\$ 300$ to $\$ 1,900$; averaging between $\$ 15$ and about $\$ 100$ per product. The average change yields savings over $2,500 \%$ when considering the low retail price and over $10,000 \%$ with the high retail choices. The largest savings (e.g. over 10,000\%) were seen with individually customized products, such as the orthotic, while the smallest savings were observed with simple mass-produced items like shower curtain rings. However, even in the case of the shower curtain rings, where there was no option for a high-cost alternative, the savings remained at over $100 \%$ for distributed manufacturing. It should be pointed out here that for most products the higher-cost retail estimate is a more appropriate comparison for the RepRap printed product as those tend to have customized or intricate designs. There is also some evidence of a 'maker premium' where consumers assign a higher value to products that as they took part in fabricating [41]. The actual perceived value varies widely, however, as it is dependent on the individual consumer. 
Table 2.2 Components and total economic costs for selected open-source designs that are printable on a RepRap compared to high and low retail costs.

\begin{tabular}{|c|c|c|c|c|c|c|c|c|c|}
\hline Product & Mass (g) & $\mathrm{kWh}$ & Cost of Plastic & Cost of Electricity & Total Reprap Cost & Total Retail Cost Low & Total Retail Cost High & Percent Change Low & Percent Change High \\
\hline iPhone 5 dock & 46.2 & 0.28 & $\$ 1.62$ & 50.03 & 51.65 & 516.99 & 539.99 & -929.78 & .2323 .82 \\
\hline iPhone 5 case & 7.5 & 0.04 & 50.26 & 50.00 & 50.27 & $\$ 60.00$ & $\$ 168.00$ & -22355.43 & -62775.19 \\
\hline $\begin{array}{c}\text { Jewelry } \\
\text { Organizer }\end{array}$ & 19.63 & 0.08 & $\$ 0.69$ & $\$ 0.01$ & $\$ 0.70$ & $\$ 9.00$ & $\$ 104.48$ & -1192.28 & -14901.97 \\
\hline Garlic Press & 45.01 & 0.26 & $\$ 1.58$ & 50.03 & $\$ 1.61$ & 55.22 & 510.25 & -225.06 & -538.28 \\
\hline Caliper & 6.37 & 0.05 & 50.22 & 50.01 & 50.23 & 56.08 & 57.88 & -2557.11 & .3343 .75 \\
\hline Wall Plate & 15.7 & 0.07 & 50.55 & 50.01 & 50.56 & $\$ 2.30$ & $\$ 22.07$ & -312.39 & -3857.20 \\
\hline Shower Curtain & & & & & $\$ 1.20$ & & & & \\
\hline iPad Stand & 11.24 & 0.1 & 50.39 & 50.01 & $\$ 0.41$ & $\$ 16.99$ & $\$ 49.00$ & -4093.61 & -11994.58 \\
\hline Orthotic & 39.08 & 0.13 & $\$ 1.37$ & 50.02 & $\$ 1.38$ & $\$ 99.00$ & $\$ 800.00$ & -7058.03 & .57742 .67 \\
\hline Safety Razor & 9.9 & 0.09 & 50.35 & 50.01 & 50.36 & $\$ 17.00$ & 578.00 & -4661.02 & -21744.70 \\
\hline Pickup & 39.31 & 0.19 & $\$ 1.38$ & 50.02 & $\$ 1.40$ & 59.99 & $\$ 22.99$ & -614.51 & -1544.31 \\
\hline Train Track Toy & 11.27 & 0.06 & $\$ 0.39$ & S0.01 & $\$ 0,40$ & $\$ 39.48$ & $\$ 58.98$ & -9733.27 & $-14590,13$ \\
\hline Nano & 015 & 005 & 5032 & 5001 & 5033 & $\$ 1608$ & 870.05 & 510669 & $2415 \% 9$ \\
\hline Spoon holder & 11.6 & 0.06 & 50.41 & S0.01 & $\$ 0.41$ & $\$ 4.95$ & $\$ 15.00$ & -1098.42 & -3531.57 \\
\hline Totals & 508.63 & 2.61 & 517.80 & 50.31 & 518.11 & $\$ 374.51$ & $\$ 2,062.85$ & -68459.58 & -265271.11 \\
\hline
\end{tabular}

\subsubsection{Electrical Energy Costs}

As RepRaps have been shown to be more efficient than conventional manufacturing of polymer products [42], the energy consumption for the selected products was expected to be small as demonstrated in Table 1 . As seen in Table 2, the total electrical cost for printing all twenty products was only 31 U.S. cents; it is inconsequential on a per-print basis. This holds true even in areas where energy prices are well above average (e.g. in the upper peninsula of Michigan, where electricity is roughly double the U.S. average). It can be assumed any energy price escalation observed over the life cycle of the RepRap would favor distributed manufacturing because of the reduced embodied energy of transportation.

This would not be the case with off-grid applications or in rural areas of developing countries. Energy in these contexts can be the largest component of the operating cost and research on reducing specific energy of parts produced is still needed. As the machine is completely DC powered at low voltage (12-24V) it is a good candidate for powering with solar photovoltaic technology. While the machines used in this study require a host PC to operate, other low cost, open-source solutions exist for making them stand-alone. The introduction of the Raspberry Pi [43] and a 
new generation of ARM microcontrollers [44,45] makes completely stand-alone web-enabled printers possible requiring less energy to operate while simultaneously expanding their feature set. This may expand the market interest beyond the U.S. into the developed world [14].

\subsubsection{Polymer Filament Costs}

Filament made up the bulk of operating costs at $\$ 17.80$ for the 20 products. It should be pointed out here that relatively common costs for filament were used $(\$ 35 / \mathrm{kg})$. Currently there is filament on the market for $\$ 20-175 / \mathrm{kg}$. There have been several efforts to create open-source RecycleBots [24, 46], which are plastic extrusion systems for fabricating RepRap feedstock. RecycleBots allow RepRap users to recycle bad prints and convert waste plastic into filament. There are versions for both the DIY enthusiasts (e.g. Lyman [47]) as well as the successful Filabot KickStarter project [48], which foreshadows eventual open market competition following the example of the RepRap itself, versions of which are sold by dozens of companies on the Internet. This RecycleBot technology essentially eliminates the plastic cost associated with failed prints and has the potential to significantly reduce filament cost by allowing for the substitution of waste containers (e.g. milk jugs or shampoo bottles) as feedstock. As this technology matures and begins to be deployed more widely there will be downward pressure on filament prices [24]. Both of these trends will be ignored in the analysis below in order to provide a conservative economic return on investment for distributed manufacturing.

\subsubsection{Print Quality and Time Investment}

The two primary concerns about the viability of wide-scale use of low-cost 3D printing are 1) print quality and thus the suitability for market applications and 2) the ease of use, which encompasses time investment in learning the software and hardware associated with a RepRap.

The RepRap print quality can be seen for the spoon rest in Figure 2.5. This kitchen item was printed in PLA with $0.2 \mathrm{~mm}$ step height, which is the current standard, although many open-source 3-D printers can already print with $0.1 \mathrm{~mm}$ 
step heights. The steps are visible and thus some printed products may not be perceived of as high-enough quality for some consumers. This perception is highly dependent on specific consumer preferences. Obviously for many parts and products that are not visible and meet the mechanical requirements of the application this is not an issue. For products where a specific aesthetic quality must be met there are several options of post processing 3-D prints. 3-D printed objects can be sanded and polished and painted to meet many consumer preferences. In addition, post-print chemical treatments have been developed. ABS prints can be smoothed with acetone (nail polish remover) either by direct brush application or via a vapor treatment. PLA, however, is the primary printing material of choice. PLA can be smoothed with a dip treatment in dichloromethane $\left(\mathrm{CH}_{2} \mathrm{Cl}_{2}, \mathrm{DCM}\right)$. The results of such a treatment are shown in Figure 6, where the handle of the razor holder was dipped into DCM for 45 seconds and rinsed with water. It is clear from Figure 2.6, that the DCM smooths the surface and creates a coat to seal it as seen on the right against the unprocessed print on the left. Future work is needed to investigate the acceptability of 3-D printed products for the average consumer, particularly in light of the cost savings discussed in the next section.

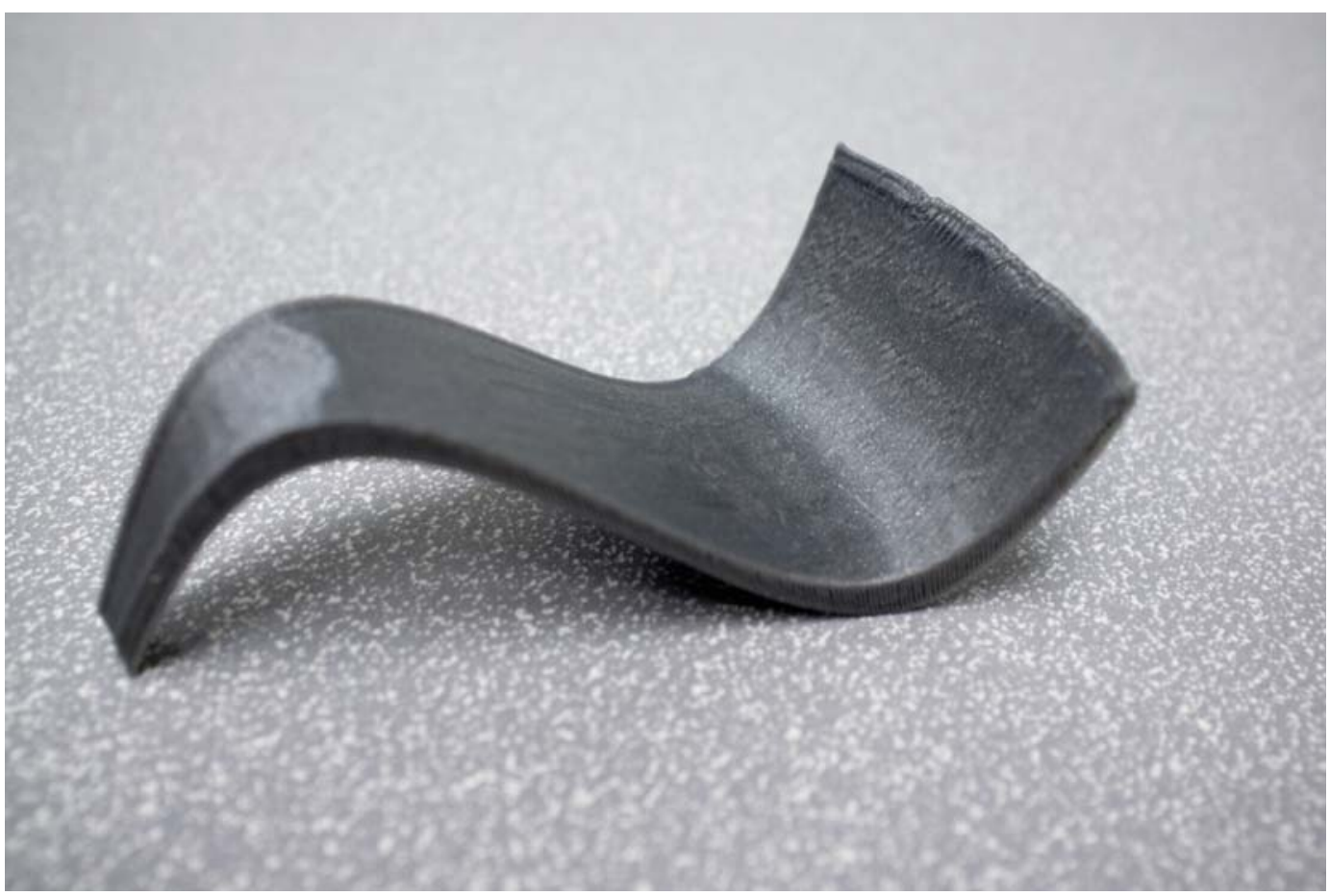


Figure 2.5: Example of RepRap print quality - close-up photograph of the spoon rest.

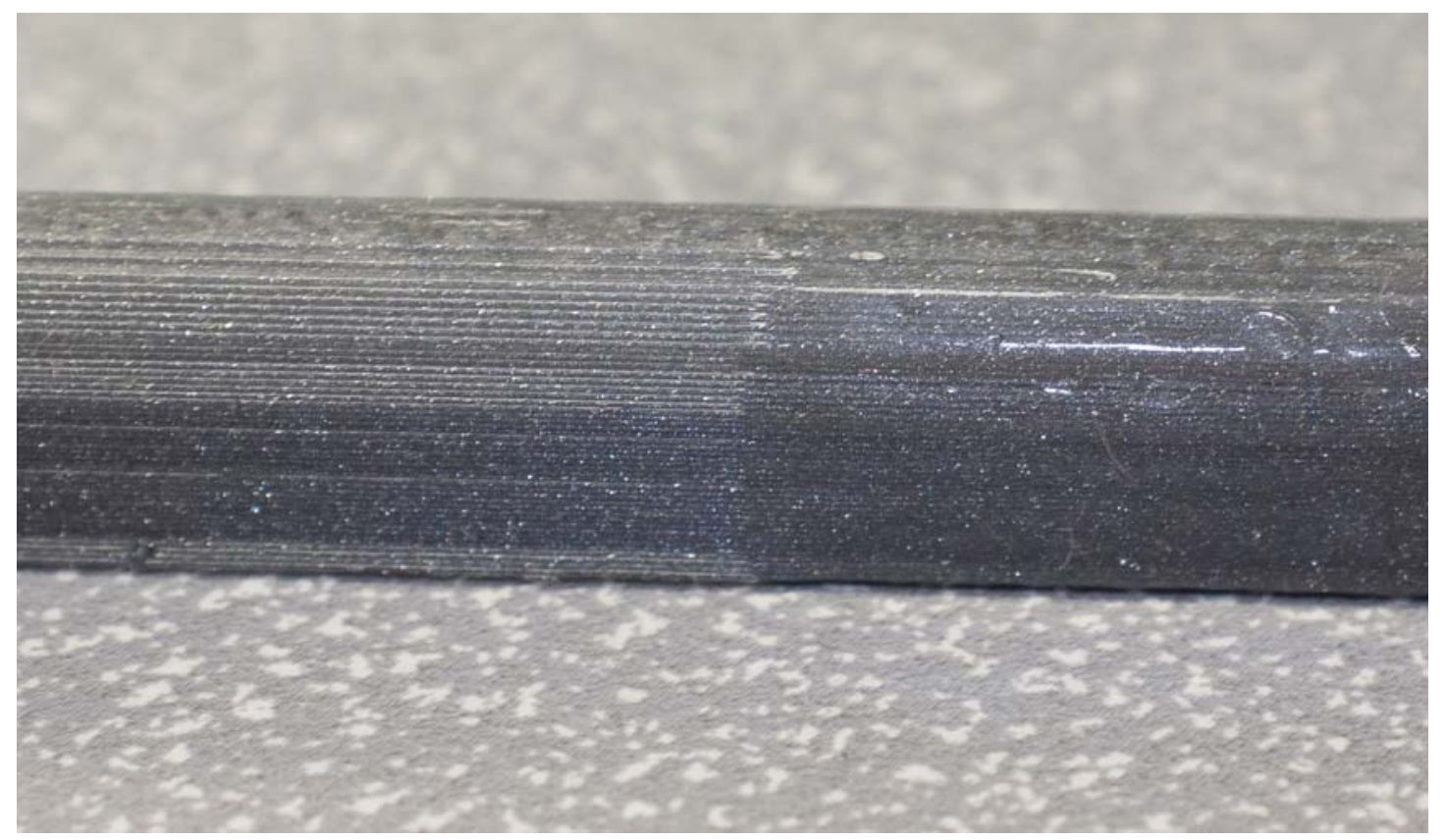

Figure 2.6: The results of post-print processing using dip smoothing of PLA with dichloromethane (right) compared to unprocessed print showing $0.2 \mathrm{~mm}$ step heights (left).

The second common concern is the ease of use, which involves the barrier to adoption created by the need for users to invest their time to learn CAD and the operation of a RepRap. First, it should be pointed out that all of the products printed for this study were pre-designed and available on Thingiverse for free and thus involved no CAD skills to print. In addition, on-line applications are now available that enable users to customize designs without knowing CAD. Thus, the there is no real investment necessary. However, it is anticipated, as will be discussed in section 4.6.4, that 3-D printer users will want to make that investment to create products for themselves that have not been designed by others. Similarly for the commercialized open-source 3-D printers the learning curve for printer maintenance and use is relatively shallow and actually less complicated than setting up a networked office color laser printer. The time investment in building a 3-D printer from parts, trouble shooting it, and working to develop it is substantial and will not be of interest to all 
consumers. However, for many individuals the RepRap can provide an access point into the innovative area of mechatronics. This can be viewed as a benefit rather than a cost as it is clear that having a greater percentage of the population knowledgeable about $\mathrm{CAD}$ and mechatronics and sharing their designs and experiences would be benefit the mechatronics community as a whole by providing more knowledgeable students and employees. The cost in the time to make the 3-D prints themselves is small as users can do other activities (e.g. read, watch tv, exercise, etc.) while products are manufactured.

\subsubsection{Avoided Costs, Payback Times, and ROI of Distributed Manufacturing}

As can be seen in Table 2 the total avoided costs for the low and high retail estimates are about $\$ 290$ and $\$ 1,920$ (including a 20\% failed print rate) and inputting these values into equation 3 gives simple payback times of less than 2 years to about 4 months. These payback times are based on the extremely conservative premise that only 20 items are printed per year and that printing is evenly distributed throughout the year despite the fact it could be accomplished in little over 1 day. Again using equation 3 the simple payback times assuming only 20 products printed per year for even the most expensive commercial open-source 3-D printers are less than 1 year or 6 years for the low and high retail prices, respectively. The payback times for the RepRap can then be inserted into equation 5 , to provide ROIs, but demand an estimated lifetime. This is less straight forward than with most capital manufacturing equipment as the components that are most likely to wear out in the RepRap are easily replaced by the self-replicating nature of the 3-D printer. In addition, the RepRap design continues to improve and evolve usually through the refinement of printed parts - so it is similar to an upgradeable computer in that lifetime can be extended. Although, this self-upgrade-ability and maintenance could indicate an infinite lifetime, if three year and five year lifetimes are chosen as illustrations, the ROI for the RepRap shown in Figure 1 compared to low retail costs is over $20 \%$ and $40 \%$ respectively. For the high retail costs the RepRap ROI $>200 \%$. These RepRap ROIs are clearly extremely conservative as they assume that the users 
do not print out more than 20 products (as listed in Table 2) per year. As these products can be printed in under less than 25 hours, any owner could print them in less than a week even if printing was restricted to after working hours. The products analyzed here represent less than $0.02 \%$ of an exponentially expanding catalog, so it is safe to assume the typical household would print far more than 20 fabricated products per year. These RepRap ROIs compare extremely favorably to after tax income from other investments (e.g. savings accounts $\sim 0 \%, 2 \%$ certificate of deposit, or $\sim 4 \%$ on the stock market, adjusted for inflation) [35]. RepRaps and distributed manufacturing thus offers a much better investment opportunity than standard manufacturing practices as the inflation adjusted before tax internal rate of return for companies is about $10 \%$, after corporate income taxes $7 \%$, and after investors pay capital gains taxes, about 4\% [49]. The RepRap can be regarded as an extremely conservative investment opportunity that has significantly higher returns than most investment opportunities with similar risks. This investment is limited, however, to only the relatively modest cost of a single RepRap for a U.S. household.

\subsubsection{Implications of Results}

The potential implications of these results are i) expected rapid growth of distributed manufacturing using open-source 3-D printing, ii) large-scale adoption and shifts to life-cycle thinking in consumption, iii) growth of localized cottage industries, and iv) a revitalization of hands-on engineering based education.

\subsubsection{Rapid Growth}

It is clear from these results that the economic benefit and the open-source nature of the RepRap project is driving rapid growth. This is verified by the rapid growth of open-source 3-D designs shown in Figure 2, which can be assumed to be due to more 3-D printer users making designs for themselves and sharing them following the open-source paradigm. This trend is likely to continue as the majority of the Thingiverse community up until this time has been using OpenSCAD [50]. OpenSCAD is an open-source, script-based computer aided design application, which allows users to describe the geometric specifications of the required object by using three primitive shapes (cylinder, sphere and cube) and complex polygons 
using polygon, polyline and the 2D-3D extrusion commands. OpenSCAD allows for parametric designs; the ability to alter a design by changing parameters of the describing geometry. This allows changes to be made to the design easily and quickly by simply adjusting the value of user-defined variables. Although extremely powerful, CAD scripting in OpenSCAD is clearly beyond the technical comfort level of the average U.S. consumer and as of this writing the vast majority of the designs on Thingiverse are from hackers/ makers with considerably higher-comfort levels with technology than average consumers. Thingiverse, however, has recently introduced a Customizer App that acts as a front end for OpenSCAD code to enable inexperienced users to customize designs interactively (e.g. with the use of sliders on parametric variables). This development makes customizing open-source CAD designs accessible to the average consumer. This significantly expands the number of participating designers. There is already some evidence of this effect seen in Figure 2 , in the sudden rise in the number of designs putting the total back on the exponential growth curve. It should be noted that the newly instituted default customizer saves any customization as a new design and thus the method of design counting used in this article will lose some utility in the future. As this App opens up design to more people, the number of open-source designers is assumed to increase along with those who begin using 3-D printers. This will provide even more designs of steadily increasing complexity and value, as users make designs relevant to their lives expands. This will create a positive feedback loop, increasing the value of owning a 3-D printer beyond the threshold of the purchase price. For many consumers the existing catalog of open-source designs already has crossed this threshold as the market for 3-D printers is expanding rapidly [51].

For many consumers the ROI of a RepRap will steadily increase as more designs are made as indicated by the results. Similar to the situation in scientific labs, which can justify the cost of a RepRap by customizing and printing a single piece of scientific equipment [26,52], for some U.S. households with high-value custom needs the printer pays for itself within a day of printing. For example, although custom orthotics can be purchased on the Internet for about $\$ 100$, those provided by a professional are normally $\$ 500-\$ 800$ and presumably of higher quality and value to the consumer. These high costs are normally prohibitive for 
those wishing more than one pair of orthotics, but with the design for thing: 46922, which uses the Thingiverse customizer, it is possible to print as many as you like for less than $1 \%$ of the cost. In addition, open-source [53,54] or free [55-57] image processing and 3-D scanning tools make possible replication of a professionally customized orthotic by direct creation of a 3-D mesh that is then suitable for printing as many as desired. This enables consumers to print \$500-800 quality orthotics for $\sim \$ 2$ as long as they have one existing pair. Such opportunities for consumers would also be expected to increase the growth rate.

\subsubsection{Mainstream Adoption and Shifts in Consumption}

If distributed manufacturing with open-source 3-D printing becomes common, there will be a steadily increasing number of products printed by consumers that would otherwise have been retail purchases. This will create a slow shift to hyper-localized manufacturing, at least for some classes of product. However, it may also create a fundamental and more subtle shift in the nature of consumption in the overall economy.

For some time now the trend in consumer goods has been towards lower cost, often disposable over the more expensive durable consumer goods [58].

Consider the case of shaving. Most American men who shave buy disposable razors or disposable razor cartridges that fit into reusable handles because the initial cost is much lower than more robust product options (e.g. a safety razor, for example, costs US $\$ 20-80$ online). This initial startup cost prevents consumers from using the more economical (over the life cycle) choice. Now that there is an open-source safety razor design available for free download (thing:43568), which costs about 36 U.S. cents to print, the barrier to entry has been eliminated for everyone with a 3-D printer. A 10 pack of double edge safety-razor blades cost about US\$5 (28 cents per blade) on Amazon. If it is assumed that an average user consumes one double blade every two weeks the blade costs for open-source safety razor shaving is about US $\$ 7 /$ year. To put this in perspective, the cost of shaving using drugstore blades or cartridges is between US $\$ 100$ and US $\$ 300 /$ year $[59,60]$. Assuming the average man shaves for about 65 years, using the printed razor and only replacing the metal blades would result in a net savings of between US\$6,500 and US\$19,000 over a lifetime. Similar 
opportunities exist for a large number of currently disposable products, whose designs may not have yet been put in the public domain, but can be expected in the near future. By shifting to distributed manufacturing in this way, consumer spending could be reduced significantly.

\subsubsection{Open-Source Cottage Industry}

It is not clear that every consumer will need or want a 3-D printer when there is the option to print custom products at competitive or lower prices. Already several Internet-based 3-D print shops [61-63] produce items as-ordered and can print a number of different materials including metal, ceramic and plastic. 3-D print shops could also be more localized similar to local bakeries. The open-source RepRap printer is well suited for cottage industry, potentially filling local niche markets [41].

A completely new inventory paradigm is introduced to micro-scale manufacturers who utilize this technology: the carrying cost for maintaining high value inventory is eliminated. As demonstrated by this analysis, the technology places one-off items that historically carry high prices well within reach of the average citizen. Micro-scale manufacturers need only inventory low-value, low-cost printer feedstock, reducing both direct and operating costs. Instead of insuring and protecting expensive inventory, micro-manufacturers produce on a per-order basis and can offer a variety of products heretofore unheard of.

\subsubsection{Education}

The widespread use of distributed manufacturing with RepRaps may also have a positive educational benefit and is in line with current pedagogical trends [64]. The educational value of building and then using a RepRap type 3-D printer can be considerable, encompassing, for example, $\mathrm{CAD} / \mathrm{CAM}$, mechanical engineering, electronics, and materials science. Most obviously widespread use of RepRaps will be an enormous benefit for pre-training students in mechatronics. Students can work to develop their fundamental mechatronics skills while servicing their RepRaps. In addition, students can create their own designs, print them and share them as open-source models on Thingiverse. The open-source 3-D printer compliments the Next Generation Science Standards (NGSS)[65], which are 
currently in the final revision phase and scheduled to be completed in early summer 2013. These new standards are slated for adoption in many states throughout the U.S. and have a primary focus on process rather than content and contain significant emphasis on science and engineering practices. The open-source 3-D printers can provide an opportunity to engage in these practices with a "hands on" and "minds on" approach. For example, the NGSS calls for students to learn about three phases of solving problems in the realm of Engineering Design, all of which can be accomplished physically with a RepRap: 1) defining the problem, 2) designing solutions and 3) optimizing design solutions. In addition, schools can simply reduce costs by fabricating learning aids in house such as chemistry models, physics bench equipment, or mechanical devices for class-room demonstrations. Already a printable collection of open-source optics components has been created, which can save schools money by printing in house [66]. More complex creations such as opensource colorimeters, automated filter wheels, and other analysis equipment have been designed and are available as open source hardware [52]. By working in teams to create these things, students will play an unprecedented role in their own education as well the education of others.

\subsubsection{Limitations and Future Work}

This study had several limitations including a limited number of products analyzed; 20. Although this study did not take into account detailed financial variables such as i) energy cost escalation rates, ii) inflation, iii) discount factors, iv) loan rates/ capital costs, or v) opportunity costs, the nature of the investment analyzed and the method of U.S. consumer decision making enables the use of the simple payback and simple ROI. For many individuals the effort needed to make their own products may not be worth the time involved even if only a fraction of print time is active user time. Although this study quantified the time it was not used in the LCEA as there is extreme variability due to individual perception of opportunity costs across the U.S. population. In addition, rarely do individuals make this calculation with 2-D printing as it is actually more effort and time consuming to employ commercial printers to print a document. 
In this study only a single printing material (PLA) was used. The cost of using other printing materials such as ABS and waste/ recycled plastic can also be investigated in future work. There are already a number of RepRap compatible designs that vastly expand the materials catalog of print media, including versions of paste extruders [67], which can be used with many viscous materials [68], a spoolhead extruder to print metal wire onto plastic, which in the future can be used to print circuit boards [29], and a granule extruder including a method to create the granules [69,70]. The classic RepRap design is also attractive for repurposing for uses beyond additive manufacturing. Lightweight CNC milling of printed circuit boards (PCB) using a RepRap fitted with a light duty cutter has been demonstrated [71] and others have fit RepRaps with pens and solid state lasers for PCB making. A full LCEA is needed for each of these material possibilities and alternative designs as one of them may further expand the economic utility of open-source 3-D printing for the consumer.

\subsection{References}

[1] M. Glesner, A. Kirschbaum, F.-M. Renner, B. Voss, State-of-the-art in rapid prototyping for mechatronic systems. Mechatronics 12 (2002) 987-998.

[2] E. Toyserkani, A. Khajepour, A mechatronics approach to laser powder deposition process. Mechatronics 16, (2006) 631- 641.

[3] A. Gebhardt, Rapid Prototyping. Hanser-Gardner, 2003. (3rd German Eiditon: Hanser, 2007).

[4] A. Gebhardt, F. Schmidt, J. Hotter, W. Sokalla, P. Sokalla, Additive Manufacturing by selective laser melting the realizer desktop machine and its application for the dental industry. Physics Procedia 5, Part B, (2010) 543- 549.

[5] N. Crane, J. Tuckerman, G. N. Nielson, Self-assembly in additive manufacturing: opportunities and obstacles, Rapid Prototyping J ournal 17, 3(2011) 211- 217. 
[6] V. Petrovic, J. V. H. Gonzalez, O. J. Ferrando, J . D. Gordillo, J. R. B. Puchades, L. P. Grinan, Additive layered manufacturing: sectors of industrial application shown though case studies, Int. J . of Production Research 49,4(2011)10611079.

[7] S. Upcraft, R. Fletcher, The Rapid Prototyping Technologies, Assembly Automation 23 (2012) 318-330.

[8] H. Lipson, M. Kurman, Fabricated: The New World of 3D Printing. Wiley, Indianapolis, In. 2013.

[9] The Economist, A third industrial revolution: Special report: Manufacturing and innovation, The Economist (2012).

[10] N. Gershenfeld, Fab: The Coming Revolution on Your Desktop - from Personal Computers to Personal Fabrication, Basic Books, New York, 2005.

[11] R. Jones, P. Haufe, E. Sells, RepRap - the Replicating Rapid Prototyper, Robotica 29, 1(2011) 177- 191.

[12] Corney, J. The next and last industrial revolution?, Assembly Automation 25, 4 (2005) 257.

[13] E. Malone, H. Lipson, Fab@Home: The Personal Desktop Fabricator Kit, Rapid PrototypingJ ournal 13, 4(2007) 245- 255.

[14] J. Pearce, C. Blair, K. J. Laciak, R. Andrews, A. Nosrat, 3-D Printing of Open Source Appropriate Technologies for Self-Directed Sustainable Development, J ournal of Sustainable Development 3, 4,(2010) 17- 29.

[15] S. Bradshaw, A. Bowyer, P. Haufe, The intellectual property implications of low-cost 3D printing, SCRIPTed 7, 1(2010) 1- 27.

[16] D. Holland, G. O'Donnell, G. Bennett, Open Design and the Reprap Project, presented at the 27th International Manufacturing Conference (2010).

[17] M. Weinberg, IT WILL BE AWESOME IF THEY DON”T SCREW IT UP (2010). [Online]. Available: http:// nlc1.nlc.state.ne.us/ epubs/ creativecommons/3DPrintingPaperPublicKn owledge.pdf [Accessed: 25-Feb-2013].

[18] J . Cano, The Cambrain exposion of popular 3D printing, International J ournal of Artificial Intelligence and Interactive Multimedia 1, 4(2011) 30- 32. 
[19] E. Sells, S. Bailard, Z. Smith, A. Bowyer, Reprap: the replicating rapid prototype: maximizing curstomizability by breeding the means of production, in F. T. Piller, M. M. Tseng (Eds.), Handbook of Research in Mass Customization and Personalization: Strategies and concepts. Vol. 1. World Scientific, 2010, pp. 568-580.

[20] R. Arnott, The Reprap project - open source meets 3D printing, Computer and Information Science Seminar Series (2008).

[21] Arduino. [Online]. Available: http:// www.arduino.cc/ . [Accessed: 25-Feb2013].

[22] J. Kentzer, B. Koch, M. Thiim, R. W. J ones, E. Villumsen, An Open Sorurce Hardware-based Mechatronics Project: The Replicating Rapid 3-D Printer, presented at the 4th International Conference on Mecatronics (2011) 1- 8.

[23] J. Gonzalez-Gomez, A. Valero-Gomez, A. Prieto-Moreno, M. Abderrahim, A new open source 3D-Printable mobile robotic platform for education, in: Advances in Autonomous Mini Robots, University of Bielefeld, Germany, 2012, pp. 49- 62 .

[24] C. Baechler, M. DeVuono, J . M. Pearce, Distributed recycling of waste polymer into reprap feedstock, Rapid ProtypingJ ournal, 19, 2(2013) 118-125.

[25] N. Grujovic, M. Radovic, V. Kanjevac, J. Borota, G. Grujovic, D. Divac, 3D printing technology in education environment, presented at the 34th International Conference on Production Engineering (2011).

[26] J. M. Pearce, Building Research Equipment with Free, Open-Source Hardware, Science 337, 6100 (2012) 1303- 1304.

[27] M. Symes, P. J . Kitson, J. Yan, C. J . Richmond, G. J. T. Cooper, Integrated 3Dprinted reactionware for chemical synthesis and analysis, Nature Chemistry 4 , 5(2012) 349-54.

[28] S. J . Leigh, R. J . Bradley, C. P. Purssell, D. R. Billson, A Simple, Low-Cost Conductive Composite Material for 3D Printing of Electronic Sensors, PLoS ONE 7, 1(2012).

[29] J. Bayless, M. Chen, and B. Dai, Wire Embedding 3D Printer, Engineering Physics Department, University of British Columbia (2010). 
[30] V. L. Tsang, S.N. Bhatia, Three-dimensional tissue fabrication. Adv. Drug Delivery Reviews 56 (2004) 1635- 1647.

[31] Thingiverse - Digital Designs for Physical Objects, Thingiverse. [Online]. Available: http://www.thingiverse.com/ . [Accessed: 9-J un-2013].

[32] U.S Energy Information Administration, Table 5.6.A Average Retail Price of Electricity to Ultimate Customers by End Use Sector, EIA-Electricty Data. [Online]. Available: http:// www.eia.gov/ electricity/monthly/ epm_table_grapher.cfm?t=epmt_5_ 06_a. [Accessed: 25-Feb-2013].

[33] Printing Material Suppliers, RepRapWiki. [Online]. Available: http:// reprap.org/ wiki/Printing_Material_Suppliers. [Accessed: 25-Feb2013].

[34] Cura. [Online]. Available: http:// daid.github.com/ Cura/ . [Accessed: 25-Feb2013].

[35] J . M. Pearce, D. Dekenberger, H. Zielonka, Accelerating Applied Sustainability by Utilizing Return on Investment for Energy Conservation Measures, Int. J . of Energy, Env. and Economics 17, 1(2009) 61- 80.

[36] TrinityLab, Aluminatus TrinityOne 3d Printer, TrinityLab. [Online]. Available: http:// trinitylabs.com/ products/ aluminatus-trinityone-3d-printer. [Accessed: 25-Feb-2013].

[37] LulzBot, AO-1013D Printer, LulzBot. [Online]. Available: http:// www.lulzbot.com/ ?q=products/ ao-101-3d-printer. [Accessed: 25-Feb2013].

[38] Type A Machines, Series 13D Printers, Type A Machines. [Online]. Available: http:// www.typeamachines.com/ cart. [Accessed: 6-J un-2013].

[39] Printrbot, Printrbot Kits [Online]. Available: http:// printrbot.com/ productcategory/ printrbot-kits/ [Accessed: 25-Feb-2013].

[40] 3Ders, Price Compare - 3d Printers [Online]. Available: http:// www.3ders.org/ pricecompare/3dprinters/ [Accessed: 25-Feb-2013].

[41] C. Anderson, Makers: The New Industrial Revolution. Crown Business. New York, 2012. 
[42] M.A. Kreiger, J.M. Pearce, Environmental Impacts of Distributed Manufacturing from 3-D Printing of Polymer Components and Products, MRS Online Proceedings (2013) 1492, mrsf12-1492-g01-02.

[43] Raspberry Pi. [Online]. Available: http://www.raspberrypi.org/ . [Accessed: 25-Feb-2013].

[44] BeagleBoard-bone, BealgeBoard. [Online]. Available: http:// beagleboard.org/ bone. [Accessed: 25-Feb-2013].

[45] Arduino, ArduinoBoardDue. [Online]. Available: http:// arduino.cc/ en/ Main/ArduinoBoardDue. [Accessed: 25-Feb-2013].

[46] M. Kreiger, G. C. Anzalone, M. L. Mulder, A. Glover, J . M Pearce. Distributed Recycling of Post-Consumer Plastic Waste in Rural Areas. MRS Online Proceedings Library, 1492, mrsf12-1492-g04-06 (2013).

[47] H. Lyman, Lyman Filament Extruder. [Online]. Available: http:// www.thingiverse.com/thing:30642 [Accessed: 25-Feb-2013].

[48] T. McNaney, Filabot: Plastic Filament Maker. [Online]. Available: http:// www.kickstarter.com/ projects/rocknail/ filabot-plastic-filament-maker [Accessed: 25-Feb-2013].

[49] R. Newell, W. Pizer. Discounting the benefits of climate change mitigation: How much do uncertain rates increase valuation? Economic Technical Series, Pew center on Global Climate Change: Arlington VA. 2001.

[50] OpenSCAD, OpenSCAD - The Programmers Solid 3D CAD Modeller, [Online]. Available: http:// www.openscad.org/ . [Accessed: 25-Feb-2013]

[51] Make. The Ultimate Guide to 3D Printing. O' Reilly, Sebastopol, CA, 2013.

[52] G.C. Anzalone, A.G. Glover, J .M. Pearce, Open-Source Colorimeter. Sensors 13(4) (2013) 5338-5346.

[53] ReconstructMe, Reconstruct your world with ReconstructMe. [Online]. Available: http:// reconstructme.net/. [Accessed: 25-Feb-2013].

[54] MakerScanner - Open Source 3D Scanning. [Online]. Available: http:// www.makerscanner.com/ . [Accessed: 25-Feb-2013].

[55] Autodesk 123D - 123D Catch turn photos into 3D models.[Online]. Available: http:// www.123dapp.com/ catch. [Accessed: 25-Feb-2013]. 
[56] DAVID 3D Scanner. [Online]. Available: http:// www.david-laserscanner.com/ . [Accessed: 25-Feb-2013].

[57] About My3DScanner. [Online]. Available: http:// my3dscanner.com/ . [Accessed: 25-Feb-2013].

[58] L. Claudio, Waste Coture: Environment Impact of the Clothing Industry, Environ. Health Perspect. 115, 9(2007) 449- 454.

[59] Antonio, Save \$300 - Learn to Shave Like a Man, Real Men Real Style. [Online]. Available: http:// www.realmenrealstyle.com/learn-to-shave-likeman/ . [Accessed: 25-Feb-2013].

[60] S. Cendrowski, How long does a razor really last? Gillette comes clean, Fortune, 2012.

[61] T. Redlich, J. P. Wulfsberg, and F. L. Bruhns, Virtual Factory for Customized Open Production, presented at the 15th International Product Development Management Conference, Tagungsband (2008).

[62] Shapeways, Shapeways - Make \& Share Your Products with 3D Printing. [Online]. Available: http:// www.shapeways.com/. [Accessed: 25-Feb-2013].

[63] Ponoko, 3D printing, laser cutting - design, make \& build your own products with Ponoko. [Online]. Available: https:// www.ponoko.com/ . [Accessed: 25Feb-2013].

[64] J. Gumbrecht. The high-tech return of high school shop class. Schools of Thought Blog, CNN. [Online]. Available: http:// schoolsofthought.blogs.cnn.com/2013/ 02/ 28/ the-high-tech-return-ofhigh-school-shop-class/ ?hpt=hp_bn1 [Accessed: 28-Feb-2013].

[65] Next Generation Science Standards. [Online]. Available: http:// www.nextgenscience.org/ . [Accessed: 25-Feb-2013].

[66] C. Zhang, N. C. Anzalone, R. P. Faria, J .M. Pearce, Open-Source 3D-Printable Optics Equipment, PLoS One 8(3) (2013) e59840.

[67] Caulk extruder, Thingiverse. [Online]. Available: http:// www.thingiverse.com/thing:39954. [Accessed: 25-Feb-2013].

[68] A. Mann, Feeding the Final Frontier: 3-D Printers Could Make Astronaut Meals, Wired Science (2013). [Online]. Available: 
http:// www.wired.com/ wiredscience/ 2013/ 02/ 3-d-food-printer-space/ . [Accessed: 25-Feb-2013].

[69] G. B. Braanker, J . E. . Duwel, J . J . Flohil, G. E. Tokaya, Developing a plastics recycling add-on for the RepRap 3D printer, Delft University of Technology, Prototyping Lab.

[70] A. Tan, T. Nxon, Rapid prototype manufacturing system, School of Mechanical Engineering, The University of Adelaide, Austria, 2007.

[71] Milling and Drilling Head, RepRapWiki. [Online]. Available: http://reprap.org/wiki/Milling_and_Drilling_Head. [Accessed: 25-Feb-2013]. 


\section{3 - Distributed Manufacturing with 3-D Printing: A Case Study of Recreational Vehicle Solar Photovoltaic Mounting Systems ${ }^{2}$}

\subsection{Background}

It has been well established that the embodied energy of transportation for a wide range of products can have an appreciable percentage of the environmental impact of a product over its life cycle [1-5]. Life cycle analysis indicates that ultradistributed manufacturing with 3-D printers by prosumers (producer/ consumers) would be beneficial from an environmental impact viewpoint [6,7]. This is the case if conventional manufacturing of equivalent products is avoided by printing them. These savings are in part due to reductions this transportation embodied energy [6,7]. Recent developments in 3-D printing (an additive manufacturing technique, which intrinsically reduces material waste) have made distributed manufacturing of highvalue products for household use both technically and economically viable, enabling individuals to fabricate an exponentially growing list of products to meet their own needs $[8,9]$. Sales figures indicate that personalized or desktop manufacturing with 3D printers is a growing trend [10-13]. A wide range of products can now be produced by low-cost 3-D printers $[8,9,14]$ and open-source self-replicating rapid prototypers (or RepRaps) enable particularly fast scaling. RepRaps can manufacture over $50 \%$ of their own components (excluding fasteners) creating a low cost and easily repairable 3-D printer that can be used for both upgrades and fabricating replacement parts for low costs [15]. To create the desired part, RepRaps sequentially deposit 100-400 microns layers of polylactic acid (PLA), acrylonitrile butadiene styrene (ABS), highdensity polyethylene (HDPE) and a wide range of other feedstock materials [16-18]. Open-source 3-D printers have already demonstrated usefulness for developing engineering prototypes [19], customizing scientific equipment [20-22], creating electronic sensors [23,24], education [22,25], co-creative product realization [26], personal manufacturing [27], wire embedding [28], modular robotics [29], tissue

\footnotetext{
2 Material contained in this chapter has been submitted for publication in Journal of Frugal Innovation
} 
engineering [30] and appropriate technology for sustainable development [8]. This paper investigates the ability of the RepRap to be used in manufacturing directly following the open-source paradigm and uses a case study of a solar photovoltaic (PV) racking technology.

Recently open-source principles have also been applied to solar PV technological development with promising results [31], and there is a growing interest in using 3-D printers to fabricate components of all kinds, but there have also been a growing number designs of PV systems on Thingiverse, an online repository for 3-D printing designs [32-35]. The PV industry is currently undergoing significant structural adjustment as the costs of PV modules per Watt has dropped 80\% in the last five years, which has resulted in i) a marked decrease in the levelized cost of solar electricity [36] driving up demand and ii) the economic role of racking has been gaining prominence relative to the modules [37]. One area where 3-D printing can be used with PV is in custom module mounting.

Recreational vehicle (RV) applications of PV are unique in that the load is geographically mobile as is the structure for with the PV is attached and thus there would be a benefit to customizing the bracket for each location to achieve an optimal tilt angle [38-41]. PV is already an attractive electricity generation option for RV users because they are often off grid and yet require electrical power and there are several RV PV mounting systems on the market. Unfortunately, these mounting systems are often prohibitively expensive. For example, current RV mounted solar PV modules use aluminum brackets attached to aluminum standoffs, which significantly hamper distribution as they have approximately the same cost per Watt as the modules themselves. As PV mounting and racking now makes up a significant fraction of PV system costs, the new developments in 3-D printing provide the potential for individuals to fabricate $\mathrm{PV}$ racking to drive down overall $\mathrm{PV}$ system prices. The primary requirement for a successful frugal RV PV mounting system is that it is mechanically stable to enable the RV to drive from location to location with the PV mounted on the top of the RV and the secondary requirement is the ability for custom tilt angle adjustment for different latitudes.

To explore the potential of distributed manufacturing of frugal innovation this paper presents a case study of RV PV racking system production with RepRaps. 
Parametric designs for a novel RV mounting system consisting of brackets and standoffs are developed. The design is a four-corner mounting device with the ability to customize tilt angle and height of the standoff, which enables performance optimization for a given latitude. The open-source 3-D printable design are fabricated and analyzed for print time, print electricity consumption, and mechanical properties. The additional electrical output for a case study RV PV system in three representative locations in the U.S. is simulated. These preliminary results are discussed and conclusions are drawn about the technical and economic viability of this distributed approach to manufacturing.

\subsection{Methods}

RV Conventional aluminum brackets for mounting RV PV modules are widely available in a Z-shape geometry composed of two horizontal mounting feet connected via a vertical riser. One of the feet is attached to the module, while the other is connected to a standoff mount. The load transferred to the mount from the module acts in such a way that a moment occurs in the bracket causing stresses to be present from bending. To serve as a functional replacement, a printed mount must be able to withstand the same moment as the aluminum mount. Therefore a baseline maximum moment (M) the aluminum bracket can support before failure was calculated for the aluminum bracket as well as stiffness to serve as design parameters for the printed mount using:

$$
\mathrm{M}=\sigma \mathrm{y} \mathrm{I} / \mathrm{y}
$$

where $\sigma y$ is the yield strength of the material, I is the second moment of inertia, and y is the distance from the neutral axis. For the 6061-O aluminum brackets, the yield strength was taken as 55.2MPa [42]. Brinell Hardness was tested on the brackets, confirming the 6061-O alloy, with $29.9 \mathrm{MPa}$ experimentally tested and $30 \mathrm{MPa}$ being handbook comparison [42]. The dimensions of aluminum brackets are $1.8 \mathrm{~mm}$ thick and 38mm ( $+/-0.005 \mathrm{~mm})$ wide resulting in an area moment of $1.847 \times 10-11 \mathrm{~m} 4$ and a distance of $0.9 \mathrm{~mm}$ from the neutral axis to the surface where stresses are highest. The 
calculated maximum supported moment is $1.13 \mathrm{Nm}$, which translates to a force of 83.4N (18.75lbs) acting at the centroid of the mounting foot.

The basic bending stiffness of the aluminum bracket was determined by:

$$
\mathrm{K}=\mathrm{EI}
$$

where $\mathrm{E}$ is the Young's Modulus. For the bracket with a Young's Modulus of 68.9GPa the bending stiffness is $1.272 \mathrm{Nm}^{\wedge} 2$.

ABS was chosen as the printing material due to its resistance to UV radiation and environmental conditions of wind, rain, and snow that it could experience while in use [43]. ABS printed parts are also able to be treated with acetone to smooth out and better seal the exterior of the parts, which see the most wear in use [43]. To compare the aluminum parts to the 3-D printed ABS parts, 10 ASTM Type I tensile test specimens were printed at 100\% infill and tested in accordance with the ASTM D638 standard for testing plastics [44]. These tests resulted in preliminary values of $27 \mathrm{MPa}$ for the tensile strength and 1.8 GPa for E [45]. In order to compensate for the decrease in strength and modulus of the printed parts, the thickness was increased to $4 \mathrm{~mm}$ and the width held constant resulting in a maximum supportable moment of $2.74 \mathrm{Nm}$ or a $201.9 \mathrm{~N}$ (45.4lbs) force and a stiffness in bending of $0.365 \mathrm{Nm} 2$. While the printed part can theoretically support a greater force than the aluminum bracket, it will deflect more due to having a lower stiffness in the loading configuration.

Due to the discrete nature layer deposition in 3-D printing, the lamination strength of the layers in the direction of the part build is much lower than the tensile strength in the plane of deposition. However, this is only an issue when the print is loaded parallel to the $\mathrm{Z}$ axis of the print and can be mitigated by loading parts perpendicular to the $\mathrm{Z}$ axis of print, such as how the mounting bracket is designed.

The 3-D printed parts were designed using OpenSCAD [46], an open-source, scriptbased, parametric 3-D modeling program. Along with increasing the thickness, the geometry of the original part was modified to ensure that it would behave similarly to the aluminum part despite differences in material properties. A chamfer was added at the junction of the mounting bracket foot and the vertical riser to add extra support, 
increasing stiffness. This serves to fortify critical sections of the part where stress concentrations would be highest.

Finally the 3-D printable racking component cost (CT) was calculated by:

$$
\mathrm{CT}=\Sigma \text { te }+\mathrm{mp}+\mathrm{v}
$$

where $t$ is the printing time, e is the electricity cost [ $\$ / \mathrm{hr}]$ made up of the power consumed times the electric rate of $\$ 0.12 / \mathrm{kW}-\mathrm{h}$ [47], $\mathrm{m}$ is the mass [kg], $\mathrm{p}$ is the polymer cost of $\$ 35 / \mathrm{kg}$ (note: ABS and PLA, the two most common polymers both sell for approximately the same cost) and $v$ is the cost of M8 threaded rod and two M8 nuts, which are required for each standoff and mounting bracket pair. The electricity use was measured to print the brackets with a multimeter $(+/-0.005 \mathrm{kWh})$ and the finished printed components were weighed $(+/-0.05 \mathrm{~g})$ with a digital balance. Bolt hardware was priced at McMaster-Carr.

The parts were printed using a modified Prusa Mendell variety of RepRap 3-D printer, with maximum build dimensions of $200 \mathrm{~mm}$ square in the $\mathrm{X}$ and $\mathrm{Y}$ directions and a $180 \mathrm{~mm}$ height limit. For current bill of materials, building and operating instructions see: http:// www.appropedia.org/MOST_HS_RepRap_build The RepRap 3-D printer is able to print every part needed for the mounting system, aside from metal fasteners, with multiple parts fitting on the build platform to decrease print times. A layer resolution of $0.25 \mathrm{~mm}$ and a positioning accuracy of $0.1 \mathrm{~mm}$ resulted in uniformity throughout the part and an aesthetic appeal that is lacking in the aluminum parts.

The yearly energy output was calculated using PV Syst 6.0.6 for four 200W RV mounted PV modules using standard Al mounting and 3-D printed optimal tilt mounting for three representative locations (Minneapolis, MN, Boulder, CO and Phoenix, AZ).

\subsection{Results and Discussion}


Figure 3.1 shows the final design of the module mount in both the a) the computer model of the $z$ bracket and the standoff, and $b$ ) the 3-D printed $z$ bracket and standoff. Figure 3.2 shows the assembled bracket and standoff with standard nuts and bolts.
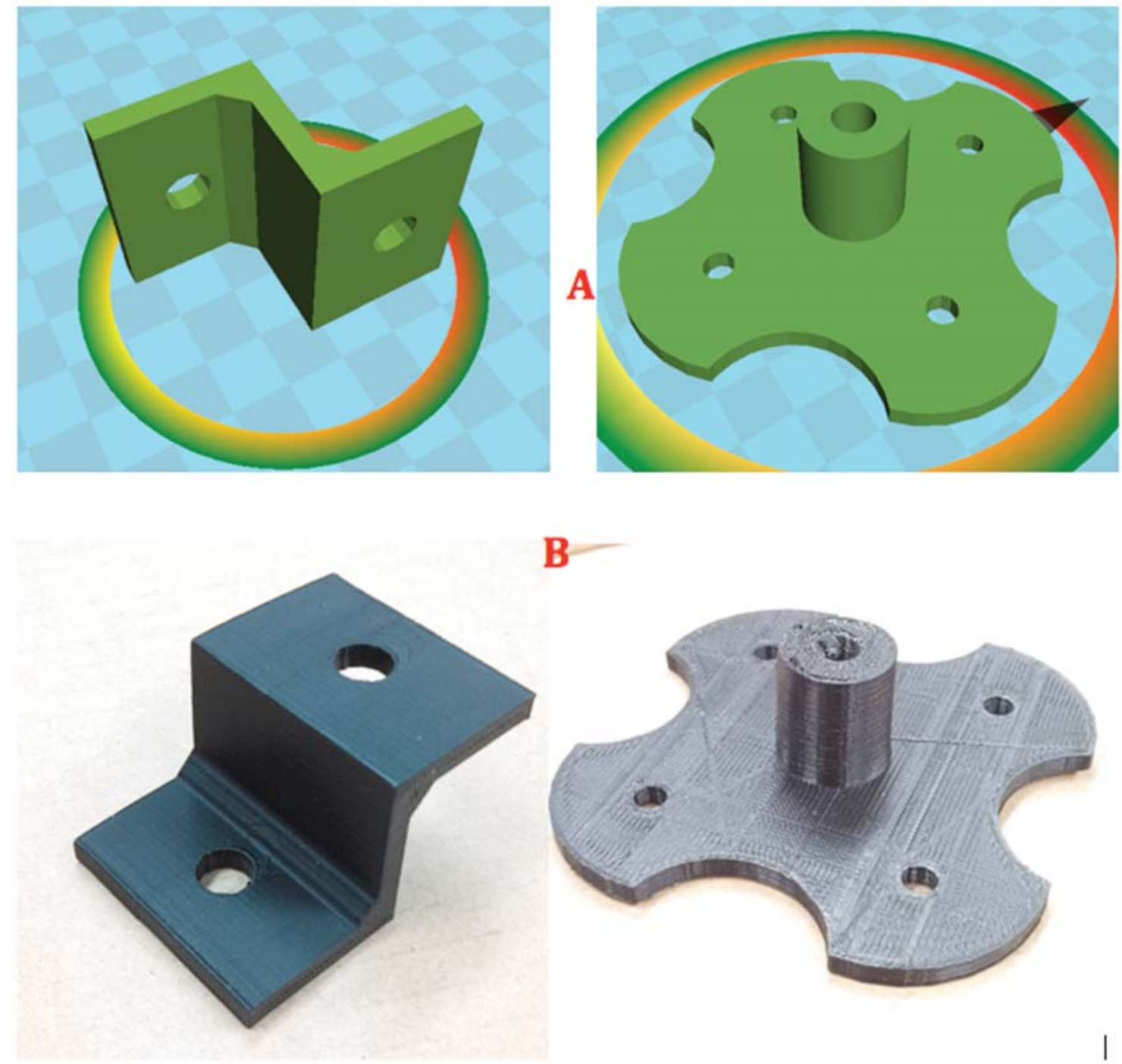

Figure 3.1: a) STL files of $z$ brackets (left) and standoff (right) b) 3-D printed model of $z$ bracket (left) and standoff (right) 


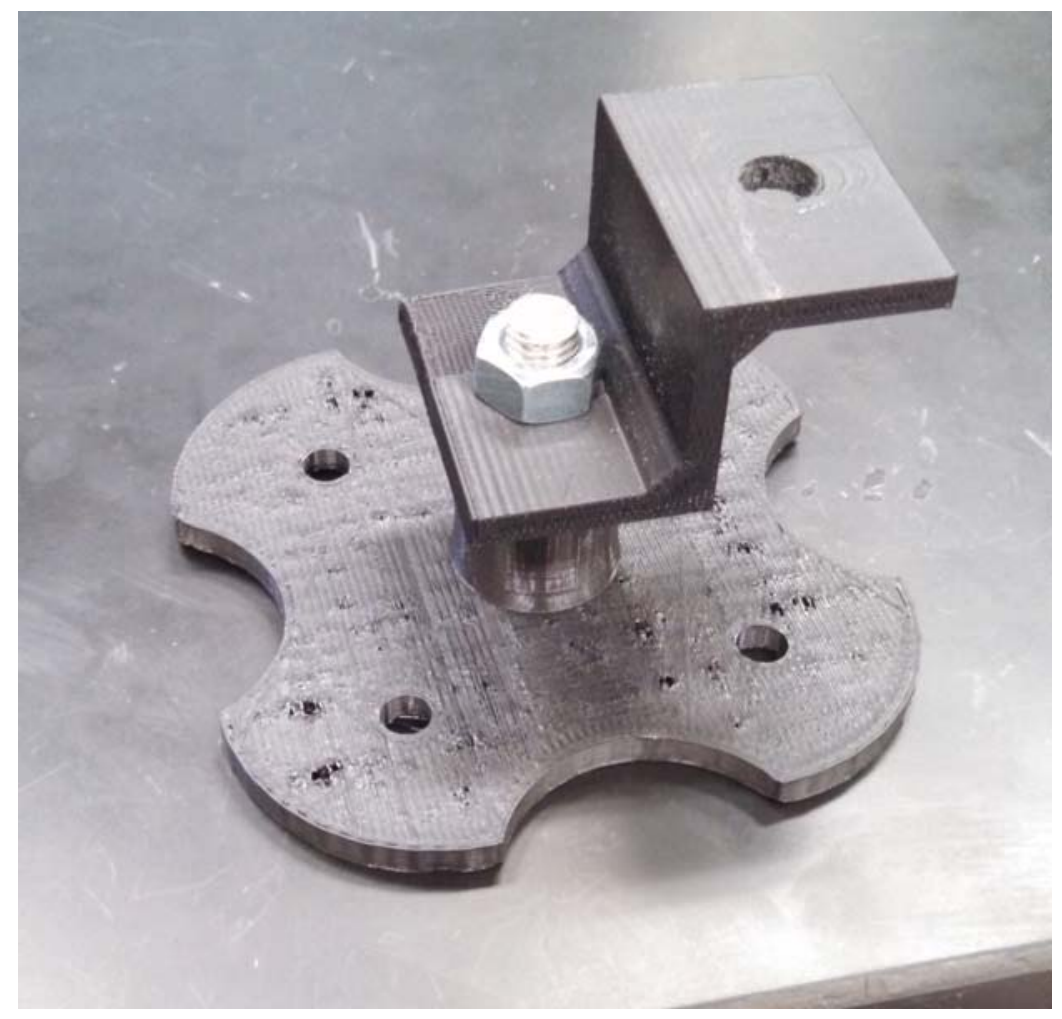

Figure 3.2: Assembled 3-D printed mounting bracket and standoff.

In addition to design changes to increase mechanical performance, the parts were designed to be customizable to fit any particular application that may useful to the end user. Tilt angle, mounting hardware type, height of standoff, and the base diameter can all be customized and tailored for a specific application using OpenSCAD to optimize the PV system as shown in Figure 3.3. 


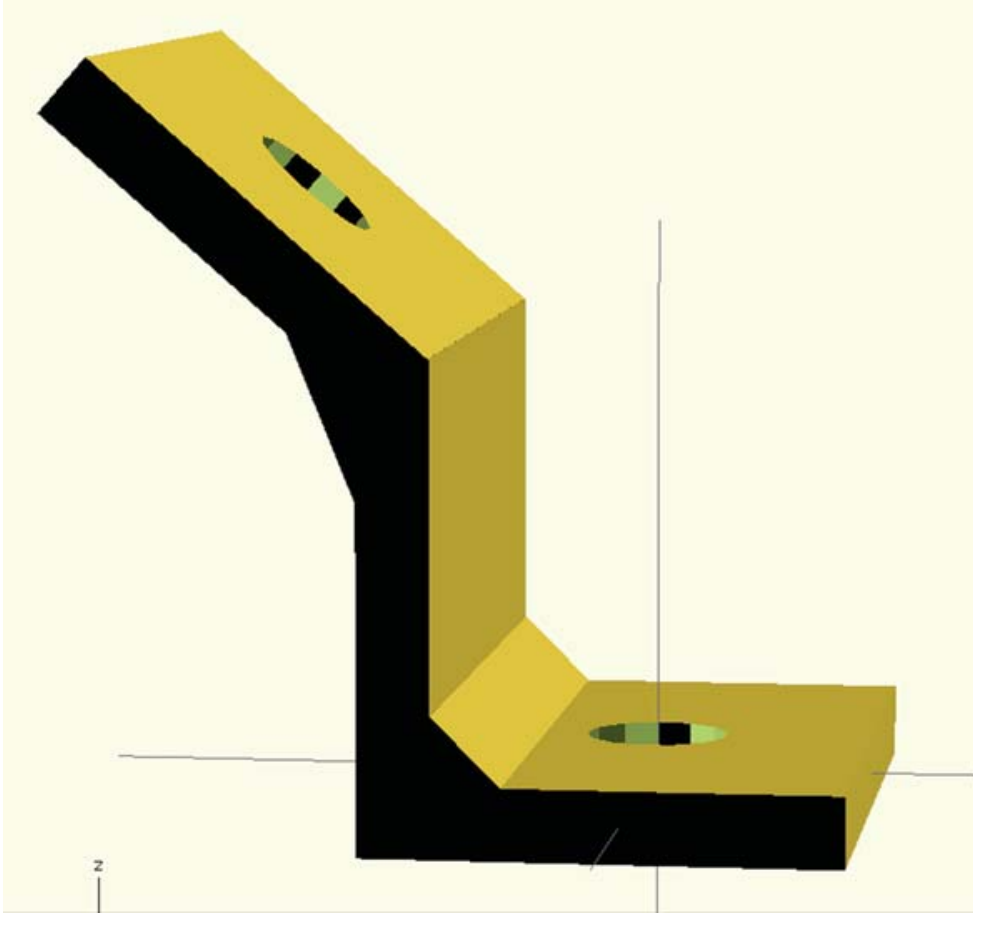

Figure 3.3: Tilt angle modifications made during modeling in OpenSCAD.

Another advantage of the 3-D printable design is the ability to easily modify the design for mechanical performance improvement, such as changing the size of a chamfer to give the end user optimized performance of the part depending on the type of conditions expected while driving and stationary. For example, those traveling through areas with known high-velocity winds may increase the cross-section of components to provide additional mechanical strength.

Traditional aluminum standoffs and mounts cost $\$ 14.00$ for a set of four mounting brackets and $\$ 15.00$ per standoff and fasterners totaling $\$ 75.23$ (37.6 cents/W) + shipping [48]. This currently is about half the cost of the PV on a per W basis. The cost of the 3-D printable RV racking is $\$ 7.21 /$ module (3.6 cents/W) when considering the printed parts plastic and embodied energy (electricity) and fasteners for four mounting brackets and standoffs. There is thus a factor of 10 savings for the 3-D printable RV mounts which also offer superior performance from the array because of the ability to tilt the modules closer to their optimal tilt angle. As the size of the PV 
system gets smaller the relative cost of the racking increases, so decreasing the cost of the racking can make smaller PV systems easier to afford for people looking to use them in apartments, or cottages that have lower electricity requirements compared to a typical household.

These traditional mounts are also expected to last the life of the module without any required maintenance. A continuation of this research could consist of adding carbon black to increase the reinforcement ability of the 3-D printed parts and aid in UV resistance [49].

With the ability to change the design of the mount in the modeling software come changes in cost. When the tilt angle is changed, the height of the mount must also change which requires more material and more cost, but with increased benefit in module performance. Operating the module at the optimal tilt angle increases the efficiency, which for three different locations was found to be an average increase over the three representative U.S. locations of over $20 \%$ as shown Table 3.1. The added total cost of the extended standoffs is $\$ 12.46$ per meter above the mounting bracket in order to operate the module at the optimal tilt angle. This increase in cost only applies to two of the four standoffs and can be minimized by tilting in landscape orientation.

It should be noted here that the costs of the RepRap 3-D printer itself and the human costs to operate the printer were not included in this study. In traditional manufacturing the cost of the manufacturing equipment can be a substantial percentage of the cost of the resultant products, in this case is was assumed that the value of the printer had already been realized in printing other products. This assumption is supported by a recent study that showed the cost of a RepRap 3-D printer could be easily recouped in under 1 year assuming only 20 common household items were printed [9]. These household items could be printed in a weekend making the fractional cost of the capital equipment irrelevant to any economic study like this one that assumed the consumer already owned a 3-D printer. 
The labor costs are slightly more complicated. It was assumed the RV owners would do the printing themselves and not hire out the task. As the designs for the RV PV system have already been designed and open-sourced as part of this publication the labor involved in manufacturing the products with an existing 3-D printer is trivial. The RV owner would either download the STL files, which were open sourced as part of this study (or customize their brackets with the open-sourced SCAD files), then slice and print on their RepRap. This process is only slightly more complicated than downloading and printing a pdf file on a color 2D printer. Much like conventional printers, tuned 3-D printers do not need to be watched as the print so the RV owner could spend their time any way they chose during the majority of the printing time. This makes the additional opportunity cost for prosumer manufacturing of the RV PV bracket system rather small (if it exists at all) as it would need to be compared to the cost (and time value lost) or either shopping in a retail store (and transportation time to and from the store) for a product or ordering it online and waiting for it to be delivered. In either case the convenience and the ability to customize would provide even more savings than have been conservatively estimated here. The values of labor, however, were not quantified here as there is a high degree of variability in opportunity costs among consumers depending on their income, employment, and geographic location. 


\section{Table 3.1: Electrical generation analysis of four 200W PV modules over 1}

\begin{tabular}{|c|c|c|c|c|c|}
\hline & & \multicolumn{2}{|c|}{ Module tilt } & \multicolumn{2}{|c|}{$\begin{array}{c}\text { Change in } \\
\text { efficiency from flat } \\
\text { orientation }\end{array}$} \\
\hline & $\begin{array}{l}\text { Optimal } \\
\text { Tilt } \\
\text { Angle }\end{array}$ & $\begin{array}{c}\text { Flat } \\
(\mathrm{kWh} / \mathrm{yr})\end{array}$ & $\begin{array}{c}\text { Optimal } \\
(\mathrm{kWh} / \mathrm{yr})\end{array}$ & $\begin{array}{l}\text { Increase } \\
(\mathrm{kWh} / \mathrm{yr})\end{array}$ & $\begin{array}{l}\text { Percent } \\
\text { increase }\end{array}$ \\
\hline Minneapolis, MN & $41^{\circ}$ & 238 & 297 & 59 & 25 \\
\hline Boulder, $\mathrm{CO}$ & $38^{\circ}$ & 280 & 345 & 65 & 23 \\
\hline Phoenix, AZ & $32^{\circ}$ & 349 & 404 & 55 & 16 \\
\hline & & & Average & 60 & 21 \\
\hline
\end{tabular}

Providing open-source designs will allow 3-D printer owners and companies everywhere to begin distributed manufacturing of custom RV PV mounts allowing distribution to take place simultaneously throughout the country and driving competition between manufactures ultimately benefiting the customers with the lowest prices possible. According to the Recreation Vehicle Industry Association, 21\% of all U.S. households stated intentions to purchase an RV at some point in the future [50]. There are $~ 115$ million households in the U.S, equating to the potential for about 24 million RV's to be modified with the design. If each RV owner installed four $200 \mathrm{~W}$ modules the total power would be over 19GW, which is over 6 times the total U.S. installations in 2012. Distributed manufacturing PV racking creates a more customized product and drops costs by an order of magnitude, which has the potential to significantly expand the PV market not only in the U.S., but as it pushes the costs down considerably - in the entire world.

In this case study the product is environmentally-friendly because of the intrinsic sustainability of PV systems [51]. However, the use of the ultra-distributed (or prosumer) manufacturing for the product will result in additional PV energy conversion improving the environmental performance of the product further. In this 
specific case high embodied energy aluminum is replaced with low-embodied energy plastic (or even recycled plastic) even further improving the environmental performance of the RV PV racking. However, material substitution is not necessary to improve the environmental performance of 3-D printed products. Preliminary life cycle analysis for manufacturing with RepRaps identical to those used in this study for more common household items indicates that distributed manufacturing has a smaller environmental impact than conventional manufacturing $[6,7]$. These environmental benefits are significantly enhanced when recycled polymers are used and even more so when using distributed recycling with RecycleBots [16,17,52]. Waste plastic filament extruders are much less developed than RepRaps, but there are several companies commercializing extruders that can act as RecycleBots directly and on KickStarter as of this writing. Filament manufactured with a RecycleBot further improves the economics of distributed manufacturing as it can produce $1 \mathrm{~kg}$ of filament from about empty 20 milkjugs for under 10 cents instead of $\$ 30-60 / \mathrm{kg}$ from centralized filament suppliers. The economics of using a distributed approach to recycling and manufacturing with open-source equipment seems clear and may be a key factor along with the ability for ultra-customization that drives the reduced environmental impact for 3-D printing at the prosumer level. If the proliferation of open-source designs continues exponential growth [9] the value of owning a personal 3-D printer increases and could become commonplace for manufacturing a wide range of products.

As it appears possible (and perhaps likely) that an ever expanding list of products will be manufactured by prosumers using personal 3-D printers future work is needed to quantify the environmental impact of both individual products, but also the wider impacts of a distributed manufacturing ecosystem. Potential large socioeconomic shifts, changes in employment, alterations to resource scarcities and concomitant reduced conflicts due to reduced spending on centrally manufactured products could have both direct and indirect effects on the environment, which are in substantial need for further study. The environmental performance of personal 3-D printing should not only address the LCA of polymer products and energy use as has been done in the past, but can also include the expanding array of printed materials and specialty chemicals. Finally, such LCAs should include the impact of chemicals 
that are sometimes used in post-processing printed objects. For example, acetone can be used to smooth out the $\sim 200$ micron step heights used in today's 3-D printing. Acetone is only toxic when considered in normal use, but other chemicals (such as dichloromethane, used to treat the common printing material PLA), are substantially more dangerous. LCAs could help guide the burgeoning industry of ultra-distributed manufacturing with open-source 3-D printing towards the safest and most environmentally benign techniques and chemicals.

\subsection{Conclusions}

The preliminary results of this study show distributed manufacturing using 3-D printing of the case study product of RV PV racking results in an order of magnitude reduction in economic cost for a superior product. The additional electrical output for a case study RV PV system in three representative locations in the U.S. was found to be on average over $20 \%$ higher than for conventional mass manufactured racking systems. The preliminary results indicate that distributed manufacturing - even at the household level - with open-source 3-D printers is technically and economically viable. Further research is necessary to expand the results of this preliminary study to other types of products and to complete full life cycle analysis on them to quantify the environmental impacts.

\subsection{References}

[1] Q. Zhu, J . Sarkis, An inter-sectoral comparison of green supply chain management in China: Drivers and practices, J ournal of Cleaner Production 14 (2006) 472-486.

[2] J . M. Pearce,S. J . J ohnson,G. B. Grant, 3D-mapping optimization of embodied energy of transportation, Resources, Conservation and Recycling 51 (2007) 435- 453.

[3] S. Cholette, K. Venkat, The energy and carbon intensity of wine distribution: A study of logistical options for delivering wine to consumers, J ournal of Cleaner Production 17 (2009) 1401- 1413. 
[4] K. Meisterling, C. Samaras, V. Schweizer, Decisions to reduce greenhouse gases from agriculture and product transport: LCA case study of organic and conventional wheat, J ournal of Cleaner Production 17 (2009) 222- 230.

[5] K. H. Winnebeck, An abbreviated alternatives assessment process for product designers: a children's furniture manufacturing case study, J . Cleaner Production 19 (2011) 464-476.

[6] M. Kreiger, and J. M. Pearce, Environmental Impacts of Distributed Manufacturing from 3-D Printing of Polymer Components and Products, MRS Online Proceedings Library (2013) 1492 mrsf12-1492-g01-02.

[7] M. Kreiger, and J. M. Pearce, Environmental Life Cycle Analysis of Distributed 3-D Printing and Conventional Manufacturing of Polymer Products, ACS Sustainable Chemistry \& Engineering 1(12) (2013) 1511- 1519.

[8] J. M. Pearce, C. M. Blair, K. J. Laciak, R. Andrews, A. Nosrat, and I. ZelenikaZovko, 3-D Printing of Open Source Appropriate Technologies for SelfDirected Sustainable Development, J of Sustainable Dev. 3(4) (2010) 17-29.

[9] B. T. Wittbrodt, A. G. Glover, J. Laureto, G. C. Anzalone, D. Oppliger, J . L. Irwin, J . M. and Pearce, Life-Cycle Economic Analysis of Distributed Manufacturing with Open-Source 3-D Printers, Mechatronics 23 (2013) 713726.

[10] A. Blua, A New Industrial Revolution: The Brave New World Of 3D Printing, Radio Free Europe Radio Library (2013) http:// www.rferl.org/ content/ printing-3d-new-industrialrevolution/ 24949765.html

[11] The Economist, A Third industrial Revolution, April 21, 2012.

[12] Make, Make: ultimate guide to 3D printing, Oreilly Winter 2013.

[13] Wohlers Associates, Additive Manufacturing and 3D Printing State of the Industry Annual Worldwide Progress Report, Wohlers Associates (2013) Fort Collins, Co.

[14] T. Martens, L. Mears, M. Dotson, M. Graham, and P. Sanger, Use of Fused Deposition Modeling of Polyphenylsulfone for Centrifugal Casting of Polyurethane: Material, Surface, and Process Considerations. J. Manuf. Sci. E. 133(5) (2011) 051003. 
[15] R. Jones, P. Haufe, E. Sells, P. Iravani, V. Olliver, C. Palmer, and A. Bowyer, RepRap - the replicating rapid prototyper, Robotica 29(1) (2011) 177-191.

[16] C. Baechler, M. DeVuono, and J. M. Pearce, Distributed recycling of waste polymer into RepRap feedstock, Rapid Protyping J ournal 19(2) (2013) 118-125.

[17] M. A. Kreiger, M. L. Mulder, A. G. Glover, and J. M. Pearce, Life cycle analysis of distributed recycling of post-consumer high density polyethylene for 3-D printing filament, J ournal of Cleaner Production 70 (2014) 90-96.

[18] J. Mireles, H. Kim, H. Lee, D. Espalin, F. Medina, E. MacDonald, and R. Wicker, Development of a Fused Deposition Modeling System for Low Melting Temperature Metal Alloys. J. Electron, Packaging 135(1) (2013) 011008.

[19] E. Sells, Z. Smith, S. Bailard, A. Bowyer, and V. Olliver, Reprap: the replicating rapid prototyper: maximizing customizability by breeding the means of production. In Piller, F. T., and Tseng, M. M., Handbook of Research in Mass Customization and Personalization: Strategies and concepts (Vol. 1). World Scientific. (2010)

[20] J. M. Pearce, Building Research Equipment with Free, Open-Source Hardware, Science 337(6100) (2012) 1303- 1304.

[21] J. M. Pearce, Open-Source Lab: How to Build Your Own Hardware and Reduce Research Costs, Elsevier (2014).

[22] C. Zhang, N. C. Anzalone, R. P. Faria, and J . M. Pearce, Open-Source 3DPrintable Optics Equipment, PLoS ONE 8(3) (2013) e59840.

[23] S. J . Leigh, R. J . Bradley, C. P. Purssell, D. R. Billson, and D. A. Hutchins, A simple, low-cost conductive composite material for 3D printing of electronic sensors, PLoS One 7(11) (2012) e49365.

[24] G. C. Anzalone, A. G. Glover, and J. M. Pearce, Open-Source Colorimeter, Sensors 13(4) (2013) 5338-5346.

[25] J. Gonzalez-Gomez, A. Valero-Gomez, A. Prieto-Moreno, and M. Abderrahim, A new open source 3d-printable mobile robotic platform for education. Advances in Autonomous Mini Robots, (2012) 49-62. In Advances in autonomous mini robots. Springer Berlin Heidelberg.

[26] T. Redlich, J. P. Wulfsberg, and F. L. Bruhns, Virtual Factory for Customized Open Production, 15th Int. Product Dev. Management Conf., Hamburg (2008). 
[27] R. E. DeVor, S. G. Kapoor, J . Cao, K. F. Ehmann, Transforming the Landscape of Manufacturing: Distributed Manufacturing Based on Desktop Manufacturing (DM)2, J . Elec. Packaging 134(4) (2012) 61801.

[28] J. Bayless, M. Chen, and B. Dai, Wire embedding 3D printer, Engineering Physics, University of British Columbia (2010).

[29] M. Moses, H. Yamaguchi, and G. S. Chirikjian, Towards cyclic fabrication systems for modular robotics and rapid manufacturing, In Proceedings of robotics: science and systems (2009).

[30] J. S. Miller, K. R. Stevens, M. T. Yang, B. M. Baker, D. H. T. Nguyen, D. M. Cohen, E. Esteban Toro, A. A. Chen, P. A. Galie, X. Yu, R. Chaturvedi, S. N. Bhatiaand, and C. S. Chen, Rapid casting of patterned vascular networks for perfusable engineered three-dimensional tissues, Nature Materials 11 (2012) 768-774.

[31] A. J . Buitenhuis, and J. M. Pearce, Open-Source Development of Solar Photovoltaic Technology, Energy for Sustainable Development 16 (2012) 379388.

[32] Makerbot Thingiverse, Solar J oos Bike Rack Mount, http:/ / www.thingiverse.com/ thing:25260 (2012)

[33] Makerbot Thingiverse, Solar Powered Stereo http:// www.thingiverse.com/ thing:38262 (2012)

[34] Makerbot Thingiverse, Dual Axis Solar Tracker http:// www.thingiverse.com/ thing:53321(2013)

[35] Makerbot Thingiverse, Solar panel terminal box http:// www.thingiverse.com/ thing:62068 (2013)

[36] K. Branker, M. J . M. Pathak, and J. M. Pearce, A Review of Solar Photovoltaic Levelized Cost of Electricity, Renewable \& Sustainable Energy Reviews 15 (2011) 4470-4482.

[37] G. Barbose, N. Darghouth, and R. Ryan Wiser, Tracking the Sun V: An Historical Summary of the Installed Price of Photovoltaics in the United States from 1998 to 2011. Lawrence Berkeley National Laboratory (2012) http:// emp.lbl.gov/ sites/ all/ files/ LBNL-5919e.pdf 
[38] G. Lewis, Optimum tilt of a solar collector, Solar \& wind Tech., 4(3) (1987) 407410.

[39] N. Shu, N. Kameda, Y. Kishida, and H. Sonoda, Experimental and theoretical study on the optimal tilt angle of photovoltaic panels, J ournal of Asian Architecture and Building Engineering 5(2) (2006) 399-405.

[40] E. Calabrò, Determining optimum tilt angles of photovoltaic panels at typical north-tropical latitudes, J ournal of renewable and sustainable energy 1(3) (2009) 033104.

[41] E. D. Mehleri, P. L. Zervas, H. Sarimveis, J . A. Palyvos, and N. C. Markatos, Determination of the optimal tilt angle and orientation for solar photovoltaic arrays, Renewable Energy 35(11) (2010) 2468-2475.

[42] ASM Aerospace Specification Metals Inc. Aluminum 6061-O (2013) http:// asm.matweb.com/ search/ SpecificMaterial.asp?bassnum=MA6061O

[43] P. Davis, B. E. Tiganis, and L. S. Burn, The effect of photo-oxidative degradation on fracture in ABS pipe resins, Polymer Degradation and Stability 84(2) (2004) 233-242.

[44] ASTM Standard D638, Standard Test method for Tensile Properties of Plastics, ASTM International, West Conshohocken, PA, (2013).

[45] B. M. Tymrak, M. Kreiger, and J. M. Pearce, Mechanical Properties of Components Fabricated with Open-Source 3-D Printers Under Realistic Environmental Conditions (2014) (to be published)

[46] M. Kintel, and C. Clifford Wolf, OpenSCAD - The Programmers Solid 3D CAD Modeller (2013) http:// www.openscad.org/

[47] U.S. Energy Information Administration, Electric Power Monthly: Average Retail Price of Electricity to Ultimate Customers (2013) http:// www.eia.gov/ electricity/ monthly/ epm_table_grapher.cfm?t=epmt_5 3

[48] Northern Arizona Wind \& Sun. Z-Bracket RV Mounting Feet (set of 4). http:// www.solar-electric.com/ sopozrvmofes.html (2014)

[49] R. J. T. Clabbum, R. J. Penneck, and C. J. Swinmurn, The Outdoor Performance of Plastic Materials Used as Cable Accessories, IEEE Transactions on Power Apparatus and Systems PAS-92(6) (1973) 1833 - 1842. 
[50] RVIA, New RVIA Research Shows Record Level of RV Ownership. http:// www.rvia.org/ ?ESID=trends (2013)

[51] J. Pearce, Photovoltaics - A Path to Sustainable Futures, Futures 34(7) (2002) 663-674.

[52] M. Kreiger, G. C. Anzalone, M. L. Mulder, A. Glover and J. M. Pearce, Distributed Recycling of Post-Consumer Plastic Waste in Rural Areas, MRS Online Proceedings Library 1492 (2013) mrsf12-1492-g04-06 


\section{4 - Total Cost Evaluation of Low-Weight Tension-Based Photovoltaic Flat-Roof Mounted Racking ${ }^{3}$}

\subsection{Introduction}

Currently the world uses 17.1TW of continuous power annually, with the U.S. consuming 3.3 TW [1]. Industrial energy consumption is expected to increase $40 \%$ from 2006 to 2030 [2]. Most of the energy consumption was from non-renewable energy sources when the Earth has 165,000 TW of constant solar energy from the sun [3]. Photovoltaic (PV) systems have the potential to reduce the dependency on nonrenewable resources and their concomitant externalities to provide that energy, while also saving businesses money [4-7]. Current projections show that demand for PV will surpass that of natural gas around 2036-2040 [2]. However, the cost of PV needs to be small enough that the initial investment can be recouped over time to better incentivize companies to adopt solar energy more rapidly [8]. The time value of solargenerated electricity can help meet this goal as during typical business peak hours for electricity consumption, PV power generation is near the maximum output, when time of use costs for electricity are also peaking [9]. This along with the overall low levelized cost of solar electricity can provide a strong financial argument to install solar on a business in many locations [4]. One of the largest opportunities for financiallyrewarding PV deployment is on the generally flat rooftops of manufacturing and retail facilities, with some retail facilities reaching nearly 100,000 sq. ft. of area [10]. United States commercial building rooftops, which are predominantly flat rooftops represent an area of more than 1,000 square miles with more than half of this area useful for electricity generation using PV [11]. Unfortunately a lot of the potential PV commercial rooftop installations are being prevented by a combination of over-designed racking and prohibitive economic costs.

The economics of PV systems installations is changing as the PV industry is undergoing significant structural adjustments as the cost per unit power of PV modules has dropped quickly in the last five years $[4,12,13]$ and now the spot price of PV modules is under US\$0.47 per Watt [14,15]. These costs reductions have two

3 The material contained in this chapter has been prepared for publication 
important results: i) a marked decrease in the levelized cost of solar electricity into ranges competitive or better than traditional electricity-generation technologies [4], which in turn is driving up demand with over 4,750 MW installed in the U.S. in 2013 $[14,16]$ and ii) the economic role of racking has been gaining prominence relative to that of the modules [17]. Historically, the academic interest in PV racking has been low, with no studies published in the non-patent literature. As this lack of attention and as the relative importance of the costs of $\mathrm{PV}$ racking has been marginal historically, there has been relatively little progress on reducing the materials and costs associated with PV racking [12]. Because of this, current PV racking components can contribute to a significant portion of the cost for an entire PV system with some of the least-expensive racking solutions costing $\$ 75$ per module [18], which would for example be over $50 \%$ of the cost of a 200W module costing $\$ 120$ at $\$ 0.60$ per Watt. Such inflated racking costs results in lower returns on investment and higher upfront costs for PV systems, which can deter investors from adopting the technology.

In order to overcome these challenge this study investigates a novel low-weight PV racking system for commercial rooftops and compares it to racking systems already available on the market. First the commercially available PV racks are reviewed, which are designed for flat-roof commercial buildings. These racking systems are compared on costs and technical specifications. The tension-based racking system investigated here eliminates the need for the rails used in the majority of commercial systems. This racking system is called $\mathrm{X}$-wire, because of the nature of the crossing steel cables, which provide the tension holding corner units that connect the modules into an array. The X-wire racking system is prototyped and then compared to the most cost-effective and claimed rapidly deployed commercialized racking system for these applications, the Unirac Roof Mount [19] on the basis of cost, time to setup, ease of installation, and adaptability. The results are presented and conclusions are drawn about the potential for tension-based racking systems to further reduce total PV systems costs.

\subsection{Background}

Currently most of the commercially available racking solutions are rail-based roof penetrating (e.g. Renusol VS, Zomeworks Fixed Racks, Unirac Solarmount, Unirac Solarframe) or ballast bay-based (e.g. Unirac RM, Renusol CS260, Instarack, Rayport 
frame-less) [18]. Advantages of the ballast bay systems are the fact that the installation takes less preparation of the roof surface and thus can be installed more rapidly. However, ballast bay systems can only be used on a sufficiently engineered roof that can support the weight, which eliminates many of the most promising unshaded flat commercial rooftops in cities [20, 21].

Although permitting agencies require assessments of the structural attachment of PV systems to rooftops, the safety of these attachments are not currently sufficiently addressed in any codes or standards [22]. This results in over-designed/ built systems and this added weight coupled to the structural deficiencies of commercial buildings for additional wind and snow loads often make the installation of traditional PV systems prohibitive because of the increased costs of structural support necessary to handle the additional loads. Static or dead loads are around 5-10 lbs/ ft2 [24.4-48.8 $\mathrm{kg} / \mathrm{m} 2$ ]. However, these loads are often transferred to the rooftop through PV mounting devices in a way that concentrates the static loads into small surface areas of the roof or individual load bearing members [23]. Thus, such conditions can significantly add to the loading conditions of a single truss, rafter, joist, decking or other roof component making structural reinforcement necessary. On the other hand, dynamic (live) loads can be much larger in magnitude, but are intermittent, and attributed to wind, snow, and maintenance personnel. Most PV modules are rated for static loading of 50-55 lbs/ ft2, or equivalent to the pressure of constant 110 - $120 \mathrm{mph}$ winds acting normal to the module surface [23].

The ballasted roof mounted system requires roughly $6.25 \mathrm{lb} / \mathrm{ft} 2$ [30.5 kg/ m2] of ballast on top of the weight of the racking components whereas the roof penetrating systems considered all require less than $1 \mathrm{lb} / \mathrm{ft} 2[4.88 \mathrm{~kg} / \mathrm{m} 2]$ of added weight from the components. Thus, a roof penetrating system is normally the better and perhaps the only choice for aging or weaker roofs or those built with no tolerance above code requirements. In this study to ensure the techno-economic viability of the racking system, the installation time of the $\mathrm{X}$-wire system is compared to the more rapidly deployed ballast-based system, while its mass per unit area and cost are compared against commercial PV racking systems with roof penetrations as shown in Table 4.1. 
Table 4.1: Commercial PV Racking system with roof penetrations

\begin{tabular}{|c|c|c|c|}
\hline Product & $\begin{array}{c}\text { Mass/area } \\
{\left[\mathrm{lb} / \mathrm{ft}^{2}\right.} \\
\left.\left(\mathrm{kg} / \mathrm{m}^{2}\right)\right]\end{array}$ & $\begin{array}{c}\text { Cost per } \\
\text { module }\end{array}$ & USD \\
\hline Solar Mount & {$[0.46(2.22)]$} & $\$ 139.00$ & $\begin{array}{c}\text { Wholesale } \\
\text { Solar }\end{array}$ \\
\hline Sunframe & {$[0.91(4.45)]$} & $\$ 135.50$ & $\begin{array}{c}\text { Wholesale } \\
\text { Solar }\end{array}$ \\
\hline UGM 36 & {$[0.57(2.78)]$} & $\$ 207.00$ & $\begin{array}{c}\text { Wholesale } \\
\text { Solar }\end{array}$ \\
\hline
\end{tabular}

\subsection{Methods and Materials}

The X-wire racking system is made up of corner brackets and crossing steel cables as seen in Figure 4.1. In any size X-wire system there are nine separate bracket configurations as shown in Figure 4.2, with a) left back, b) middle back, c) right back, d) left middle, e) center), f) right middle, g) left front, h) middle front, and i) left front. The corner brackets, shown in Figure 4.2, were designed in OpenSCAD 2014.03 [24]. The prototype X-wire rack was fabricated using a RepRap 3-D printer in PLA (as shown in Figure 4.3) and stabilized using a steel threaded rod. Figure 4.4 shows the insertion of the steel wire around the metal rod. Mass-produced brackets could couple the rod and bracket into a single component. 


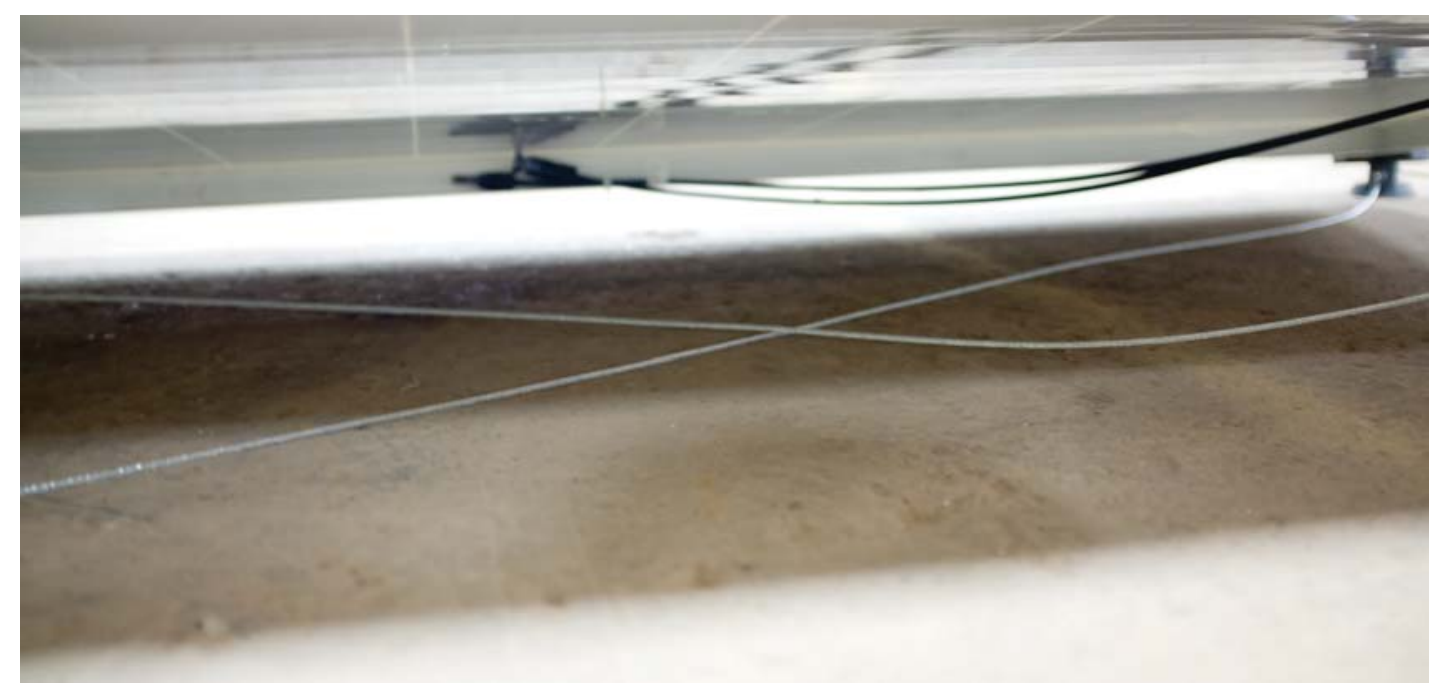

Figure 4.1: Steel wires crossing under the PV module in the X-wire system. 


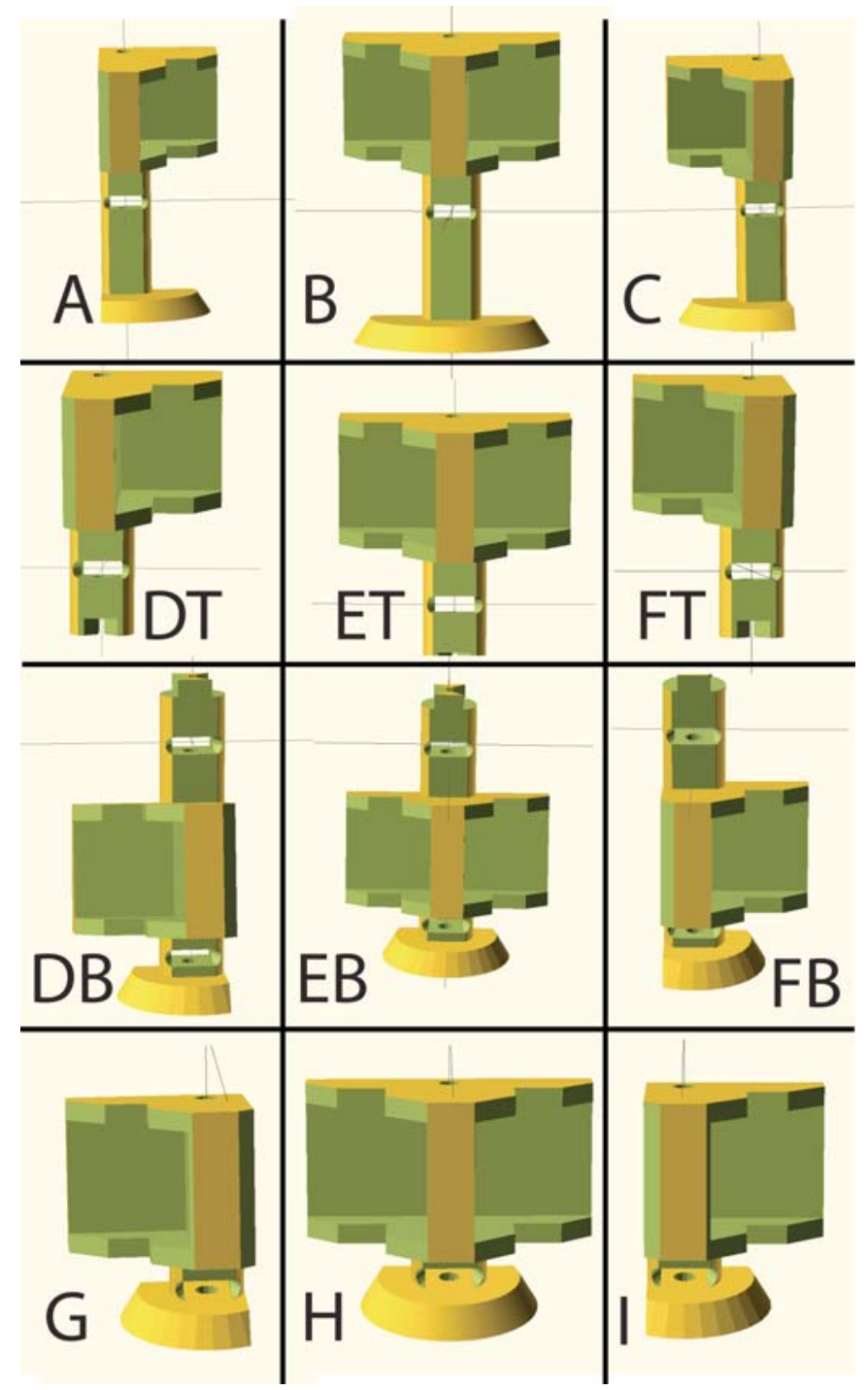

Figure 4.2: OpenSCAD rendering of one of the 3-D printed components: a) left back, b) middle back, c) right back, d) left middle (top, bottom), e) center (top, bottom), f) right middle (top, bottom), g) left front, h) middle front, and i) left front. T denotes top piece, B denotes bottom piece. 


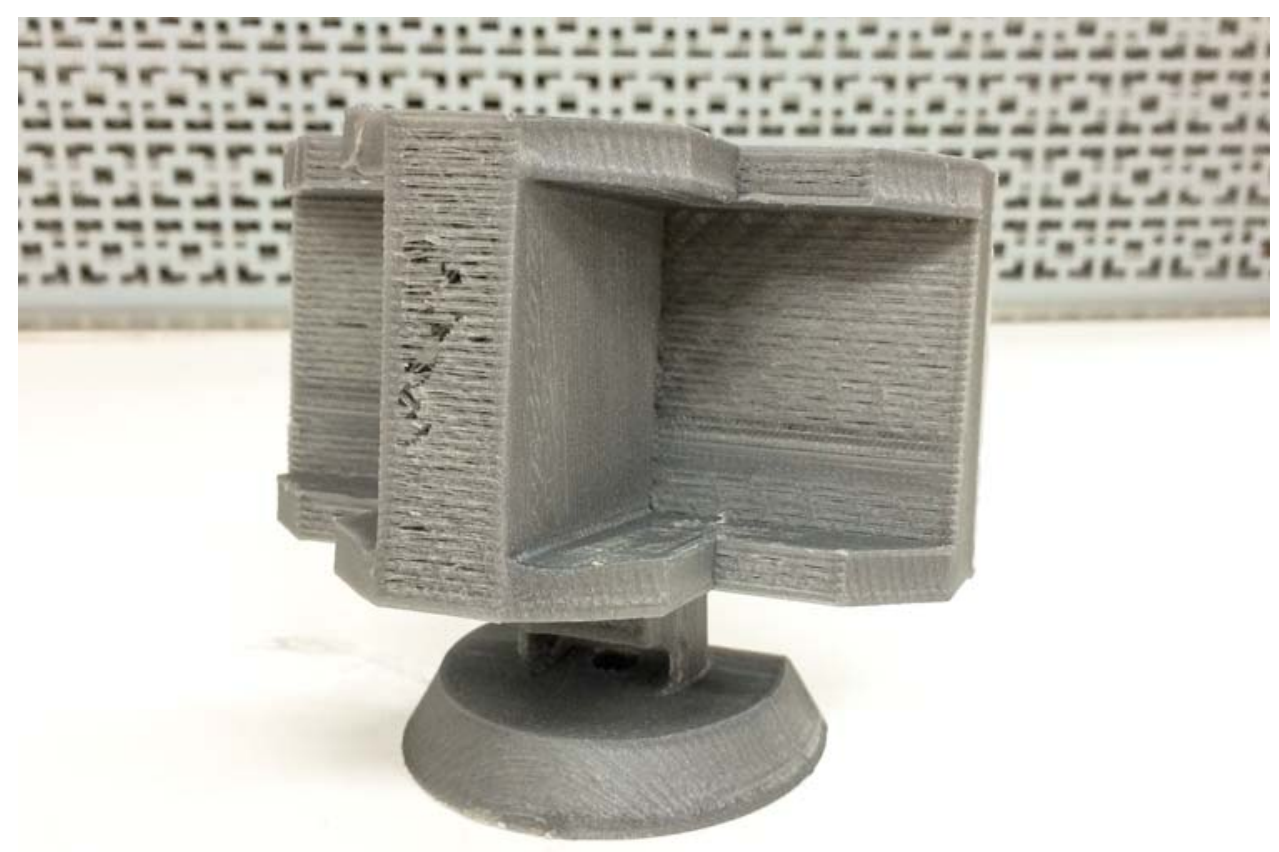

Figure 4.3: Printed front middle bracket of Figure 4.2.

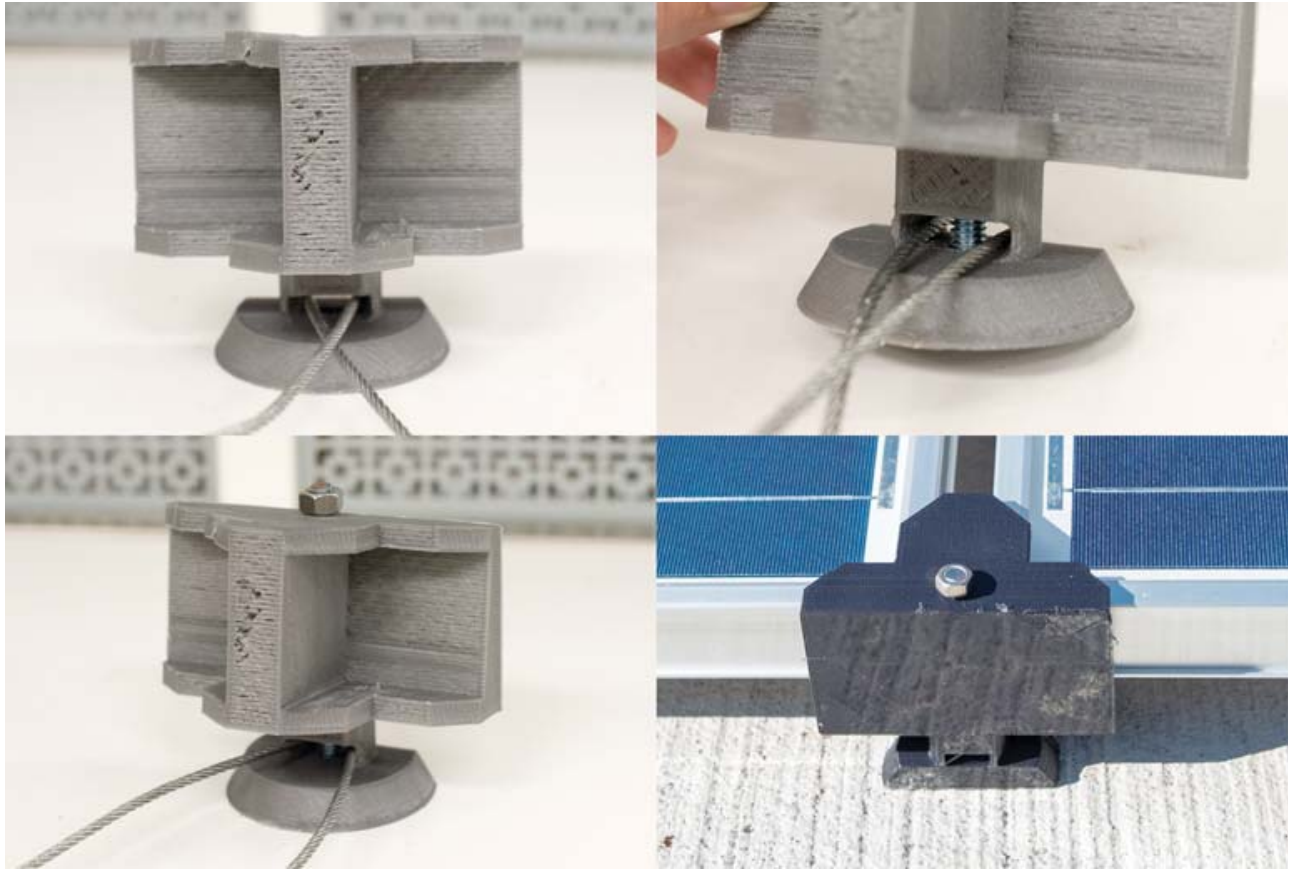

Figure 4.4: Assembly of $X$-wire system bracket. 
Time trials were conducted on 10-degree tilt 1kW PV systems consisting of four 250W J inko J KM250P-60 polycrystalline silicon PV modules on 1) the X-wire racking system and 2) a Unirac Roof Mount (RM) system [19], which was advertised as one of the fastest and easiest systems to assemble and set up at 12 modules per man-hour [19]. The X-wire system works by using the existing aluminum frame of the PV module as structure and keeping them in place with the end brackets pulled against the frame with the steel cable. The rectangular slot in the corner bracket (shown in Figure 4.4) allows the steel wire to be inserted from the front eliminating the need to thread any wire behind rods, through holes, or around objects. Figure 4.5 diagrams the wiring methodology for the $1 \mathrm{~kW}$ X-wire racking with labeled start and end points for each row. Once the wire is inserted the threaded rod can be inserted from the top of the corner bracket and between the wires creating an anchor point. Then two hex nuts are fit, one into the nut-trap in the bottom, and one on the top, to secure all components in place. The wire can then be pulled until it locks tightly around the rod at which time the installer can move onto the next bracket. Once all of the wire is inserted each length can be adjusted by pushing the loop through the back of the corner bracket and tightened, much like a shoelace through and eyelet.

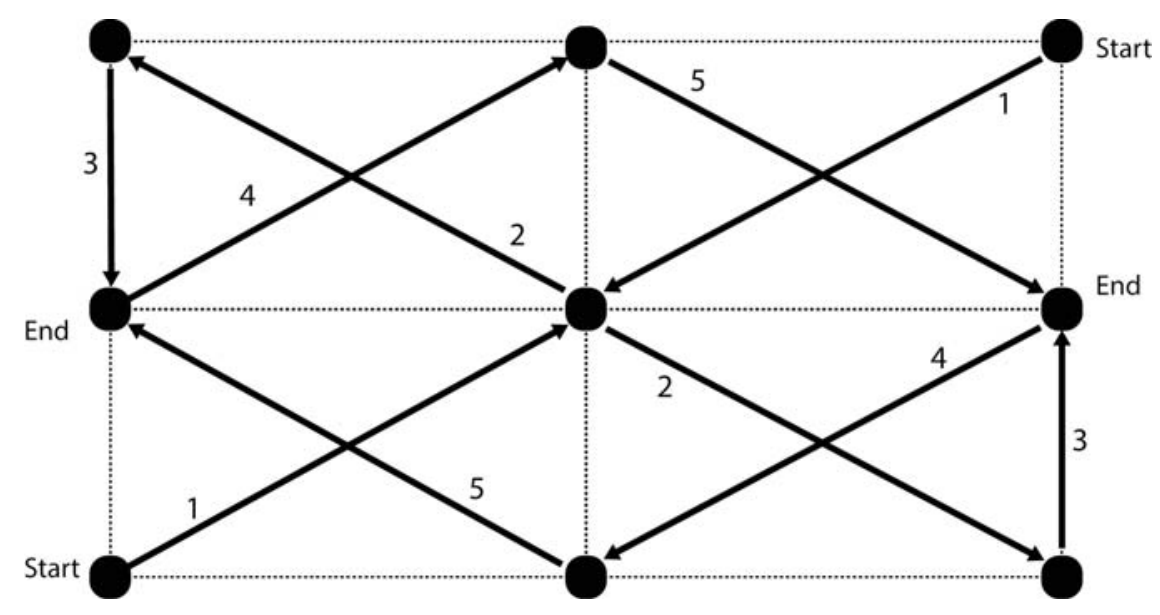

Figure 4.5: Wiring diagram of the $X$-wire system with labels for start and end points for each row. 
Both systems were tested for installation time using a single installer and then repeated to ensure there was no experience differential. For the RM system the installation instructions [25] were followed from the manufacturer. The tools required for constructing the RM system were a drill with hex socket attachment and a hammer. The ballast bays were laid out and the module clips set in with the hammer. After the module clips were in place the hex bolts were screwed in to be set and the modules were lowered in place. Once the modules were in place the hex bolts were tightened evenly and the process was repeated for the other four modules. The ballast bays did need to be weighed down during installation to stop the modules from tipping over in the rack. However, the weight would not be needed if more than one person was installing the system. The X-wire system requires a hex socket to secure the threaded rod and a means to fix the system through roof penetrations. This last fastening was not included in the X-wire system, nor was ballast loading for the RM system. During the timing trials for the RM and X-wire systems the racking was assembled from a pile of parts laid out in onder of need for installation. While the setups were timed, the pace of installation was relatively relaxed to minimize fatigue mistakes and better represent a typically install atmosphere.

In addition, a prototype $3 \times 3$ module system was built to demonstrate the use of all $\mathrm{X}$ wire components and the ability of the system to scale. Cost analysis was made on the bill of materials priced per component for both systems. Pricing the X-wire system consisted of weighing the printed parts with a digital balance and using a nominal cost of $\$ 35 / \mathrm{kg}$ of commercial PLA filament. Cost analysis was performed on both racking systems using 1-kilowatt system building blocks consisting of the four 250-Watt modules used in the time trials. Additionally, the shipping cost for the systems were excluded due to possible discount shipping rates, or different rates based on geographical location.

\subsection{Results}

A successful prototype of theX-wire racking system was fabricated in Figure 4.6. Each part was tested after printing to ensure dimensional conformity with the PV modules selected and threaded rod. Using a $1 \mathrm{~kW}$ system allowed for round measuring of part costs and weights, but for a system to have any viability on the large scale a larger 
array was needed to ensure the integrity of the parts when combined with more modules. This is demonstrated in Figure 4.7, which shows a prototype 3x3 module system, which uses all of the potential brackets shown in Figure 4.2. This system uses a different module (255-Watt Sharp polycrystalline) to demonstrate the adaptability Xwire racking components to different modules types and geometries. With the prototype of the $3 \times 3$ array it is possible to hypothesize the effectiveness of scaling a larger system targeted at the retail and manufacturing building market.

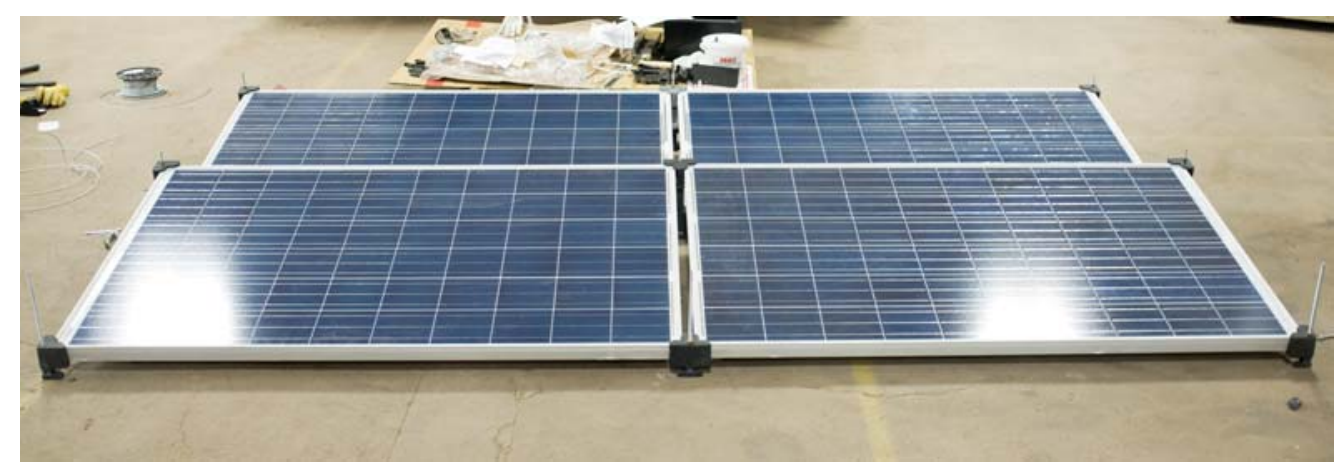

Figure 4.6: Assembly of $1 \mathrm{~kW}$ X-wire racking system.

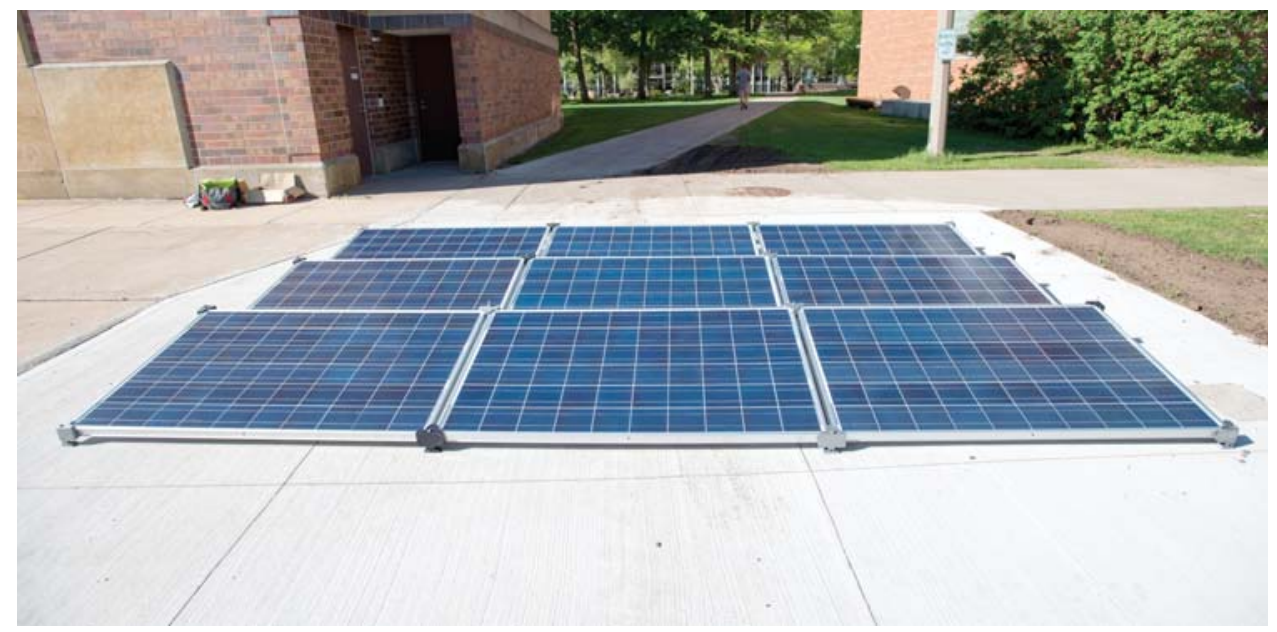

Figure 4.7: Prototype 3x3 module X-wire system. 
When comparing the setup time for each racking type, the X-wire system was slightly faster at 47 minutes and 15 seconds averaged over two trials, but should be considered essentially the same with error of the setup times as the RM system took 51 minutes and 28 seconds on average to assemble over two trials. Each system was set up by the same person having no experience in assembling any PV racking prior and was disassembled completely to a pile of parts between trials. Each trial was very similar in time for both the X-wire and RM systems with the second trial of each being the fastest by roughly 4 minutes.

By design, the RM system has 19 inches [0.48m] of space between each row of modules and with a typical module width of 39 inches nearly every two rows of modules has enough space between them to put another row if they were spaced closer. This required spacing leads to $0.10275 \mathrm{~kW} / \mathrm{m} 2$. In contrast the footprint of the close-packed X-wire system was much smaller than the RM system at compared to $0.1527 \mathrm{~kW} / \mathrm{m} 2$, which is a $48.6 \%$ improvement. This is due to the smaller parts and close packing of the modules. Figure 6 shows the finished $1 \mathrm{~kW}$ array with the close packing of the modules.

The RM system is a ballast-based system and thus the mass per unit area of rack depends on the maximum wind loads expected in a given region. The RM system can require up to 128lbs [58 kg] of ballast per ballast bay resulting in a large amount of overall weight required [25]. The RM system thus adds $1.8 \mathrm{lb} / \mathrm{ft} 2[8.79 \mathrm{~kg} / \mathrm{m} 2]$ to the roof, before any weight is added to the ballast bays, which brings the total to about 130 $\mathrm{lbs} / \mathrm{ft} 2[634.7 \mathrm{~kg} / \mathrm{m} 2]$. The X-wire system, by contrast only adds $2.57 \mathrm{lb} / \mathrm{ft} 2$ [12.55 $\mathrm{kg} / \mathrm{m} 2$ ] total of an installed system, modules included. However, the X-wire system demands the use of roof penetrations to tie down the modules since no weight ballasts are used. The X-wire mass per unit area is thus comparable to similar roof penetrating systems shown in Table 4.1.

For the cost analysis, the RM system has three different components: ballast bays, module clips, and hex bolts with their costs represented in Table 4.2. For the 1kilowatt system the RM racking totaled $\$ 575.64$. TheX-wire system consisted of the brackets, threaded rod, hex nuts, and steel cable with their costs represented in Table 4.2. The cost of the 1-kilowatt system totaled $\$ 96.41$. It should be noted that the Xwire system prototyping costs were used with 3-D printed parts being printed at 100\% 
infill (solid). Using the X-wire system results in a cost reduction of $\$ 479.23$ (83.25\%) compared to the RM system, despite the fact that inflated retail values of 3-D printing filament was used as the primary material rather than base material costs.

Table 4.2: Cost comparison of the components of the Unirac RM and XWire racking systems.

\begin{tabular}{lrrrr} 
Unirac RM & \multicolumn{3}{l}{} \\
\hline Item & Quantity & & Price/count & Cost \\
\hline Ballast Bay & 9 & & $\$ 58.12$ & $\$ 523.08$ \\
Module Clip & 24 & & $\$ 1.54$ & $\$ 36.96$ \\
Hex Bolt & 24 & & $\$ 0.65$ & $\$ 15.60$ \\
\hline & & & Total & $\$ 575.64$ \\
X-Wire & & & & \\
\hline Item & Quantity & Unit & Price/count & Cost \\
\hline M8 Rod & 1.2735 & meter & $\$ 8.31$ & $\$ 10.58$ \\
Steel Wire & 11.88 & meter & $\$ 2.76$ & $\$ 32.74$ \\
M8 Nut & 18 & count & $\$ 0.20$ & $\$ 3.60$ \\
Plastic & 1.5 & $\mathrm{~kg}$ & $\$ 33.00$ & $\$ 49.50$ \\
\hline
\end{tabular}

Mass manufacturing of the X-wire brackets will utilize different materials (aluminum (Al) or polycarbonate (PC)) than the prototypes and thus be considerably less costly. To estimate the costs in $\mathrm{Al}$ and $\mathrm{PC}$ the same design was used. It should be noted that these are thus conservative estimates as the component structural dimensions could be reduced due to the higher tensile strengths of aluminum (310 MPa for 6061 [26]) and PC (65.5 MPa [27]) compared to PLA (56.6 MPa [28]). The price-per-pound of aluminum of $\$ 0.818$ [29] the total cost of the X-wire components in aluminum would be $\$ 5.11$ and with the price of $\$ 2.18$ per pound of PC [30] the total cost of PC components would be $\$ 6.85$. Mass manufacturing with these materials would bring the total X-wire cost to $\$ 52.03$ in aluminum and \$53.77 in PC, which is roughly half of 
the cost of the prototype and $9.04 \%$ of the mass-manufactured RM system for aluminum, and $9.34 \%$ for PC.

\subsection{Discussion}

The time differential between setting up the $\mathrm{RM}$ and $\mathrm{X}$-wire systems was negligible for a single installer, but both systems could be installed faster. According to the company website the RM system can be installed at a rate of 12 modules per man hour, which is roughly twice as fast as the results of this study showed. It is possible to decrease the time needed to setup the RM system using a second installer. However, it is also possible to reduce the time by adding the proper amount of weight to the ballast bays, reduce the time spent aligning the modules and ensuring the ballast bays do not tip over before the modules are secured. Decreasing the time to setup for the X-wire system would include more accurately measured wire and a better laid out assembly area so little wire length adjustment is needed to tension the modules in addition to adding installers. Both systems install times would also benefit from the use of experienced installers.

Due to the wide variety of shipping options, discount rates, and geographical locations both the fastening and the shipping cost of all parts were omitted for both systems, but could be expected to be similar. The shipped components of the RM system weigh less than the X-wire prototype by $1.2 \%$, but this excludes the cost of shipping the ballast, which is assumed to be sourced locally. Similarly the cost of ballast was excluded along with the cost of performing roof penetrations and resealing the fastening of the $\mathrm{X}$-wire system. Future work on building installed systems could better determine these costs as a function of type of building and market. Additionally, the cost associated with the roof penetrations for the $\mathrm{X}$-wire system would be similar for all the systems shown in Table 4.1. The costs of the $\mathrm{X}$-wire system per module itself is $\$ 24.11$, which is significantly lower (82.2\%-88.25\%) of the systems shown in Table 4.1.

This tighter packing of the X-wire system allows it to be utilized in both smaller areas, but also to provide more power per unit area. Scaling up the maximum retail building size of 100,000 sq ft [10] and assuming a $320 \mathrm{ft} \mathrm{x} 320 \mathrm{ft}$ square geometry, a total of 65 rows of modules may be mounted with the RM system, and a total of 97 rows may be mounted with the X-wire system providing 942.5 and $1407 \mathrm{MW}$, respectively (a 33\% 
difference). The RM system has the advantage that all modules are equally accessible by default. In the X-wire case, spaces could be left between $\mathrm{X}$-wire arrays depending on the electrical wiring of the system. For easier access to the modules for service the user can choose how big a gap between rows will be and if it is every row or every other row. Any gaps would decrease the packing factor.

No racking system is ideal for all flat roofed buildings. Many buildings posses little additional roof loading capacity. Typical American big-box stores only design for up to $25 \mathrm{lb} / \mathrm{ft} 2$ [122.06 kg/ m2], making any additional weight dangerous for the integrity of the roof without costly modifications [31]. The Unirac RM system and other ballastbased systems require weighted sleds to hold the modules down that may introduce too much weight on the roof for many such buildings without additional and costly mechanical reinforcement. In contrast, although the X-wire system and other roof penetrating systems have a much lower roof loading challenge, they demand the use of roof penetrations, which may not be acceptable for building managers because of roof warranties or liability depending on the use of the building. It has been shown, through the proposition of green roofing systems, that $24.58 \mathrm{lb} / \mathrm{ft} 2$ to $30.72 \mathrm{lb} / \mathrm{ft} 2$ [120 $\mathrm{kg} / \mathrm{m} 2$ to $150 \mathrm{~kg} / \mathrm{m} 2$ ] of added load do not require any additional support of the roof in some cases [32]. So in most cases the X-wire racking system could be used if roof penetrations are acceptable. In addition, future work is needed to determine if it would be technically viable to run the tie wires down to the ground for short buildings rather than penetrate the roof.

While the X-wire system is much less expensive than the commercially available RM systems as shown in Table 2, theX-wire racking design can also pay for itself based on the greater energy generation density. For example, in April 2014, over residential, industrial, and commercial sectors, the average cost of electricity was 10.01 cents per $\mathrm{kWh}$ [33]. Using the energy density of the $\mathrm{X}$-wire system, $0.1527 \mathrm{~kW} / \mathrm{m} 2$, and the area of the gap of modules in the RM system, $0.797 \mathrm{~m} 2$, there are potentially $0.122 \mathrm{~kW}$ of missing energy in the gap of the RM system. Utilizing a value of 4.75 sun hours per day in Topeka, Kansas [34] the X-wire system can generate an extra $0.487 \mathrm{kWh}$ per day for every gap that would exist in a RM system that is filled with modules in the Xwire system. With the average dollars per $\mathrm{kWh}$ that American energy consumers pay of $0.10 \$ / \mathrm{kWh}$, the X-wire system can generate an extra $\$ 0.17$ of electricity for each 
$\mathrm{RM}$ gap replaced in net metering utility regions. This means that if 4 gaps are filled in with modules and extra $\$ 0.69$ of electricity are generated every day and $1 \mathrm{~kW}$ of X-wire racking can pay for itself in extra net-metered electricity alone in 140 days. It should also be noted, that the benefits of a roof system for large buildings is greater than just the energy savings due to the energy production of the modules since the modules help shade the roof allowing for less overall cooling for the building [35].

Currently many commercially available racking systems come built standard to one tilt angle, which does not allow for tilt angle optimization at different latitudes. For example, the general rule of tilting modules is to tilt above horizontal the same angle that corresponds to the latitude of the location of the array. Typical $10^{\circ}$ tilt angles for such racking systems are only optimized for southern Central America, and northern South America. The United States is located between roughly 25 degrees and 50 degree latitude meaning optimized racking solutions need to tilt at least 25 degrees, and would be ideal to tilt up to 50 for northern Alaska. There is a significant trade off between optimizing the tilt angle for solar collection and additional ballast and thus roof loading for the RM system. The X-wire system, however, can be made to accommodate any location by modifying the tilt angle and fabricating the associated brackets. This added functionality would increase the overall cost of the system due to the higher angles of tilt resulting in larger support arms and thus more raw materials. In addition, as the support arms lengthen depending on the material choice the crosssectional area of the bracket will need to increase to handle the additional mechanical loading. Due to the low-cost nature of the X-wire system it is not expected to ever match the relatively high costs with the RM system regardless of the tilt angle required. If the application were to be halfway between the equator and North Pole, at $45^{\circ}$ latitude, the total cost of the threaded rod to support the polymer holder is estimated to increase to $\$ 45.66$ and the plastic is estimated to increase to $\$ 74.25$. With these increases and the steel wire and M8 nut prices, the cost of a $45^{\circ}$ tilt system is estimated to be $\$ 156.24$ which is still only $27 \%$ the cost of the standard RM system. Due to the nature of the X-wire system and the close packing of the modules it could be challenging to service any module or racking component that may fail over the life of the system - in a large array made up of more than 3 rows. Thus it is important to keep into consideration access points for servicing while designing a system layout. 
However, the X-wire system allows for more flexibility in the location and spacing of the access points while maintaining the higher energy density.

PV installers responsible for PV systems over their warrantied lifetimes (20-30years) are naturally conservative in using new products. For PV racking systems to be commercialized and scaled not only most the cost-effectiveness be shown as the system has in this study, but it also must be certified, vetted and tested at a scale acceptable to the industry. Future work is needed to test the structural stability of this new PV racking system, it will be necessary to perform a loading case study on the panel array and system. The goal of this loading scenario will be to analyze the system under average and 50 year extreme loading conditions in order to gain a perspective into the dynamic and static loads the system will need to endure. These will involve dynamic loads like wind loading as well as static loads such as snow and the actual module weight.

The dynamic load will need to be determined from other data sources as wind tables do not readily exist for inclined PV panels, which have mixed wind reactions due to lift, drag, and shear wind forces. Basic calculations for the complete array following American Society of Civil Engineers (ASCE) Standard 7-05 derived by [22] will be followed along with wind tunnel tests on more conventional PV systems, which will be adapted for this purpose. These wind loads will have to incorporate average wind data for the proposed location as well as 1 in 50 year max wind gusts as per the appropriate building code. These wind loads will act on the panels and give an approximate value of restraining force needed. The upward wind pressures determined in this study will be based on wind tunnel tests employing procedures that exceed the requirements set out in Section 6.6 of the ASCE 7-05 Standard. The upward wind pressures on the panels, for use in ballasting considerations, will be consistent with both the International Code Council Chapter 16 [36] and the ASCE 7 Standard [37]. The static loading will need to incorporate the snow loading, depending again on the systems location [38] as well as the static load of the system itself, which will depend on the type of PV panel chosen and the total size of the array. The snow loading data can be found in the building code as well as values for max snow drift pressures and max fresh snow fall pressure. Again these values will depend on the solar module choice which will affect the snow area and the therefore the snow loading. A sensitivity 
analysis using numerical simulation will be performed to obtain basic minimum material performance properties needed for the clip and wire components.

Testing will be needed to determine compliance with the applicable requirements of the U.S. and Canadian standards referenced or ETL/ CETL Listing for North America. This will include ULC ORD C1703 (Issued:2001/ 01/ 01 Flat-Plate Photovoltaic Modules and Panels) and UL SUBJ ECT 2703 (Issue:2010/ 10/ 04 Outline of Investigation Rack Mounting Systems and Clamping) that includes Devices for FlatPlate Photovoltaic Modules and Panels - Issue No.1, Initial Bonding Path Resistance Test, Humidity Conditioning, Temperature Cycling Test, and Bonding Path Resistance Test following Humidity and Temperature Cycling $[39,40]$.

Finally, suitably scaled commercial PV systems on the order of $100 \mathrm{~kW}$ or larger will need to be tested with the data provided in the public domain [41] for installers to accept this racking system. In addition to evaluating the effectiveness of the X-wire system with commercial rooftops, the system could also be applicable in rural areas and developing countries where electricity is either very expensive or non-existent, where rapid prototypers [42] could be used for the manufacture of the racking systems and could further be powered by the PV of which it manufactured.

\subsection{Conclusions}

Although the costs of PV modules themselves are decreasing aggressively, the costs associated with racking have not fallen as rapidly, which is limiting even more widespread solar electrical energy generation. Here, a more cost effective racking system has been evaluated and shown to reduce the cost by over $80 \%$ compared to the commercial ballast counterpart and perform comparatively in ease, and speed of assembly while out-performing in customizability. The close-packed nature of the design has the potential to improve energy density by up to 33\%. In addition, the costs of the X-wire system per module itself is significantly lower (82\%-88\%) of directly comparable roof-penetrating racking systems. 


\subsection{References}

[1] EIA. How much of the world's energy does the United States use? http:/ / www.eia.gov/ tools/ faqs/ faq.cfm?id=87\&t=1 (Accessed $18 \mathrm{~J}$ une 2014)

[2] EIA. Annual Energy Outlook 2014 http:// www.eia.gov/ forecasts/aeo/MT_electric.cfm\#cap_natgas?src=Electricit y-b1 (Accessed 18 J une 2014)

[3] R.E. Smalley. Future Global Energy Prosperity: The Terawatt Challenge. MRS Bulletin. Volume 30. J une 2005

[4] K. Branker, M.J.M. Pathak, J.M. Pearce, A review of solar photovoltaic levelized cost of electricity. Renewable and Sustainable Energy Reviews. Volume 15, Issue 9, December 2011, Pages 4470-4482

[5] P. Pal Singh, S. Singh. Realistic generation cost of solar photovoltaic electricity. Renewable Energy. Volume 35, Issue 3, March 2010, Pages 563-569

[6] K. Fang, N. Uhan, F. Zhao, John W. Sutherland. A new approach to scheduling in manufacturing for power consumption and carbon footprint reduction. J ournal of Manufacturing Systems. Volume 30, Issue 4, October 2011, Pages 234-240

[7] J . Pearce. Photovoltaics - A Path to Sustainable Futures. Futures 34(7), 663674, 2002.

[8] N. S. Lewis. Toward Cost-Effective Solar Energy Use Science. 9 February 2007 Vol. 315 no. 5813 pp. 798-801

[9] Pacific Power. On Peak and Off Peak hours. https:// www.pacificpower.net/ya/ po/ otou/ ooh.html (Accessed 10 J une 2014)

[10] Economist. How big can it grow? http:/ / www.economist.com/ node/ 2593089 (Accessed 10 June 2014)

[11] B. J eppesen, Rooftop solar power: The solar energy potential of commercial building rooftops in the USA, Refocus, Volume 5, Issue 4, J uly-August 2004, Pages 32-34.

[12] D. Feldman, G. Barbose, R. Margolis, R. Wiser, N. Darghout, A. Goodrich. Sunshot Photovoltaic (PV) Pricing Trends: Historical, Recent, and Near-Term Projections. November 2012 
[13] M. Bazilian, I. Onyeji, M. Liebreich, I. MacGill, J . Chase, J . Shah, D. Gielen, D. Arent, D. Landfear, and S. Zhengrong. Re-considering the economics of photovoltaic power. Renewable Energy, 53, 329-338 (2013).

[14] SEIA. Solar Market Insight 2013 Q3. http:// www.seia.org/ researchresources/ solar-market-insight-2013-q3 (Accessed 10 J une 2014)

[15] Mercom Solar Market Intelligence Report: Week of J une 22014 http:/ / clicks.skem1.com/ trkr/ ?c=3048\&g=1503\&p=ba655567024ae63b93c8b 4ba2363e55e\&u=2ead78ba420b79ae0dd0c1996e913197\&q=\&t=1

[16] J. Heeter, T. Nicholas. Status and Trends in the U.S. Voluntary Green Power Market October 2013

[17] G. Barbose (2014). Tracking the Sun VI: An Historical Summary of the Installed Price of Photovoltaics in the United States from 1998 to 2012 . Lawrence Berkeley National Laboratory: Lawrence Berkeley National Laboratory. LBNL Paper LBNL-6350E

[18] Wholesale Solar. All Brands of Solar Panel Mounts. http:// www.wholesalesolar.com/ mounts.html (Accessed 8 J uly 2014)

[19] Unirac. RM Roof Mount. http:// www.unirac.com/ commercial/commercialproducts/rm-commercial (Accessed $10 \mathrm{~J}$ une 2014)

[20] L.K. Wiginton, H. T. Nguyen, J.M. Pearce, Quantifying rooftop solar photovoltaic potential for regional renewable energy policy. Computers, Environment and Urban Systems. 34, (2010) pp. 345-357.

[21] H. T. Nguyen and J. M. Pearce. Incorporating Shading Losses in Solar Photovoltaic Potential Assessment at the Municipal Scale. Solar Energy 86(5), pp. 1245- 1260 (2012).

[22] S. Barkaszi, C. O’Brien, Wind Load Calculations for PV Arrays. Solar American Board for Codes and Standards Report, J une 2010.

[23] S. Barkaszi and J. Dunlop Discussion of Strategies for Mounting Photovoltaic Arrays on Rooftops. Proceedings of Solar Forum 2001, Solar Energy: The Power to Choose, Washington, DC, April 21 - 26, 2001.

[24] OpenSCAD http:// www.openscad.org/ (Accessed 29 May 2014)

[25] Unirac. Design and Engineering Guide. http:/ / unirac.com/ sites/ default/ files/rm_de.pdf (Accessed 13 J une 2014) 
[26] ASM. Aluminum 6061-T6.

http:// asm.matweb.com/ search/ SpecificMaterial.asp?bassnum=MA6061T6 (accessed 9J uly 2014).

[27] Advanced Gasket \& Supply Inc. Polycarbonate.

http:// advancedgasket.com/pages/plastic/plastic_pcarb.htm (accessed $9 \mathrm{~J}$ uly 2014).

[28] B.M. Tymrak, M. Kreiger, J . M. Pearce. Mechanical properties of components fabricated with open-source 3-D printers under realistic environmental conditions. Materials \& Design, 58, pp. 242-246 (2014).

[29] Kitco. Aluminum Prices. www.kitcometals.com (Accessed 17J une 2014)

[30] Spend Matters. Polycarbonate Prices Are on the Rise - What Does This Mean? http:// spendmatters.com/ 2014/ 05/ 27/ polycarbonate-prices-are-on-the-risewhat-does-this-mean/ (Accessed 17 J une 2014)

[31] Philip Hodge, Brian Rainey. Big-Box Industrial Buildings: Don't Let Challenges Ruin The Opportunities. Solar Industry Magazine. J une 2013 http:// www.solarindustrymag.com/issues/SI 1306/FEAT_05_Big_Box.html

[32] H.F. Castleton, V. Stovin, S.B.M. Beck, J.B. Davison. Green roofs; building energy savings and the potential for retrofit. Energy and Buildings. Volume 42, Issue 10, October 2010, Pages 1582-1591

[33] EIA. Electric Power Monthly. J une 2014. http:// www.eia.gov/ electricity/ monthly/ epm_table_grapher.cfm?t=epmt_5_ 6_a

[34] NREL. Solar Radiation maps: Kansas http:// www.nrel.gov/gis/mapsearch/

[35] Adam Scherba, David J. Sailor, Todd N. Rosenstiel, Carl C. Wamser. Modeling impacts of roof reflectivity, integrated photovoltaic panels and green roof systems on sensible heat flux into the urban environment. Building and Environment. Volume 46, Issue 12, December 2011, Pages 2542-2551

[36] ICC. Structural Design. Chaper 16. 2006. http:// www2.iccsafe.org/states/newjersey/nj_building/PDFs/NJ_Bldg_Chapt er16.pdf

[37] ASCE. Minimum Design Loads for Buildings and Other Structures. Standards ASCE/SEI 7-10. 2013. 
[38] R. W. Andrews, A. Pollard, J. M. Pearce, The Effects of Snowfall on Solar Photovoltaic Performance, Solar Energy (2013) 92, 8497.

[39] ULC. Flat Plate Photovoltaic Module and Panels. ULC/ ORD-C1703-01. 2008

[40] UL. Rack Mounting Systems and Clamping Devices for Flat-plate Photovoltaic Modules and Panels. UL 2703. 2014.

[41] A. J. Buitenhuis and J. M. Pearce. Open-Source Development of Solar Photovoltaic Technology. Energy for Sustainable Development, 16, pp. 379-388 (2012).

[42] D. L. King, A. Babasola, J . Rozario, and J . M. Pearce, . Development of Mobile Solar Photovoltaic Powered Open-source 3-D Printers for Distributed Customized Manufacturing in Off-grid Communities. (to be published). 


\section{5 - 3-D Printing Solar Photovoltaic Racking in Developing World $^{4}$}

\subsection{Introduction}

Various additive manufacturing technologies has been used in industry to prototype new products for decades [1-5], but until the introduction of the RepRap project (SelfReplicating Rapid Prototyper) brought entry level devices s to the market, 3-D printing was not a realistic purchase for most households. The RepRap project aims to provide a cost effective 3-D printer based on open-source software and libre hardware that encourages collaboration between many people throughout the world [6]. This allows a greater number of people to both contribute to and benefit from the project simultaneously [6]. Currently, an entry-level RepRap can be built near, or below, $\$ 500$ in parts [7] with costs continuing to decline as the popularity of 3-D printing rises [8]. These price declines are moving the technology from an industry specific technology to one that could be used in the developing world [9-12].

Current estimates of the world's poor show that the issue of poverty is a much greater threat than initially thought and it is imperative that efforts are made to increase the standard of living [13]. Today it is estimated that 2.6 billion without any sanitation [14] and for cooking, 2.5 billion people are forced to use biomass, fuel wood, charcoal, or animal dung as energy in order to eat [15]. In addition, over 2 billion people live without access to electricity [16]. For example, with only $0.2 \%$ of rural areas in Zimbabwe having access to the grid the cost of extending the grid hinder the growth and development of the country [17]. As efforts are made to develop other areas of the world, with electrification for example, it is important to utilize sustainable development practices to reduce the future impact of a greater number of developing areas [17].

Access to electricity has been shown to accelerate development [16] and being able to use basic electric appliances (e.g. lighting, water pumps, cell phones) can springboard development with improvements to education, sanitation, nutrition, and industry [16,18]. 3-D printers can be one of the electrical appliances and further their ability to

${ }^{4}$ The material contained in this chapter has been prepared for publication 
develop and produce needed items and replace broken components of a large variety of systems with specialized parts that would otherwise be unavailable [9]. One technology that has been shown to be particularly useful in sustainable electrification of rural developing communities is solar photovoltaic (PV) technology $[19,20]$. Although PV prices have dropped considerably [21], one of the remaining fixed costs that have not declined is the relative cost of the balance of systems (BOS) related to the total cost of a PV array [22]. The BOS includes racking, wiring and electronics necessary to complete a PV system. Hence, for PV to be competitive with traditional energy generation methods, more work must be done to reduce manufacturing PV costs and BOS costs [23]. One way presented to decrease the BOS costs is utilizing low-cost distributed manufacturing with a RepRap 3-D printerfor small-scale mobile PV arrays [24].

This study evaluates the technical and economic viability of distributed manufacturing of PV racking in the developing world using entry-level RepRap 3-D printers. A customizable open-source PV racking concept is designed, prototyped for three types of modules, constructed into a system, and outdoor tested under extreme conditions for one year. The technical viability of using commercial 3-D printer filament and recycled plastic waste is determined for outdoor use in this application. Finally, a detailed economic analysis is performed.

\subsection{Methods and Materials}

A ground-mounted PV racking system was designed in OpenSCAD 2014.03 [25] a free and open-source solid modeling program, using parametric variables that automatically manipulate the entire part to enable simple modifications without the need for knowledge in 3-D modeling. These OpenSCAD code generates 12 different STL files for all the potential geometries of an infinite scaled array. The STL files were sliced in the open-source Cura [26] before printing with solid 100\% infill on a MOST Prusa RepRap [27] using Repetier-Host [28] to drive the printer. Once the parts were completed threaded steel rods were inserted into the parts for added strength and support and tightened down with nuts. Steel wire was threaded through the mounting brackets in a X shaped pattern under the modules to tensions the modules together 
giving name to the system of X-wire. The detailed bill of materials (BOM) needed to assemble the X-wire system can be found in Table 5.1, including the cost of the tools.

Table 5.1: BOM of the $1 \mathrm{~kW}$ assembled $X$-wire system

\begin{tabular}{|c|c|c|c|c|c|c|c|}
\hline \multicolumn{8}{|c|}{ Bill of Materials } \\
\hline Type & Item name & Source & Item No. & Quantity & Unit & \$/Qty. & $\begin{array}{l}\text { Price per } \\
\text { item }\end{array}$ \\
\hline \multirow[t]{3}{*}{ Metal } & M8 Rod & McMaster & 90024A080 & 1.25 & Meter & $\$ 8.31$ & $\$ 10.39$ \\
\hline & Steel Wire & McMaster & 8908T66 & 11.88 & Meter & $\$ 2.76$ & $\$ 32.74$ \\
\hline & Hex Nuts & McMaster & $91828 \mathrm{~A} 410$ & 18 & Count & $\$ 0.20$ & $\$ 3.60$ \\
\hline \multirow{2}{*}{ Plastic } & & & & & & $\$ 36.0$ & \\
\hline & PLA Filament & Prototype Supply & $3 \mathrm{~mm}$ Silver & 1.5 & $\mathrm{Kg}$ & 0 & $\$ 54.00$ \\
\hline \multirow{2}{*}{ Tools } & & & & & & $\$ 10.9$ & \\
\hline & $13 \mathrm{~mm}$ Wrench & McMaster & $71405 \mathrm{~A} 38$ & 1 & Count & 8 & $\$ 10.98$ \\
\hline
\end{tabular}

The OpenSCAD design includes parametric variables that allow quick and easy changes to the module tilt angle and size of the module as shown in Figure 5.1.

Pictured are two brackets setup for 10 degrees of tilt and 20 degrees of tilt showing the difference in the cup angle and height. Each bracket is paired with an extension bar of appropriate height as well. If the user decides to expand the PV array in the future additional parts can be printed out to fit the new modules and simply added to the existing array. It is also possible to use this system on every framed PV module whether it be a smaller mobile module [29], or large full-scale modules used here [30]. 


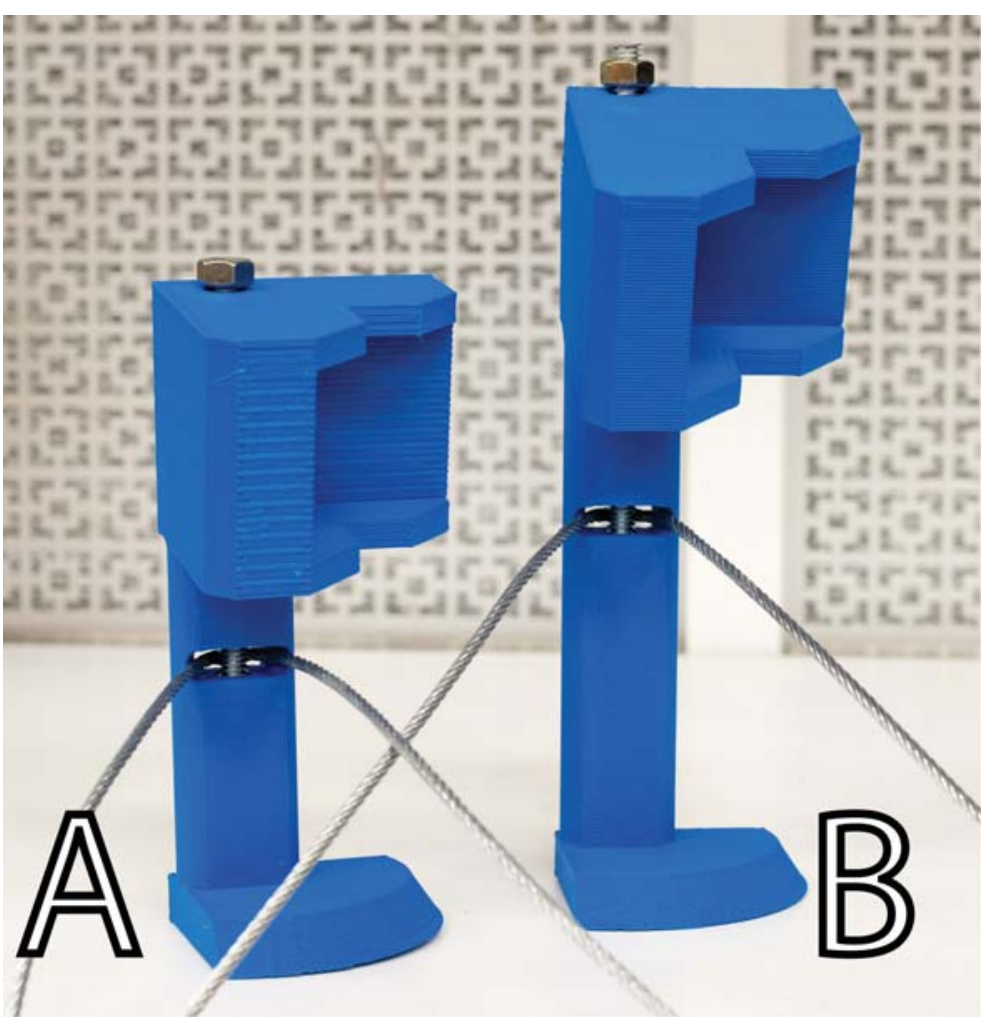

Figure 5.1: a) 10 degree and b) 20 degree tilt angle $x$-wire 3-D printed brackets fully assembled. Those shown here are for the back corners of the array. The cups in the upper portion of the brackets hold the corners of the PV modules.

Once the parts were printed and fit for the modules the racking system was assembled and placed outside and the brackets were tied down with more wire and tent stakes to ensure the modules did not lift off the ground due to wind loads.

The brackets were subjected to outdoor weather conditions for one year to validate the resilience of the parts. The parts were massed and the printing time was monitored to evaluate the cost of production. A 10-degree tilt system was used for analysis but a sample bracket at 20 degrees was printed to prove the customizability of the design (as shown in Figure 1). Following the printing and assembly a detailed economic analysis was performed comparing the Unirac RM [31] racking system to the X-wire system when printed in commercially available polylactic acid (PLA) and recycled highdensity polyethylene (HDPE) filament. The Unirac system is advertised as one of the 
easiest and quickest racking systems to setup. While it is a roof mounted system it can be ballasted on the ground or easily staked into the ground to properly secure the RM system. Additionally the outdoor material behavior was examined theoretically using available literature on UV degradation and resilience of common 3-D printable materials.

\subsection{Results}

A 1kW PV array consisting of four 250 W PV modules, was successfully constructed, as shown in Figure 5.2, using the X-wire system. The array was deployed outside for the winter of 2013/2014 in the upper peninsula of Michigan and subjected to harsh temperatures and heavy snow loads as measured by the Keweenaw Research Center (KRC) [32], where the system was setup. Once the snow fell the temperature at the level of the racking was between $19^{\circ} \mathrm{F}\left[-7.22^{\circ} \mathrm{C}\right]$ and $24^{\circ} \mathrm{F}\left[-4.44^{\circ} \mathrm{C}\right]$ for the duration of winter and had a maximum depth of snow of 39 inches [0.99 meters]. With a ground snow load of $100 \mathrm{lbs} / \mathrm{ft} 2$ [488.2 kg/m2] [33] an estimate of the snow load on the 10 degree tilted modules is $84 \mathrm{lbs} / \mathrm{ft} 2$ [410.12 kg/ m2] [34]. All 100\% fill parts remained in tact. 


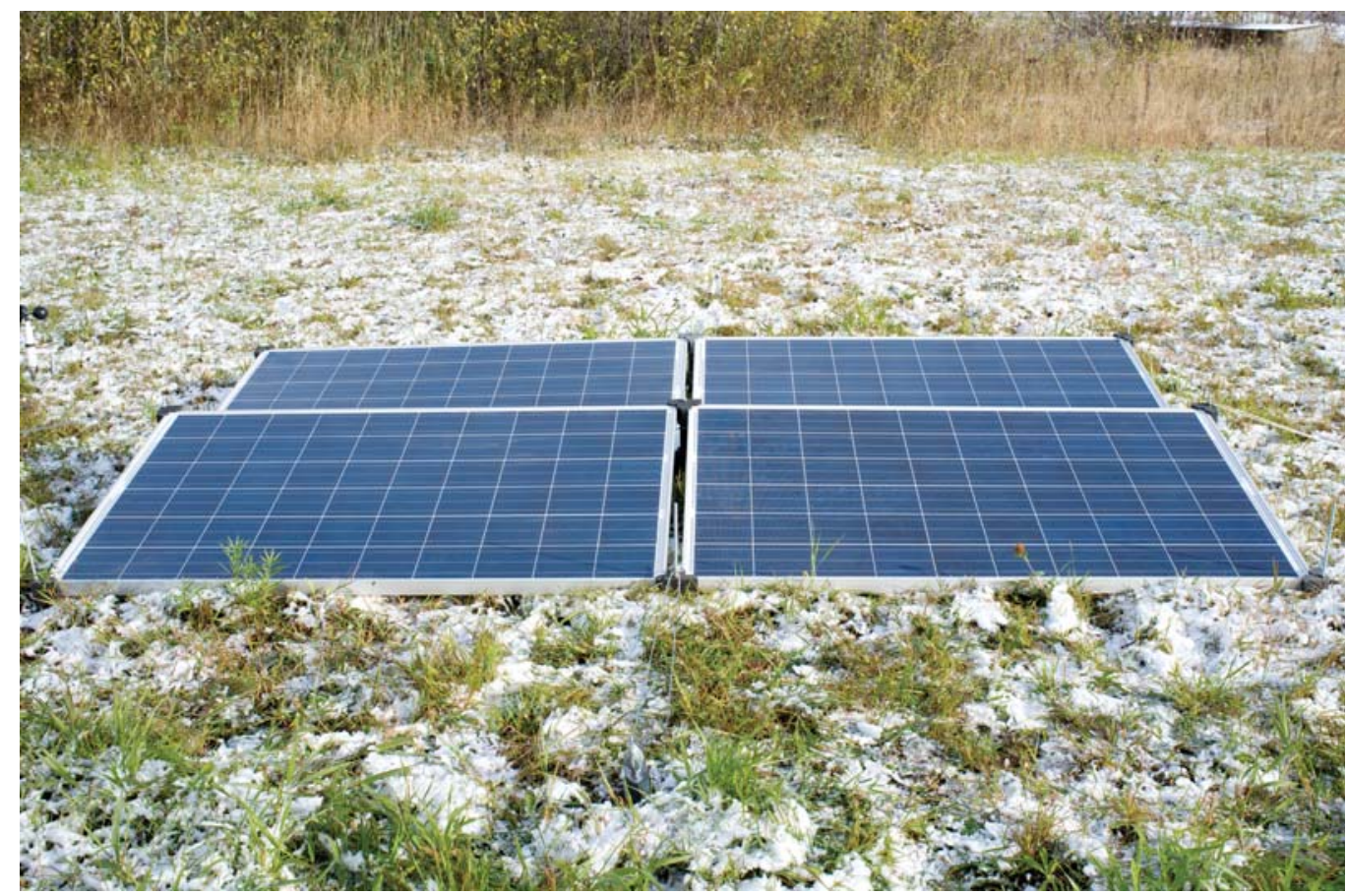

Figure 5.2: $\quad$ Assembled $1 \mathrm{~kW} P V$ array with $X$-wire system. The 3-D printed components are shown in grey in Figure 2 are at the corners. The wiring forms an $\mathrm{x}$ pattern beneath the modules.

When compared to a commercial racking system the X-wire system is significantly less expensive with a savings of $83 \%$ (with commercial PLA) to 92\% (with recycled HDPE) as shown in Table 5.2, which does not include import duties. With the X-wire system the largest individual cost is the printed plastic with $1.5 \mathrm{~kg} / \mathrm{kW}$ used at $\$ 33$ per $\mathrm{kg}$. Using a new technology, the Recyclebot [35], which converts waste plastic to 3-D printer feedstock the cost of the X-wire system can be lowered even further. The material cost from a Recyclebot are only \$0.10 USD per kg [36] when labor is excluded. Thus using Recyclebot filament will result in a total cost of \$47.07 USD for the X-wire system, a savings of $92 \%$ from the commercial racking alternative and a $51 \%$ savings when compared to the PLA plastic X-wire system. Recyclebot extruded filament is particularly applicable in the developing world as there has already been efforts to create ethical filament standards [37], which would allow waste pickers to lift themselves out of poverty by capturing a larger share of the value from recycling plastics into 3-D printer filament. 
Table 5.2: Cost breakdown of commercial racking and $\mathrm{X}$-wire racking systems.

\begin{tabular}{lrrr} 
Unirac RM & & & \\
\hline Item & Quantity & Price/count & Cost \\
\hline Ballast Bay & 9 & $\$ 58.12$ & $\$ 523.08$ \\
Clip & 24 & $\$ 1.54$ & $\$ 36.96$ \\
Hex Bolt & 24 & $\$ 0.65$ & $\$ 15.60$ \\
\hline & & Total & $\$ 575.64$
\end{tabular}

X-wire - Commercial PLA filament

\begin{tabular}{lrlrr}
\hline Item & Quantity & Unit & Price/count & Cost \\
\hline M8 Rod & 1.2735 & meter & $\$ 8.31$ & $\$ 10.58$ \\
Steel Wire & 11.88 & meter & $\$ 2.76$ & $\$ 32.74$ \\
M8 Nut & 18 & count & $\$ 0.20$ & $\$ 3.60$ \\
Plastic & 1.5 & $\mathrm{~kg}$ & $\$ 33.00$ & $\$ 49.50$ \\
\hline & & & Total & $\$ 96.42$ \\
X-Wire - Recyclebot Filament & & & \\
\hline Item & Quantity & Unit & Price/count & Cost \\
\hline M8 Rod & 1.2735 & meter & $\$ 8.31$ & $\$ 10.58$ \\
Steel Wire & 11.88 & meter & $\$ 2.76$ & $\$ 32.74$ \\
M8 Nut & 18 & count & $\$ 0.20$ & $\$ 3.60$ \\
Plastic & 1.5 & kg & $\$ 0.10$ & $\$ 0.15$ \\
\hline & & & Total & $\$ 47.07$
\end{tabular}

Typically aluminum is used with PV racking due to the strength and outdoor resilience but printed PLA plastic has been shown to be sufficiently strong in appropriate designs when compared to typical PLA properties [38]. Tensile yield strength for the 6063 aluminum alloy used in the Unirac system is $145 \mathrm{MPa}$ [39] and an experimental value for printed PLA tensile strength is 56.6 MPa [38]. Using the expression for tensile 
strength in equation 1 and equating the forces of fracture for PLA and aluminum it is possible to estimate the increase in cross-sectional area required for a PLA part to withstand the same force as an aluminum part:

$$
\sigma=\mathrm{F} / \mathrm{A}
$$

where, $\sigma$ is the tensile strength, $\mathrm{F}$ is the force applied, and $\mathrm{A}$ is the cross sectional area. The Unirac RM technical data sheet [31] specifies that the ballast tray is $2.54 \mathrm{~mm}$ thick with a cross-sectional area of $215.48 \mathrm{~mm} 2$. Using equation 1 and the yield strength for aluminum, negating geometrical strengthening, the estimated force at fracture for 6063 aluminum is $31.24 \mathrm{kN}$. The X-wire system has a cross-sectional area of 660 $\mathrm{mm} 2$ in the supports and using equation 1 again along with the tensile strength of PLA the ultimate force of $37.36 \mathrm{kN}$ can be withstood by the plastic alone. With the addition of the steel bar the $\mathrm{X}$-wire system is able to perform adequately within the test environment and withstand the elements outdoors over the testing period.

\subsection{Discussion}

The entire PV racking system can be manufactured in the communities of the developing world using an entry-level RepRap 3-D printer. This enables total control over the entire process and the design of the PV racking by the end user to suit their needs depending on geographic location, cultural sensitivities and potential weather concerns. An additional benefit to distributed manufacturing is the close relationship to the parts and assembly allowing for quick and easy repairs or upgrades throughout the use of the PV system which can span well over 20 years [40].

The lifespan of a PV system is an important consideration for 3-D printing material choice. Throughout the duration of use of the PV system the PLA will be subjected to solar ultraviolet (UV) light causing some degradation and it has been shown that longterm UV exposure of PLA can cause the plastic to become brittle [41]. This was not found after 1 year of outdoor testing with the PV racking, most likely due to the fact that the majority of the rack is not directly exposed to sunlight. The same printed PLA 
was used in an outdoor hinge and found to become brittle after 2 years of use thus indicating that unprotected PLA should not be used for outdoor applications that span many years such as this one. The transition to brittle material characteristics is common in many polymers when subjected to prolonged UV light exposure [42]. However, it has been shown that HDPE with additives can maintain a relatively constant elastic modulus and elongation at the yield stress meaning HDPE can resist the brittle transition observed [43]. HDPE filament is not common but can be successfully manufactured with a Recyclebot or any of a long list of pro-sumer filament extruders [44-49]. This also has the added benefit of improved environmental impact [36]. It has also been shown that HDPE responds more to temperature fluctuations than solar radiation [50] meaning a material optimization may be possible for geographic location based on temperature profiles and insulating the plastic parts with a sealant could help. Depending on location, the elevated operating temperatures of PV modules may help regulate the temperature of the plastic by providing a consistent operating temperature and aid in the reduction of the degradation rate that can be accelerated due to cyclical temperatures [50]. More information on mechanical data for PLA is required to offer a more in-depth estimate of the strength but as shown over the course of one year of outdoor testing the X-wire system performed adequately.

The X-wire system only requires a basic wrench to tighten the bolts down to the brackets meaning it can be assembled and disassembled almost anywhere. In addition, the RepRap can print the wrench [51]. This also allows easy repairs for nearly anyone as compared to other PV systems and other energy generation technologies, such as wind power, where repairs are a notorious problem in the developing world and can be immensely challenging even in the United States [52]. Open source designs of appropriate technology [53] allow for instant collaboration throughout the world with just an exchange of information allowing rapid improvement and iterative performance enhancements. With this quick exchange of information it is possible to take advise from other users for repairs if desired.

When a retail product is typically purchased it serves one purpose and, usually, is set up for one use. This can become a problem for people that may wish to use it in a 
different environment and those who move locations. Since this new system is opensource and easily customizable it is possible to optimize the PV racking system for any location or application. For example, the 3-D printed parts may be printed or spraypainted in any color to blend into the surroundings better (in addition to providing UV protection discussed above). Should it be desired that the racking components be virtually invisible on the mounting site that can be obtained through color variations. With PV theft rising [54] the value of reducing the visibility of the high-value racking is great with the new $\mathrm{X}$-wire system. In addition to the ability to hide the components easily the customizable nature of the $\mathrm{X}$-wire design allows for geographical optimization of the system which has been shown in simulations to reflect a $20 \%$ efficiency increase on average [24].

While it has been presented that the overall cost of a PV system is decreasing and the relative cost of the BOS is increasing, this new racking system can reverse that effect since the racking costs are estimated to be about $10 \%$ of the PV materials itself instead of the 50-55\% currently. Using a low cost racking system will allow the subject of racking to be a non-concern when designing a PV array and the cost is so low the entire PV system can begin to reach an affordable level for all consumers.

While the RepRap can be an extremely useful tool to increase the standard of living in the developing world it is imperative to aid in the education of its' use in this goal. In addition, applications of 3-D printing similar to this can help adapt the technology from at-home RepRap to viable manufacturing method [55]. This study explores the continued use of 3-D printing to provide more economic alternatives to conventional commercially available products, specifically PV module racking. An additional benefit to the use of 3-D printing will allow the proposed racking system to be customizable for the location in which it will be used allowing the PV system to be optimized beyond what common commercial racking can provide, resulting in even greater return on investment. Merging the 3-D printing process with solar can help erase current questions about the sustainability of the technology as well [56]. Consequently the RepRap has the potential to sustain its' operation by printing replacement parts for 
itself and continuing to provide the user with tools, toys, educational aids, and many other things.

In addition to the economic benefit to people wanting to adopt solar power, this racking system has enormous potential in the developing world. With a 1kW PV array, an entire village could potentially have lights inside their dwellings drastically improving their standard of living. Beyond light bulbs (or LEDs), the addition of refrigeration, water pumps, and other appliances could greatly improve the sanitation in these areas as well as improving the ability to make better food. Even a RepRap 3-D printer is not out of consideration in the list of possible utilities since they only draw about 100 Watts while running, fewer if no heated bed is used.

\subsection{Conclusions}

This study has shown that entry-level 3-D printing is a viable option for manufacturing solar photovoltaic racking for developing world applications. PV has been shown previously to be a valuable technology for sustainable development, however the BOS costs have reduced deployment velocity. The results presented here show that the use of 3-D printing to fabricate PV racking can reduce the racking cost by over $80 \%$ significantly improving the economic case for multi-module PV systems in the developing world. Due to the remote locations of rural developing areas a distributed manufacturing model fits well with attempts to jump start economic and standard of living improvements. The ability of RepRap printers for development appear to be particularly well suited as these 3-D printers can not only print out valuable components for renewable energy systems, but also the repair parts and tools necessary to maintain themselves.

\subsection{References}

[1] X. Yan, and P. Gu, A review of rapid prototyping technologies and systems, Computer-Aided Design 28 (1996) 307-318.

[2] D. T. Pham, and R. S. Gault, A comparison of rapid prototyping technologies, International J ournal of Machine Tools and Manufacture 38 (1998) 1257-1287. 
[3] J. P. Kruth, M. C. Leu, and T. Nakagawa, Progress in Additive Manufacturing and Rapid Prototyping, CIRP Annals - Manufacturing Technology 47 (1998) 525-540.

[4] M. C. Leu, B. K. Deuser, L. Tang, R. G. Landers, G. E. Hilmas, and J . L. Watts, Freeze-form extrusion fabrication of functionally graded materials, CIRP Annals - Manufacturing Technology 61 (2012) 223-226.

[5] M. Mitsuishi, J. Cao, P. Bártolo, D. Friedrich, A. J. Shih, K. Rajurkar, N. Sugita, and K. Harada, Biomanufacturing, CIRP Annals - Manufacturing Technology 62 (2013) 585-606.

[6] R. J ones, P. Haufe, E. Sells, P. Iravani, V. Olliver, C. Palmer, and A. Bowyer, RepRap - the replicating rapid prototyper, Robotica 29 (2011) 177-191.

[7] B. T. Wittbrodt, A. G. Glover, J . Laureto, G. C. Anzalone, D. Oppliger, J . L. Irwin, and J . M. Pearce, Life-cycle economic analysis of distributed manufacturing with open-source 3-D printers, Mechatronics 23 (2013) 713726.

[8] Wohlers Associates, Wohlers Report 2013: Additive Manufacturing and 3D Printing State of the Industry Executive Summary (2013).

[9] J. M. Pearce, C. Morris Blair, K. J. Laciak, R. Andrews, A. Nosrat, and I. Zelenika-Zovko, 3-D Printing of Open Source Appropriate Technologies for Self-Directed Sustainable Development, J ournal of Sustainable Development (2010) 3.

[10] T. Campbell, C. Williams, O. Ivanova, and B. Garrett, Could 3D Printing Change the World?, Technologies, Potential, and Implications of Additive Manufacturing. Washington, DC: Atlantic Council (2011).

[11] H. Lipson, and M. Kurman, Fabricated: The new world of 3D printing, J ohn Wiley \& Sons (2013).

[12] J. G. Tanenbaum, A. M. Williams, A. Desjardins, and K. Tanenbaum, Democratizing technology: pleasure, utility and expressiveness in DIY and maker practice. Proceedings of the SIGCHI Conference on Human Factors in Computing Systems, ACM (2013) 2603-2612. 
[13] S. Chen, and M. Ravallion, The Developing World Is Poorer Than We Thought, But No Less Successful in the Fight against Poverty, Development Research (2008).

[14] C. W. Dugger, Toilets Underused to Fight Disease, U.N. Study Finds. The New York Times (2006).

[15] A. Shah, Poverty Facts and Stats, Global Issues (2013)

http:// www.globalissues.org/ article/ 26/ poverty-facts-and-stats [Accessed J uly 29 2014].

[16] K. Reiche, A. Covarrubias, and E. Martinot, Expanding electricity access to remote areas: off-grid rural electrification in developing countries, Fuel 1 (2000) 1.4 .

[17] T. E. Drennen, J . D. Erickson, and D. Chapman, Solar power and climate change policy in developing countries, Energy Policy 24 (1996) 9- 16.

[18] M. Kanagawa, and T. Nakata, Assessment of access to electricity and the socioeconomic impacts in rural areas of developing countries, Energy Policy 36 (2008) 2016-2029.

[19] R. H. Acker, and D. M. Kammen, The quiet (energy) revolution: Analysing the dissemination of photovoltaic power systems in Kenya, Energy Policy 24 (1996) 81-111.

[20] J. M. Pearce, Photovoltaics - a path to sustainable futures, Futures 34 (2002) 663-674.

[21] K. Branker, M. J. M. Pathak, and J. M. Pearce, A review of solar photovoltaic levelized cost of electricity, Renewable and Sustainable Energy Reviews 15 (2011) 4470-4482.

[22] V. Fthenakis, and E. Alsema, Photovoltaics energy payback times, greenhouse gas emissions and external costs: 2004- early 2005 status, Progress in Photovoltaics: Research and Applications 14 (2006) 275-280.

[23] N. S. Lewis, Toward cost-effective solar energy use, Science 315 (2007) 798801.

[24] B. T. Wittbrodt, J. Laureto, B. Tymrak, and J. M. Pearce, Distributed Manufacturing with 3- D Printing: A Case Study of Recreational Vehicle Solar Photovoltaic Mounting Systems (2014) (to be published). 
[25] OpenSCAD, http:// www.openscad.org (2014) (Accessed May 29 2014).

[26] Ultimaker, http:// wiki.ultimaker.com/Cura (2014) (Accessed March 17 2014).

[27] MOST, MOST RepRap Primer, http:// www.appropedia.org/MOST_RepRap_Primer (2014) (Accessed J anuary 232014$)$.

[28] Repetier, http:// www.repetier.com/ (2014) (Accessed J anuary 23 2014).

[29] Goalzero, Boulder 30 Solar Panel, (2014) http:// www.goalzero.com/p/ 21/ boulder-30-solar-panel (Accessed J uly 22 2014).

[30] Sharp, Residential Products http:/ / www.sharpusa.com/SolarElectricity/ SolarProducts/ ResidentialSolarPr oducts.aspx (2014) (Accessed J uly 22 2014).

[31] Unirac, Unirac RM Technical Datasheet (2014).

[32] Keweenaw Research Center, KRC Weather Station, (2014) http:/ / www.mtukrc.org/ weather.htm (Accessed J uly 272014 ).

[33] D. O. Energy, Building Code, In: GROWTH, L. A. E. (ed.) (2010).

[34] J. Ochshorn, Example 2.3: Find snow laods, (2009) https:// courses.cit.cornell.edu/ arch264/ calculators/ example2.3/ (Accessed July 29 2014).

[35] C. Baechler, M. Devuono, and J. M. Pearce, Distributed recycling of waste polymer into RepRap feedstock, Rapid Prototyping J ournal 19 (2013) 118-125.

[36] M. A. Kreiger, M. L. Mulder, A. G. Glover, and J. M. Pearce, Life cycle analysis of distributed recycling of post-consumer high density polyethylene for 3-D printing filament, J ournal of Cleaner Production 70 (2014) 90-96.

[37] S. R. Feeley, B. Wijnen, and J . M. Pearce, Evaluation of Potential Fair Trade Standards for an Ethical 3-D Printing Filament. J ournal of Sustainable Development 7(5) (2014) 1-12.

[38] B. M. Tymrak, M. Kreiger, and J. M. Pearce, Mechanical properties of components fabricated with open-source 3-D printers under realistic environmental conditions, Materials \& Design 58 (2014) 242-246. 
ASM, Aluminum 6063-T5

http:// asm.matweb.com/ search/ SpecificMaterial.asp?bassnum=MA6063T5 (Accessed May 18 2014).

[40] A. Skoczek, T. Sample, and E. D. Dunlop, The results of performance measurements of field - aged crystalline silicon photovoltaic modules, Progress in photovoltaics: Research and Applications 17 (2009) 227-240.

[41] A. Copinet, C. Bertrand, S. Govindin, V. Coma, and Y. Couturier, Effects of ultraviolet light ( $315 \mathrm{~nm}$ ), temperature and relative humidity on the degradation of polylactic acid plastic films, Chemosphere 55 (2004) 763-773.

[42] P. Gijsman, G. Meijers, and G. Vitarelli, Comparison of the UV-degradation chemistry of polypropylene, polyethylene, polyamide 6 and polybutylene terephthalate, Polymer Degradation and Stability 65 (1999) 433-441.

[43] L. C. Mendes, E. S. Rufino, F. O. C. De Paula, and A. C. Torres Jr, Mechanical, thermal and microstructure evaluation of HDPE after weathering in Rio de J aneiro City, Polymer Degradation and Stability 79 (2003) 371-383.

[44] O. Dynamics, Strooder http:// omnidynamics.co.uk/ shop/strooder (Accessed July 30 2014).

[45] Filamaker, http:// filamaker.eu/ (Accessed J uly 30 2014).

[46] Filabot, http:// www.filabot.com/ (Accessed J uly 30 2014).

[47] H. Lyman, Lyman Filament Extruder V4.1, (2014) http:// www.thingiverse.com/ thing:265375 (Accessed J uly 30 2014).

[48] Filaab, http:// www.filafab.co.uk/ (Accessed J uly 30 2014).

[49] Filastruder, http:/ / www.filastruder.com/ (Accessed J uly 30 2014).

[50] R. Satoto, W. S. Subowo, R. Yusiasih, Y. Takane, Y. Watanabe, and T. Hatakeyama, Weathering of high-density polyethylene in different latitudes, Polymer Degradation and Stability 56 (1997) 275-279.

[51] Gr0b, Customizeable Wrench, Thingiverse (2013) http:/ / www.thingiverse.com/thing:47842 (Accessed J uly 29 2014).

[52] T. Faulkner, No Easy Fix for Broken Wind Turbine at US High School, Renewable Energy World (2013) http:/ / www.renewableenergyworld.com/ rea/ news/ article/ 2013/ 05/ no- easyfix-for-broken-wind-turbine-at-us-high-school (Accessed J uly 22 2014). 
[53] J. M. Pearce, The case for open source appropriate technology, Environment, Development and Sustainability 14 (2012) 425-431.

[54] J . Lawson, The PV Industry Tackles Solar Theft, (2012) Available from: http:/ / www.renewableenergyworld.com/rea/ news/ article/ 2012/ 04/ the-pvindustry-tackles-solar-theft [Accessed J uly 22 2014].

[55] R. J . Bateman, and K. Cheng, Rapid Manufacturing as a tool for agile manufacturing: application and implementation perspectives, International J ournal of Agile Manufacturing 9 (2007) 39-52.

[56] J . Bertling, J. Blömer, M. Rechberger, and S. Schreiner, DDM-An Approach Towards Sustainable Production?, Young 35 (2014) 30. 


\section{6 - The Effects of PLA Color on Material Properties of 3-D Printed Components 5}

\subsection{Introduction}

With the rise in popularity of low-cost at-home 3-D printers using fused filament fabrication (FFF), specifically the open-source RepRap (self-Replicating Rapidprototyper) [1-4], comes a demand for the education about how to properly use and apply the technology. It is estimated that the consumer, low cost, 3-D printing market will reach $\$ 5.1$ billion in revenue by $2018[4,5]$. Additive manufacturing took 20 years to reach a $\$ 1$ billion USD and has grown to $\$ 3.07$ billion USD two years later in 2013 [4]. There have been efforts made already to promote the use of at-home 3-D printing [6] and it has been shown that decentralizing the manufacturing process not only allows for a lower cost of goods for the consumer[7], but a lower impact on the environment as well [8]. There has been an exponential growth of open-source designs for 3-D printing and this trend is expected to continue growing as consumer level 3-D has been proven to be an economically viable purchase for American middleclass consumers [7]. Prosumer 3-D printers in general, and more specifically RepRap 3-D printers, account for the majority of 3-D printers in use now [9]. In addition, the appeal of democratized manufacturing has been moving from an exclusively hobbyist idea to become more commonplace [10]. Currently, there are many different materials available on the market for prosumer FFF 3-D printing including ABS, Nylon, polycarbonate, high-density polyethylene, high impact polystyrene, PLA (poly-lactic acid), and others [11]. PLA has emerged as one of the favorites among the prosumer 3$\mathrm{D}$ printer users. PLA has a relatively low melting point, $150^{\circ}-160^{\circ} \mathrm{C}$, thus requiring less energy to print with the material, which also provides advantages for off-grid applications in the developing world [12]. In addition, PLA has been shown to be a safer alternative to the possibly toxic ABS plastic [13]. With the introduction of many new and affordable 3-D printing technologies the amount of materials that may become common will grow $[14,15]$. Efforts have been made to add strengthening

5 The material contained in this chapter has been prepared for publication 
agents to common 3-D printable materials [16,17], and treating 3-D printable materials to increase strength [18]. With the introduction of Recyclebot, an opensource prosumer plastic filament extruder, these potential strengthening mechanisms can be implemented and tested by the end-user directly [19].

However, there is a severe lack of data and standards relating to the prosumer lowcost entry-level 3-D printing material properties, and few studies centered around commercial printers, that limits the applications with the result that prosumers are focusing on lower value products (e.g. toys) at the expense of more sophisticated designs for higher value products like tools or scientific equipment [20-22]. Current studies have described what effect the orientation of layers may have on the properties by using commercial grade powder printers [23] and using commercial grade fused deposition modeling (FDM) printers has shown a strength dependency on different types of infill patterns and internal structures [24]. Using a similar 3-D printer as Rosas [24] there has been data showing the ability of printed parts to perform between $65 \%$ and $72 \%$ as well in comparison to injection molded parts of the same material [25]. Additionally, commercial printers have been used to show a difference in layer adhesion when parts were printed using various fabrication preferences, including temperature [26]. In order for users to manufacture more functional products with their RepRaps, a recent study was completed on the mechanical properties of RepRap printed parts printed in realistic environmental conditions, which showed RepRap prints can perform match and even out perform commercial 3-D printers using proprietary FDM in terms of tensile strength with the same polymers [27]. While RepRap printers can outperform commercial printers there can be inconsistencies causing the tensile strengths to fluctuate and a preliminary evaluation of the results indicated that some of the strength variation may have been due to the color of the filament [27]. In addition, as the nature of that study had different 3-D printers running at the users chosen optimal conditions the processing temperatures varies. It has been shown already that polymers will contain different degrees of crystallinity depending on the processing history and temperature [28]. Traditional manufacturing methods have also shown a relation to mechanical properties depending on the processing history [29] but this has not been proven in FFF 3-D printing industry. 
In order to close the knowledge gap surrounding prosumer 3-D printed part strength and determine the effect of color and processing temperature on material properties of PLA deposited in FFF this study provides characterizations of PLA in various colors and manufacturers. Commercially available filament processed from 4043 PLA is tested from one manufacturer and five colors, white, black, blue, grey, and natural, for crystallinity with XRD, tensile strength following ASTM D638 and the microstructure is evaluated with environmental scanning electron microscope (ESEM). The results are presented and conclusions are drawn about the effects of color and processing temperature on the material properties of 3-D printed PLA to promote the opensource development of RepRap 3-D printing.

\subsection{Methods and Materials}

The test samples were printed on a Lulzbot TAZ 4 open-source 3-D printer supplied by Aleph Objects Inc. (Aleph Objects 2014) using 3mm PLA filament from Lulzbot in the following colors: natural, white, black, silver, and blue. All parts, tensile and X-ray diffraction were printed with identical parameters at $190^{\circ} \mathrm{C}$ for the extruder and $60^{\circ} \mathrm{C}$ for the build platform. Additionally, white samples were printed with varying extruder temperatures between $190^{\circ} \mathrm{C}$ and $215^{\circ} \mathrm{C}$.

Printed tensile samples were then subjected to tensile testing consistent with ASTM D638 standards [30] with an STL found here [31] using an Instron 4206 tensometer. In addition XRD samples [32] were printed at 100\% infill and measured using a Scintag XDS-2000 Powder diffractometer, with specific goals of measuring percent crystalinity, at the Michigan Tech Applied Chemical and Morphological Analysis Laboratory (ACMAL) [33]. Scan settings were 5-50 ${ }^{\circ}(2 \theta)$ with count times of 2.5 seconds per $0.2^{\circ}(2 \theta)$ following procedures outlined by MOST [34]. Once the XRD samples were run an analysis of the percent crystallinity of each sample was performed using Pearson 7 peak fitting within the DSMNT software to fit the amorphous peaks and crystalline peaks and taking a ratio of the fitted integrated area under the 
diffraction peak. The tensile testing and XRD measurements utilized ten samples each of the different colors printed at $190^{\circ} \mathrm{C}$ and five samples each of the elevated temperature samples. The fracture surfaces of the samples were analyzed using a Philips XL 40 ESEM [35].

\subsection{Results}

The results clearly show that percent crystallinity of 3-D printed parts is color dependent as summarized in Table 6.1. Natural PLA (no dye added) contains the lowest percent of crystalline regions with $0.93 \%$. In contrast the white material was shown to include the greatest percentage of crystalline regions with 5.05\%. Table 6.1 shows the ultimate tensile strength, the strain at that tensile strength, and the percent crystallinity averages for each color along with the associated errors. The yield strength was calculated at a $0.2 \%$ offset.

\section{Table 6.1: Ultimate tensile strength, maximum strain, and percent} crystallinity as a function of color for PLA.

\begin{tabular}{lrrrr} 
Color & $\begin{array}{r}\text { Utlimate Tensile } \\
\text { Strength (MPa) }\end{array}$ & $\begin{array}{r}\text { Yield Strength } \\
(\mathrm{MPa})\end{array}$ & $\begin{array}{r}\text { Maximum } \\
\text { Strain }(\%)\end{array}$ & $\begin{array}{r}\text { Crystallinity } \\
(\%)\end{array}$ \\
\hline Natural & $57.16+/-0.35$ & $52.47+/-0.35$ & $2.35+/-0.05$ & $0.93+/-0.06$ \\
Black & $52.81+/-1.18$ & $49.23+/-1.18$ & $2.02+/-0.08$ & $2.62+/-0.09$ \\
Grey & $50.84+/-0.23$ & $46.08+/-0.23$ & $1.98+/-0.04$ & $4.79+/-0.10$ \\
Blue & $54.11+/-0.30$ & $50.10+/-0.30$ & $2.13+/-0.02$ & $4.85+/-0.15$ \\
White & $53.97+/-0.26$ & $50.51+/-0.26$ & $2.22+/-0.04$ & $5.05+/-0.18$ \\
\hline
\end{tabular}

Figure 6.1 shows a selection of the raw stress-strain curve for $215^{\circ} \mathrm{C}$ white PLA and $190^{\circ} \mathrm{C}$ white PLA showing a linear section of loading before a curved area and finally a yield point and break. 


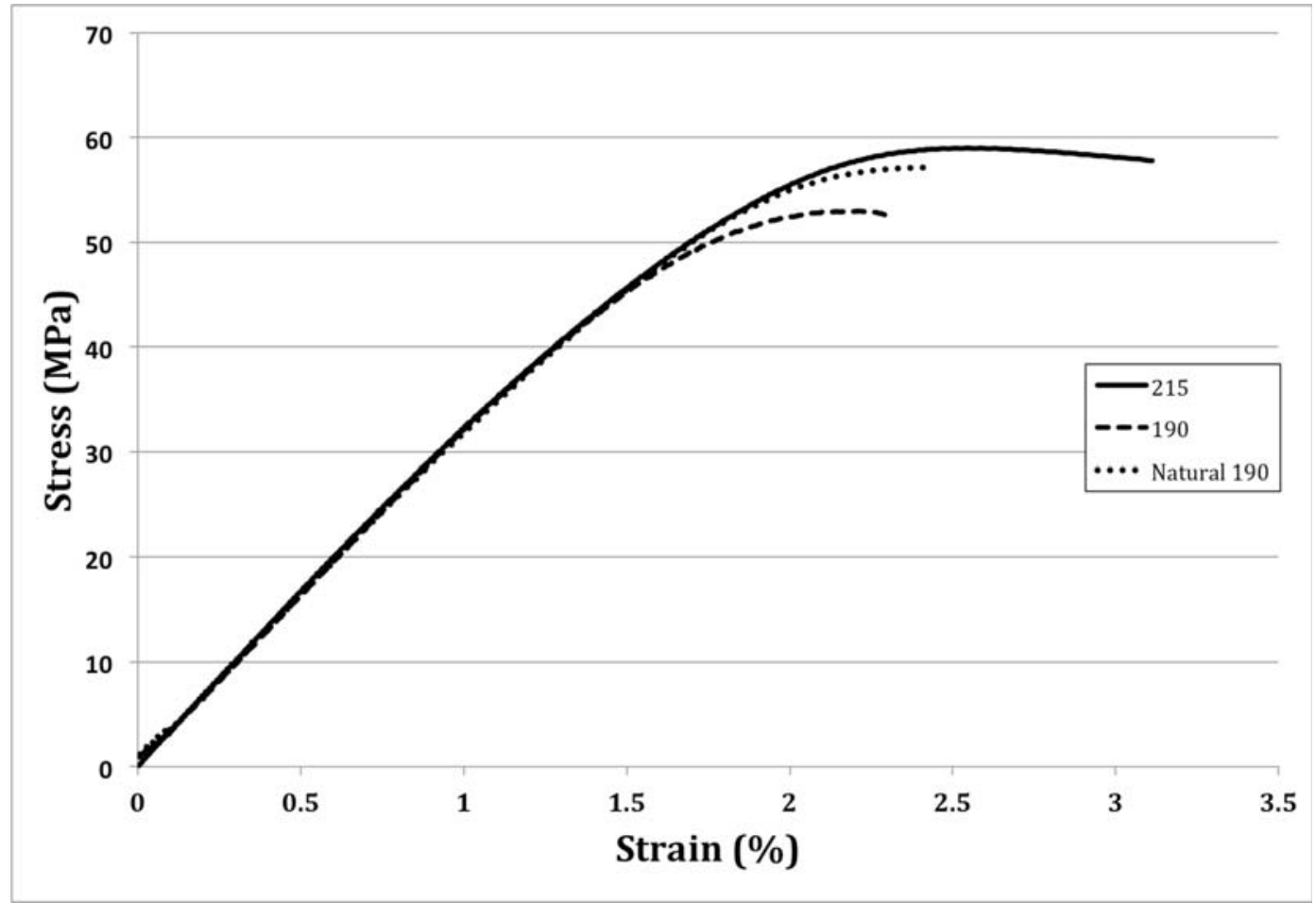

Figure 6.1: Raw stress vs. strain curve for white PLA printed at $215^{\circ} \mathrm{C}$ and $190^{\circ} \mathrm{C}$ and natural PLA at $190^{\circ} \mathrm{C}$

The raw XRD data is plotted in Figure 6.2 for the different colors of PLA showing the difference in crystalline peaks as the color changes. Figure 6.3 shows the difference in percent crystallinity when printed at different temperatures. 


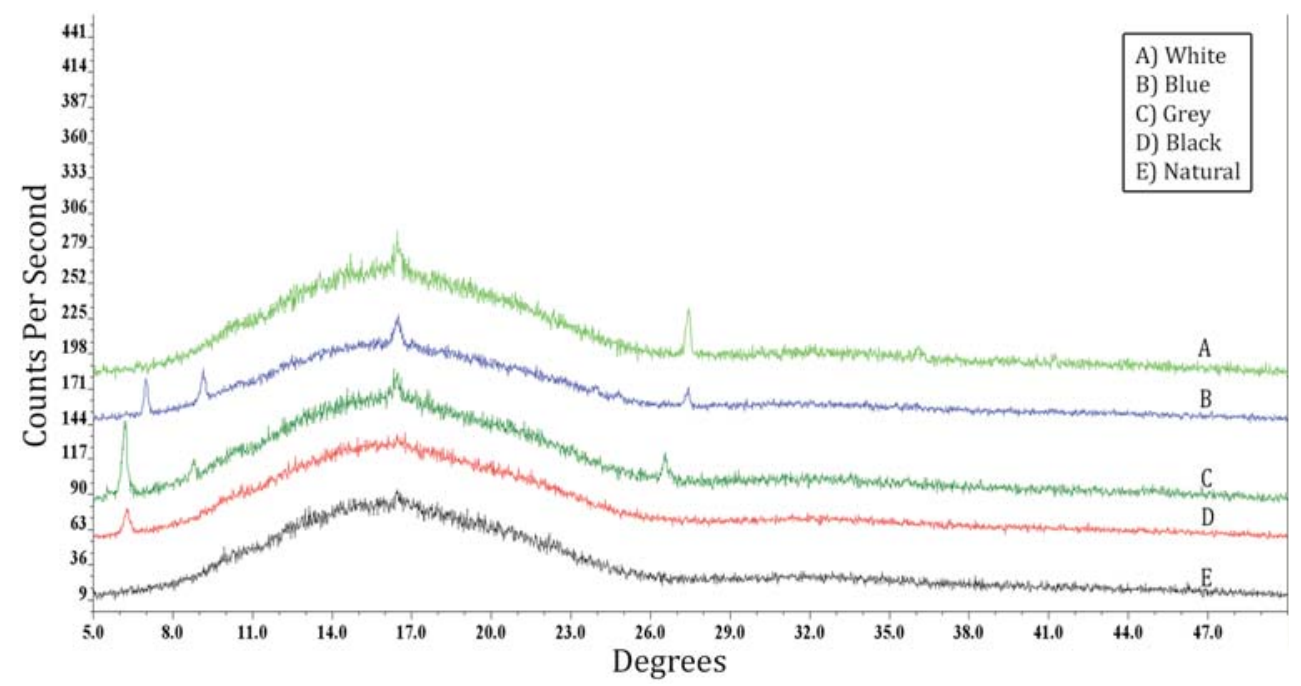

Figure 6.2: Composite XRD scans for different colors of PLA in order of percent crystallinity with the highest percent at the top. Colors: A) White, B) Blue, C) Grey, D) Black, E) Natural.

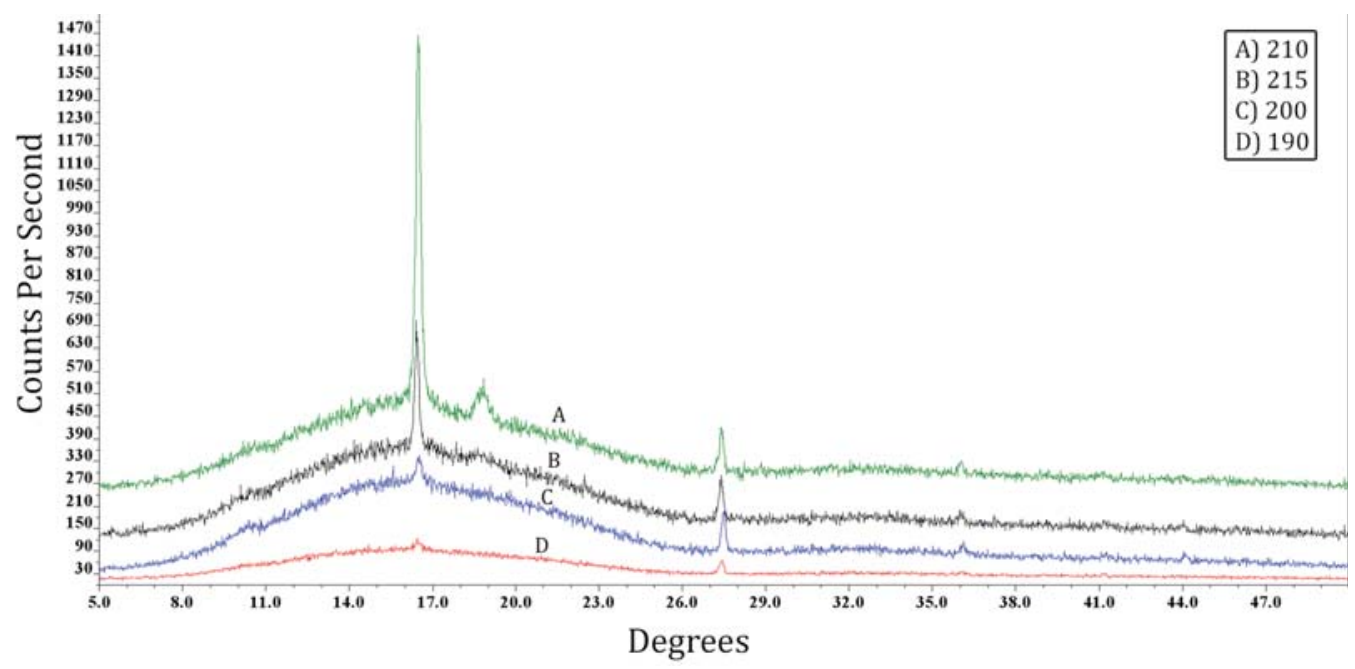

Figure 6.3: Composite XRD data for white PLA when printed at various temperatures plotted with the highest percent crystallinity on top and decreasing downward. Temperatures:A) $\left.210^{\circ} \mathrm{C}, \mathrm{B}\right) 215^{\circ} \mathrm{C}$, C) $\left.200^{\circ} \mathrm{C}, \mathrm{D}\right) 190^{\circ} \mathrm{C}$.

While Figure 6.3 shows that each color has a different, specific, percent crystallinity there is also a significant change in tensile strength with different percent 
crystallinities. The difference in tensile strengths compared to colors can be seen in Figure 6.4 with every sample printed at $190^{\circ} \mathrm{C}$ represented.

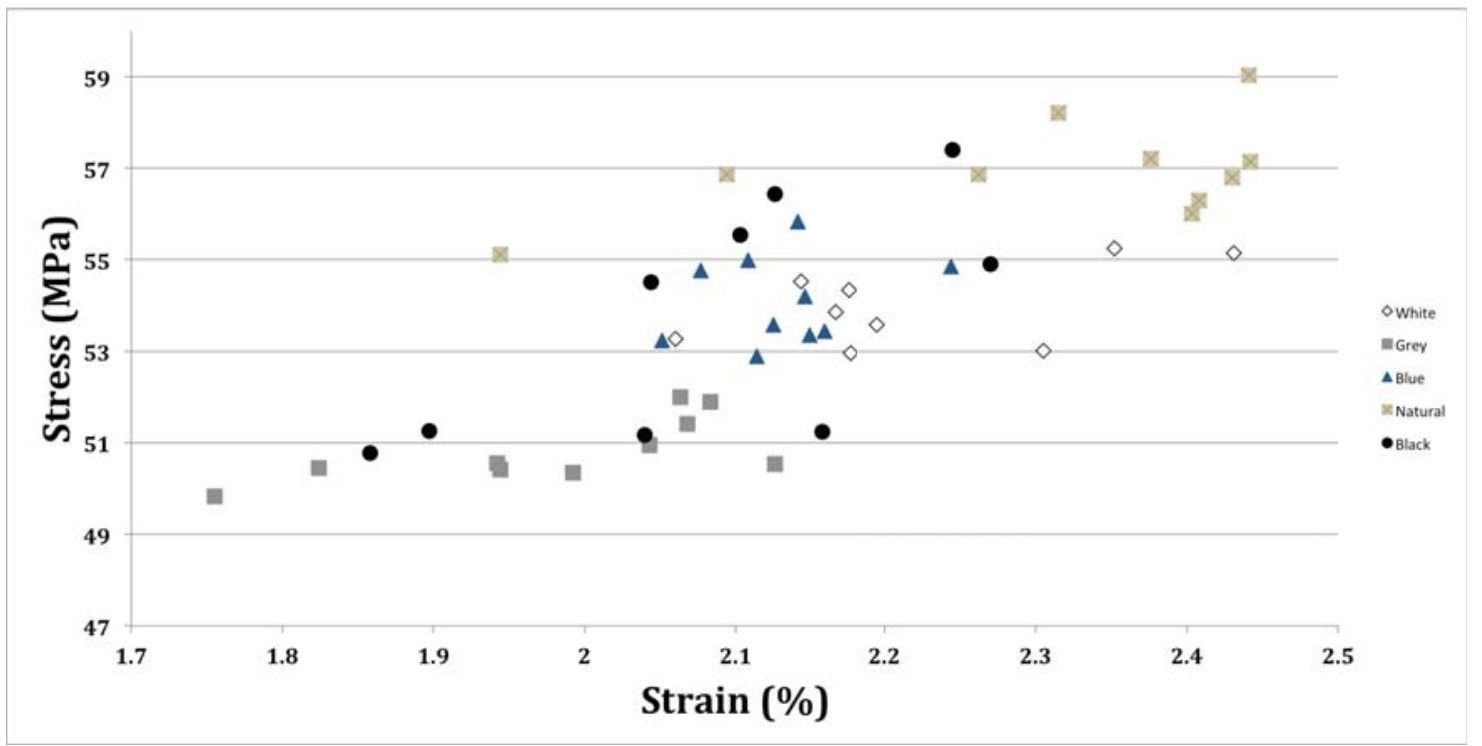

Figure 6.4: Maximum stress vs. Strain for printed samples

After linear fitting of the data in Figure 6.4 a correlation of 0.66 was obtained suggesting that there is a correlation between the tensile strength of a PLA. The regression line has a slope of 11.4 suggesting a fairly significant change in ultimate tensile strength vs. strain for different colors. Standard deviations for the samples are 0.82 for white, 0.71 for grey, 0.96 for blue, 3.72 for black, and 1.09 for natural with standard errors of 0.26 for white, 0.23 for grey, 0.30 for blue, 1.8 for black, and 0.34 for natural. With the exception of black, all of these deviations are acceptable given the standard error in measurements of ultimate tensile strength as shown in Table 6.1.

Due to the apparent prevalence of white PLA to form crystalline regions the color was selected for additional tests. It was found that the different printing temperatures of the white PLA yielded different ultimate tensile strength and percent crystallinity results as well. Figure 6.5 shows the relationship between printing temperature and strength. 


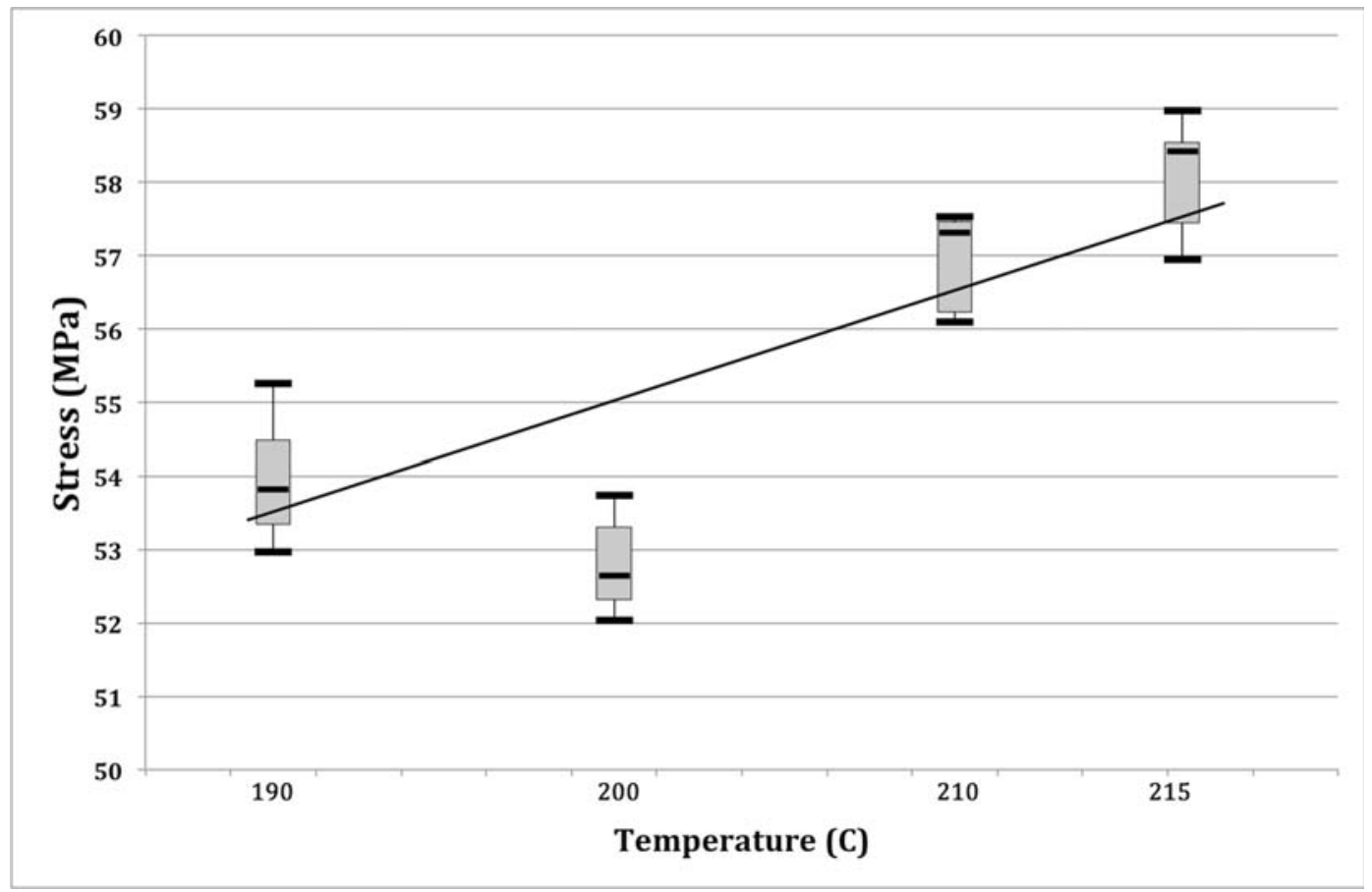

Figure 6.5: Tensile strength of white PLA printed at different temperatures

Figure 6.5 is suggesting a mild linear relationship between strength and print temperature with a correlation value of 0.62 with all temperatures represented. In Figure 6.5 the error bars represent the minimum value, $1^{\text {st }}$ quartile, median, $3^{\text {rd }}$ quartile, and maximum from the bottom to top, respectively. However, if the $200^{\circ} \mathrm{C}$ samples are omitted the correlation becomes 0.85 suggesting a strong linear relationship. This temperature dependence is consistent with trends regarding there being an ideal processing temperature of a material and a range of acceptable temperatures giving similar strengths. Presented in Figure 6.6 are the percent crystallinities of white PLA samples printed at different temperatures. 


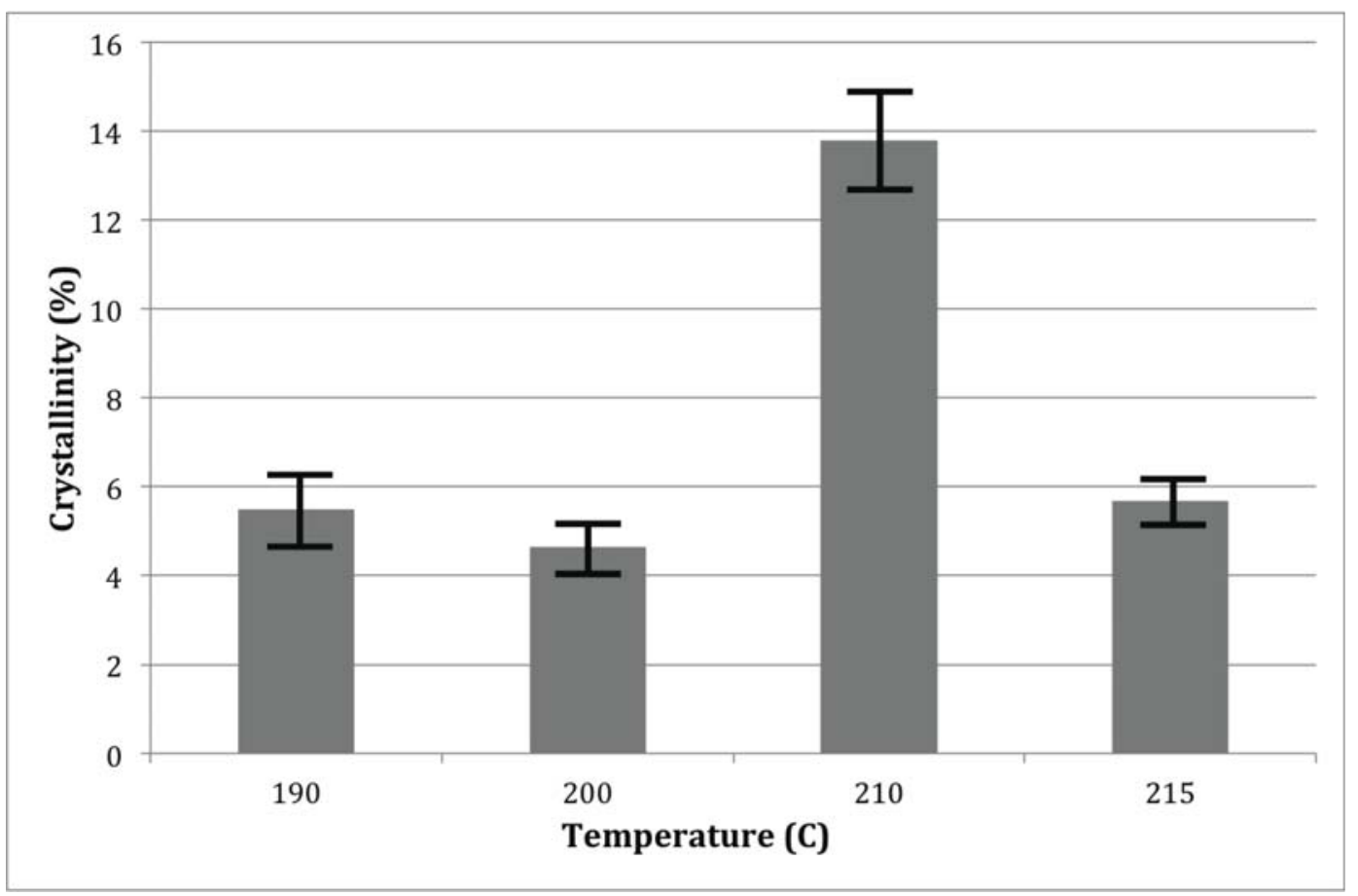

Figure 6.6: Percent crystallinity vs. temperature of printing for white PLA samples

The results shown in Figure 6.6 indicate that there is a critical temperature at which a maximum percent crystallinity can be achieved for white PLA. Error bars in Figure 6.6 represent $+/$ - twice the standard error of the percent crystallinity measurement for 10 samples of each temperature.

The fracture surface of a representative sample with the ESEM is shown in Figure 6.7. As can be seen the difference between the nominal 100\% setting used to print the part and the actual part itself, which exhibits small (10-200 micron) extruded triangleshaped gaps and using imageJ to analyze the area were $10.8 \%$ of the cross-section. As the extruder head temperature is increased these gaps are reduced and at some layers disappear. This can be clearly seen by comparing Figure 6.7 to Figure 6.8, which shows a higher temperature white sample and gaps accounting for 3.0\%. 


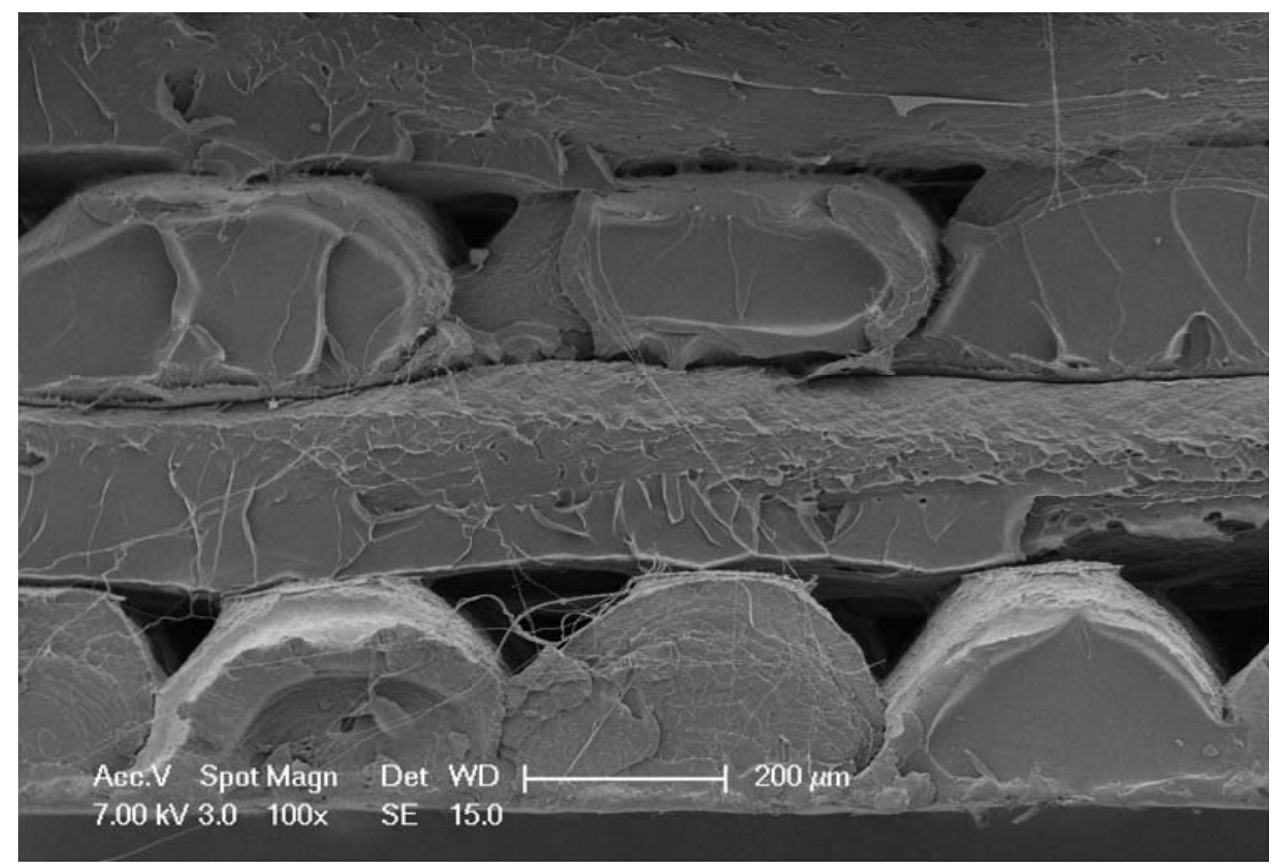

Figure 6.7: Scanning electron image of the white PLA sample printed at $190^{\circ} \mathrm{C}$ showing the first four layers of the print with the bottom of the image corresponding to the bottom of the part when printing.

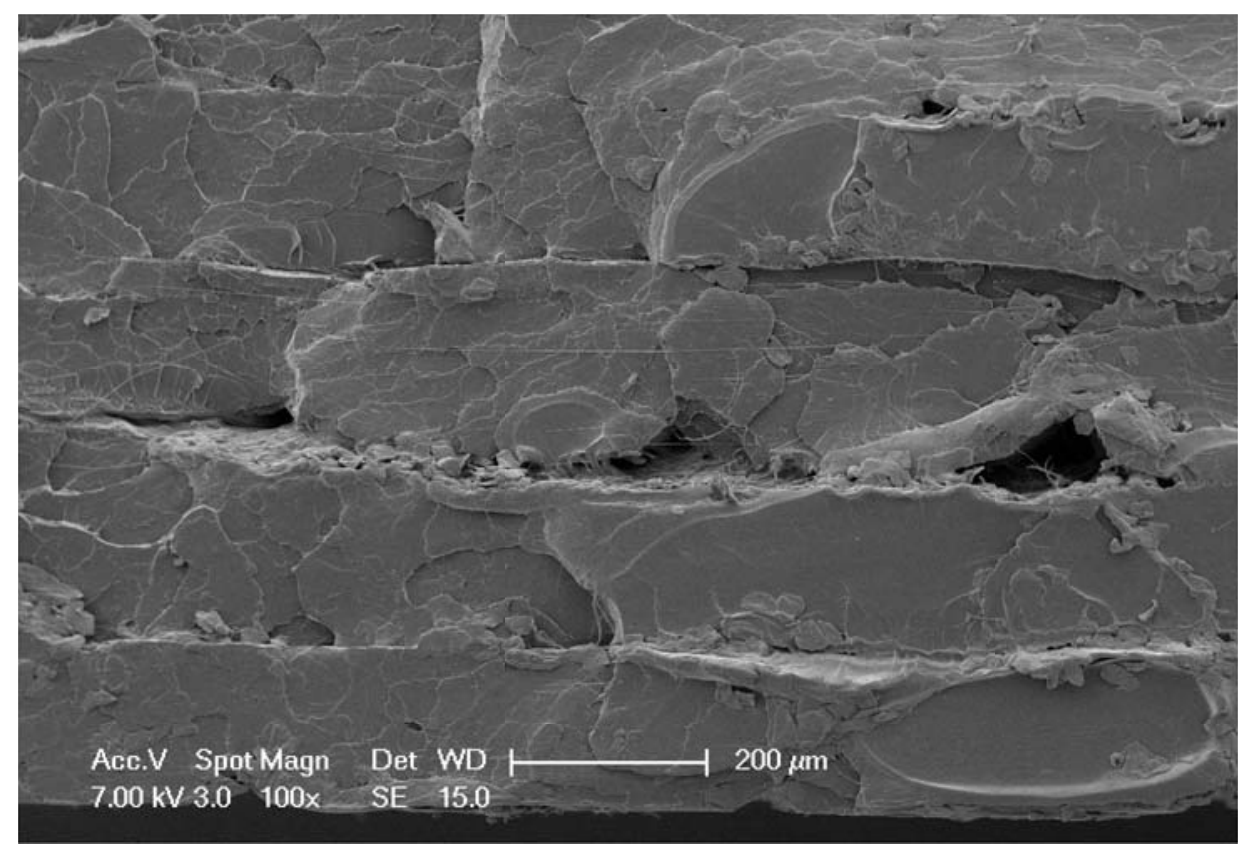

Figure 6.8: Scanning electron image of white PLA printed at $210^{\circ} \mathrm{C}$ oriented with the first printed layer on the bottom and including a total of 4 layers in the field of view. 
The natural PLA sample was analyzed under the ESEM to attempt to provide more information regarding the material behavior and a high magnification image is shown in Figure 6.9. This sample showed a gap percentage of $10.6 \%$ when analyzed with image . Figure 6.10 shows the gaps present in un-tested natural PLA showing that the gaps are present due to the nature of the printing process.

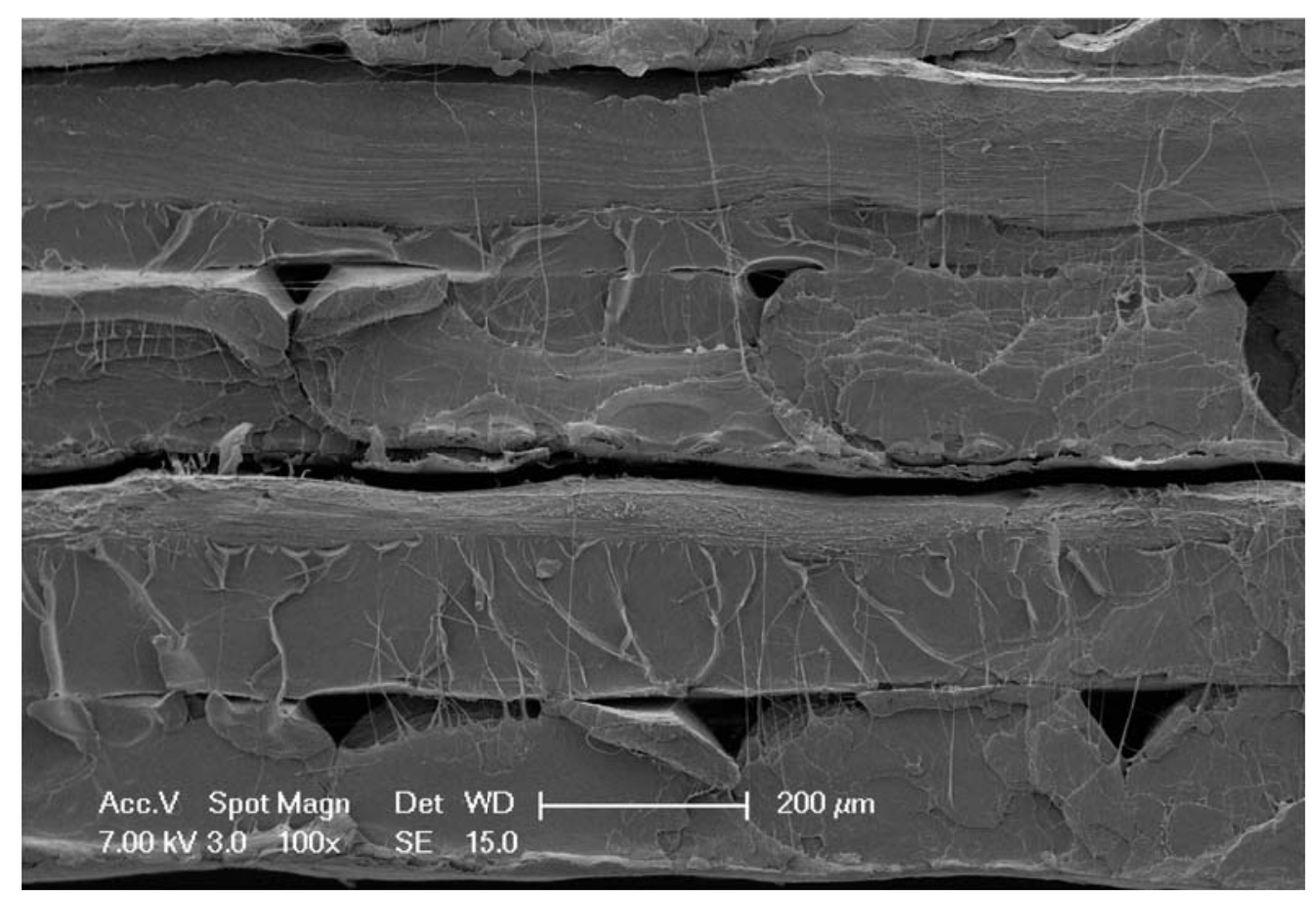

Figure 6.9: Natural PLA sample printed at $190^{\circ} \mathrm{C}$ imaged under the ESEM showing the bottom four layers oriented bottom layer at the bottom of the image. 


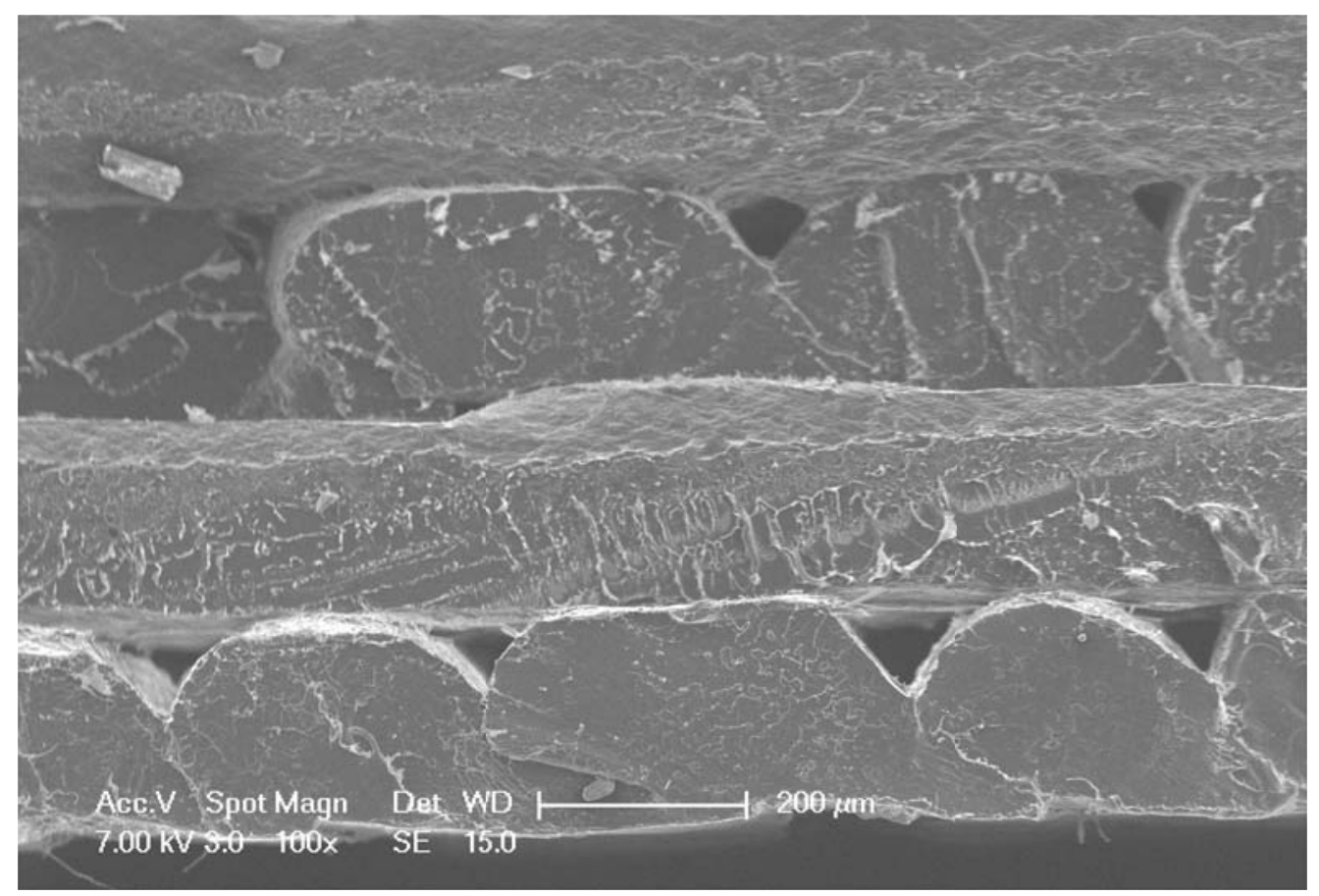

Figure 6.10: Raw sample of natural PLA (not tensile tested) showing the bottom 4 layers.

\subsection{Discussion}

The data presented further verifies the claim that RepRap 3-D printers can produce parts of equal, or greater, tensile strength as prints from proprietary 3-D printers [27]. Furthermore the data was consistent with previously experienced behavior in tensile testing printed materials including PLA [36]. Additionally, all samples had a fairly constant Young's modulus of $2.78 \mathrm{GPa}(+/-0.35)$ which is in the acceptable range for PLA [37]. These 3-D printed parts may also be tailored for a given use by changing the color, or temperature the part is printed in. Each color presented, when printed at $190^{\circ} \mathrm{C}$, had a distinct tensile strength and percent crystallinity when analyzed with tensile testing and XRD. This shows that a conscious decision can be made for the choice of color that a part is printed in to achieve desired material properties. Also shown is the relative extrusion temperature dependence of a material's tensile strength and, again, percent crystallinity. While the tensile strength increases with extrusion temperature, the crystallinity increases from $190^{\circ} \mathrm{C}$ to a maximum at $210^{\circ} \mathrm{C}$ and back 
down to a lower value at $215^{\circ} \mathrm{C}$ as seen in Table 6.2. Using this data it is possible to hypothesize that there can be a critical extrusion temperature of the percent crystallinity present in a given material. Since each sample was printed at the same bed temperature, $60^{\circ} \mathrm{C}$, the variation must be dependent on the printing temperature itself.

One possible explanation for the changing crystallinity is the different dyes used to color the PLA material. Since raw PLA has 0-1\% crysallinity [37], and the data presented here is consistent with that range, the addition of other dyes, strengtheners, or other agents must be the contributing factor for the different crystallinity percentages seen in the colored samples. Tensile strength differences can be explained by the behavior of the material itself. When the cyrstallinity is very low the strength is dependent on the material itself causing a high tensile strength. Crystallinity increases as printing temperature increases until it reaches a maximum value, $210^{\circ} \mathrm{C}$ in this case, and declines as extrusion temperatures become greater than the maximum. Tensile strength increased at every printing temperature except $200^{\circ} \mathrm{C}$, perhaps related to a preferential orientation of the crystalline grains perpendicular to the direction in which the samples were pulled at that extrusion temperature. Figures 6.5 and 6.6 show this potential relationship where $200^{\circ} \mathrm{C}$ has a minimum value of both strength and percent crystallinity.

When looking at the extrusion temperature dependence of the strength of the material the trend of tensile strength in respect to crystallinity is not followed. Once the material is printed at $215^{\circ} \mathrm{C}$ the tensile strength is higher but the percent crystallinity is lower than the critical crystallinity at $210^{\circ} \mathrm{C}$. Due to the layered nature of the 3-D printing process a higher printing temperature can give the different layers more time to bond together before reaching the glass transition temperature of PLA.

Figures 6.2 and 6.3 show that there exist different crystalline peaks for samples that contain different percent crystallinities between colors. In Figure 6.5 there is a presence of higher degree peaks as the percent crystallinity increases showing that the lower degree peaks may not be essential in the strengthening process. Figure 6.3 
illustrates the fact that the magnitude of the crystalline peaks will indeed increase when the percent crystallinity increases as expected.

Overall, the PLA samples tested had a lower tensile strength than the standard value for PLA (between $60 \mathrm{MPa}$ and 70MPa [38]), as the process of 3-D printing allows different strands of plastic to be deposited in different orientations reducing the anisotropic nature of the strength if it were to be printed all in one direction. Also, while the sample was printed at a nominal 100\% fill percentage, Figure 6.7 shows that, at higher magnification, the PLA is not a completely solid material and has some gaps that could lower the ultimate tensile strength. As shown, when the PLA samples were examined under SEM, the average percentage of area represented by pores was $10.6 \%$ for natural and a tensile test of the raw filament showed a tensile strength of 63.64 $\mathrm{MPa}$, or $11.4 \%$ stronger than the printed part. When the printing temperature was increased the layers adhered better together and nearer a solid material as presented in Figure 6.8. Figure 6.9 showing the natural PLA samples exhibits string-like artifacts over the fracture surface. These strings could potentially be amorphous chains of the base monomer extending under load and snapping once the stress surpassed the tensile strength causing fracture.

As RepRap printers become more sophisticated the ability to select colors and vary printing temperature for a specific component or part of a component will be possible and already these feature are supported in open-source slicing packages $[39,40]$ and some multihead printers (e.g. Lulzbot FlexyDually Tool Head). Future work is needed to characterize all of the printing materials in this way to develop a database of material properties to be used in future generations of open-source slicing programs. In addition, the effect of printing speed on strength and percent crystallinity should be evaluated.

\subsection{Conclusions}

With the rapid growth of the consumer FFF 3-D printing market and a large focus on providing useful, real-world applications of the technology comes an increasing 
demand to fully understand the material properties of the final 3-D printed components. Contrary to conventional belief it has been shown that consumer level 3D printers can produce parts that perform comparatively and in some cases exceptionally to those produced by professional and proprietary printers [27]. Additionally, fused filament fabrication style printers are able to produce parts with consistent material properties and it is also possible to estimate the properties expected using the presented data dependent on the color and printing temperature of the filament. According to the results of this study there appears to be a critical printing temperature for each color to optimize a maximum percent crystallinity.

\subsection{References}

[1] E. Sells, Z. Smith, S. Bailard, A. Bowyer, and V. Olliver, RepRap: The Replicating Rapid Prototyper: Maximizing Customizability by Breeding the Means of Production, In Piller, F. T., and Tseng, M. M., Handbook of Research in Mass Customization and Personalization: Strategies and concepts (Vol. 1), World Scientific. (2010)

[2] R. J ones, P. Haufe, E. Sells, P. Iravani, V. Olliver, C. Palmer, and A. Bowyer, RepRap - the replicating rapid prototyper, Robotica. 29(01) (2011) 177- 191.

[3] J. M. Pearce, C. M. Blair, K. J . Laciak, R. Andrews, A. Nosrat, and I. ZelenikaZovko, 3-D Printing of Open Source Appropriate Technologies for SelfDirected Sustainable Development, J . Sustain. Dev. 3(4) (2010) 17.

[4] T. Wohlers, T. Caffrey, Wohlers Report 2014: 3D Printing and Additive Manufacturing State of the Industry Annual Worldwide Progress Report, Wohlers Associates. (2014)

[5] M. Molitch-Hou, Consumer 3D Printing in Growth Phase, 3D Printing Industry, [Online]. Available: http:/ / 3dprintingindustry.com/ 2014/ 08/ 14/ consumer-3d-printing-seriousgrowth-phase-according-photizo-group/ . [Accessed: 16-Nov-2014].

[6] C. Mota, The Rise of Personal Fabrication, in Proceedings of the 8th ACM Conference on Creativity and Cognition, New York, NY, USA, (2011) 279- 288. 
[7] B. T. Wittbrodt, A. G. Glover, J. Laureto, G. C. Anzalone, D. Oppliger, J . L. Irwin, and J . M. Pearce, Life-cycle economic analysis of distributed manufacturing with open-source 3-D printers, Mechatronics, 23(6) (2013) 713- 726.

[8] M. Kreiger and J. M. Pearce, Environmental Impacts of Distributed Manufacturing from 3-D Printing of Polymer Components and Products, in Symposium D/ G - Materials for Sustainable Development-Challenges and Opportunities. 1492 (2013) 85- 90.

[9] J. Moilanen, V. Tere, Manufacturing in motion: first survey on 3D printing community. [Online] Available: http:// surveys.peerproduction.net/2012/ 05/ manufacturing-in-motion/ . [Accessed: 22-Nov-2014].

[10] J. G. Tanenbaum, A. M. Williams, A. Desjardins, and K. Tanenbaum, Democratizing Technology: Pleasure, Utility and Expressiveness in DIY and Maker Practice, in Proceedings of the SIGCHI Conference on Human Factors in Computing Systems, New York, NY, USA, (2013) 2603- 2612.

[11] E. J. Hunt, C. Zhang, N. Anzalone, and J . M. Pearce, Voluntary Polymer Recycling Codes for Distributed Manufacturing with 3-D Printers, (to be published).

[12] D. L. King, A. Babasola, J. Rozario, and J . M. Pearce, Mobile Open-Source Solar-Powered 3-D Printers for Distributed Manufacturing in Off-Grid Communities, Challenges in Sustainability 2(1) (2014) 18-27.

[13] M. Groenendyk and R. Gallant, 3D printing and scanning at the Dalhousie University Libraries: a pilot project, Libr. Hi Tech. 31(1) (2013) 34- 41.

[14] D. T. Pham and R. S. Gault, A comparison of rapid prototyping technologies, Int. J . Mach. Tools Manuf. 38(10-11) (1998) 1257- 1287.

[15] X. Yan and P. Gu, A review of rapid prototyping technologies and systems, Comput.-Aided Des. 28(4) (1996) 307- 318.

[16] A. R. T. Perez, D. A. Roberson, and R. B. Wicker, Fracture Surface Analysis of 3D-Printed Tensile Specimens of Novel ABS-Based Materials, J Fail. Anal. Prev. 14(3) (2014) 343-353. 
[17] B. G. Compton and J . A. Lewis, 3D-Printing of Lightweight Cellular Composites, Adv. Mater. 26(34) (2014) 5930- 5935.

[18] S. Shaffer, K. Yang, J. Vargas, M. A. Di Prima, and W. Voit, On reducing anisotropy in 3D printed polymers via ionizing radiation, Polymer. 55(23) (2014) 5969-5979.

[19] C. Baechler, M. DeVuono, and J. M. Pearce, Distributed recycling of waste polymer into RepRap feedstock, Rapid Prototyp. J . 19(2) (2013) 118- 125.

[20] J. M. Pearce, Building Research Equipment with Free, Open-Source Hardware, Science, 337(6100) (2012) 1303- 1304.

[21] J . de Ciurana, L. Serenóa, and È. Vallès, Selecting Process Parameters in RepRap Additive Manufacturing System for PLA Scaffolds Manufacture, Procedia CIRP. 5 (2013) 152- 157.

[22] J. M. Pearce, Open-Source Lab, 1st ed. Elsevier. 2014.

[23] V. Vega, J . Clements, T. Lam, A. Abad, B. Fritz, N. Ula, and O. S. Es-Said, The Effect of Layer Orientation on the Mechanical Properties and Microstructure of a Polymer, J . Mater. Eng. Perform. 20(6) (2011) 978- 988.

[24] L. Rosas, Characterization of Parametric Internal Structures for Components Built by Fused Deposition Modeling, University of Windsor. (2013)

[25] S. Ahn, M. Montero, D. Odell, S. Roundy, and P. K. Wright, Anisotropic material properties of fused deposition modeling ABS, Rapid Prototyp. J . 8(4) (2002) 248- 257.

[26] Q. Sun, G.M. Rizvi, C.T. Bellehumeur, and P. Gu, Effect of processing conditions on the bonding quality of FDM polymer filaments, Rapid Prototyp. J. 14(2) (2008) 72-80.

[27] B. M. Tymrak, M. Kreiger, and J . M. Pearce, Mechanical properties of components fabricated with open-source 3-D printers under realistic environmental conditions, Mater. Des. 58 (2014) 242- 246.

[28] D. G. Brady, The crystallinity of poly(phenylene sulfide) and its effect on polymer properties, J . Appl. Polym. Sci. 20(9) (1976) 2541- 2551.

[29] D. M. Lincoln, R. A. Vaia, Z.-G. Wang, B. S. Hsiao, and R. Krishnamoorti, Temperature dependence of polymer crystalline morphology in nylon 6/montmorillonite nanocomposites, Polymer. 42(25) (2001) 09975- 09985. 
[30] D20 Committee, Test Method for Tensile Properties of Plastics, ASTM International. 2010.

[31] B. M. Tymrak, ASTM Tensile Test Specimen, Thingiverse. [Online]. Available: http:// www.thingiverse.com/thing:13694. [Accessed: 22-Nov-2014].

[32] B. T. Wittbrodt X-Ray diffraction sample piece. Thingiverse. [Online]. Available: http:// www.thingiverse.com/thing:559229. [Accessed: 22-Nov2014].

[33] ACMAL, Scintag XDS-2000 Powder - ACMAL - Michigan Tech, [Online]. Available: http:// mcff.mtu.edu/ acmal/ x-ray-facility/ scintag-xds-2000powder/ . [Accessed: 16-Nov-2014].

[34] MOST, XRD (X-ray Diffraction) protocol: MOST. [Online]. Available: http:// www.appropedia.org/XRD_(X-ray_Diffraction)_protocol:_MOST. [Accessed: 22-Nov-2014].

[35] ACMAL, Philips XL 40 ESEM. [Online]. Available: http:// mcff.mtu.edu/ acmal/ electron-microscopy/ philips-xl-40-esem/ . [Accessed: 22-Nov-2014].

[36] M. Domingos, F. Chiellini, A. Gloria, L. Ambrosio, P. Bartolo, and E. Chiellini, Effect of process parameters on the morphological and mechanical properties of 3D Bioextruded poly( $\varepsilon$ - caprolactone) scaffolds, Rapid Prototyp. J ., 18(1) (2012) 56-67.

[37] MakeitFrom, Polylactic Acid (PLA). [Online]. Available: http:// www.makeitfrom.com/ material-properties/ Polylactic-Acid-PLAPolylactide/ . [Accessed: 20-Nov-2014].

[38] Proscpector, Polylactic Acid (PLA) Typical Properties. [Online]. Available: http:/ / plastics.ulprospector.com/ generics/34/ c/ t/ polylactic-acid-plaproperties-processing. [Accessed: 21-Nov-2014].

[39] Ultimaker, Software Downlaods, Ultimaker. [Online]. Available: http:// software.ultimaker.com. [Accessed: 22-Nov-2014].

[40] Slic3r, Slic3r. [Online]. Available: http:// slic3r.org. [Accessed: 22-Nov-2014]. 


\section{7 - Future Work}

In continuation of the work presented here there is great potential in analyzing further ways in which a RepRap may be economically advantageous for consumers. While the currently available RepRaps offer low cost entrance into the 3-D printing technology, future printers will be even lower in cost and higher quality in the final product they produce. This leaves room for future studies about more items a RepRap may print and could erase some of the concerns individuals may have on the part quality currently.

Considering the currently available 3-D printed PV racking components there are many different ways in which to utilize new designs for multiple applications. Railing mounted, deck, window, sloped-roof, and even mobile PV racking could be realized with further development of the currently available designs. As shown here, RepRap and 3-D printing can greatly increase the standard of living for developing areas and the technology should be used continually in efforts to help advance the development of impoverished areas of the world.

One of the biggest issues with the adoption of 3-D printing is diverting attention away from small value items that serve no practical purpose and focusing on high value items capable of directly impacting the life of the individual that created it. Additional work should be conducted regarding a full characterization of 3-D printed PLA and ideally some of the newer materials that offer greater flexibility, strength, or wear resistance. There is a great potential for different processing temperatures, speeds, and material additives to customize the material for a particular use. Variables such as manufacture should be tested along with the deposition rate and in depth look into the different printing temperature. First, multiple manufactures of PLA filament should be compared to determine if all commercially available PLA follows the same trend shown here. Temperatures from $180^{\circ} \mathrm{C}$ to $230^{\circ} \mathrm{C}$ should be tested as this is the most widely accepted printing temperature range. Using a variety of colors, such as the 5 used in this study, and all acceptable printing temperatures can allow a composite material property table to be constructed aiding in the task of determining what PLA looks like, and how it behaves once 3-D printed. 
Furthermore, the data collected in further studies on materials can be used to help engineer a new filament for a given application. If there is a composite matrix of 3-D printed materials and a gap of strength, elasticity, crystallinity, or toughness present there is a possibility for new filaments and materials to fill that gap. 


\section{8 - Conclusions}

The data shown here illustrate the current capabilities of RepRap style 3-D printers and present potential applications of these printers. My data suggest the cost of a RepRap can be recouped within one year of ownership by printing common household items, without any design experience, suggesting the technology is a worthwhile investment. Secondly, these benefits are scalable, and, as we have demonstrated with the large cost reduction, (> 70\%) for PV racking, 3-D printers can be extremely beneficial in the developing world. Our data also demonstrate that a 3-D printing based racking system can offer a greater energy density of PV compared to commercial racking and therefore has benefits beyond cost reduction. Lastly, this work demonstrates that consumer and prosumer level 3-D printers produce parts that meet (or exceed) the strength of industrial 3-D printers and are capable of having material properties (tensile strength, crystallinity) tailored for a given application. 


\section{Appendix 1: License agreement for Chapter 2}

\section{ELSEVIER LICENSE TERMS AND CONDITIONS}

This is a License Agreement between Benjamin Wittbrodt ("You") and Elsevier ("Elsevier") provided by Copyright Clearance Center ("CCC"). The license consists of your order details, the terms and conditions provided by Elsevier, and the payment terms and conditions.

All payments must be made in full to CCC. For payment instructions, please see information listed at the bottom of this form.

Supplier: Elsevier Limited The Boulevard, Langford Lane Kidlington, Oxford, OX5 1GB, UK

Registered Company Number: 1982084

Customer name: Benjamin Wittbrodt

Customer address: 210 east st

HOUGHTON, MI 49931

License number: 3530251448041

License date: Dec 15, 2014

Licensed content publisher: Elsevier

Licensed content publication: Mechatronics

Licensed content title: Life-cycle economic analysis of distributed manufacturing with open-source 3-D printers

Licensed content author: B.T. Wittbrodt, A.G. Glover, J . Laureto, G.C. Anzalone, D.

Oppliger, J .L. Irwin, J .M. Pearce

Licensed content date: September 2013

Licensed content volume number: 23

Licensed content issue number: 6

Number of pages: 14

Start Page: 713

End Page: 726

Type of Use: reuse in a thesis/ dissertation

Portion: full article 
Format: both print and electronic

Are you the author of this Elsevier article? Yes

Will you be translating? No

Title of your thesis/ dissertation: Development of practical applications for RepRap

style 3-D printers in engineering

Expected completion date: Dec 2014

Estimated size (number of pages): 113

Elsevier VAT number: GB 494627212

Permissions price: 0.00 USD

VAT/Local Sales Tax: 0.00 USD

Total: 0.00 USD

Terms and Conditions:

\section{INTRODUCTION}

1. The publisher for this copyrighted material is Elsevier. By clicking "accept" in connection with completing this licensing transaction, you agree that the following terms and conditions apply to this transaction (along with the Billing and Payment terms and conditions established by Copyright Clearance Center, Inc. ("CCC"), at the time that you opened your Rightslink account and that are available at any time at http:// myaccount.copyright.com).

\section{GENERAL TERMS}

2. Elsevier hereby grants you permission to reproduce the aforementioned material subject to the terms and conditions indicated.

3. Acknowledgement: If any part of the material to be used (for example, figures) has appeared in our publication with credit or acknowledgement to another source, permission must also be sought from that source. If such permission is not obtained then that material may not be included in your publication/ copies. Suitable 
acknowledgement to the source must be made, either as a footnote or in a reference list at the end of your publication, as follows:

"Reprinted from Publication title, Vol / edition number, Author(s), Title of article / title of chapter, Pages No., Copyright (Year), with permission from Elsevier [OR APPLICABLE SOCIETY COPYRIGHT OWNER].” Also Lancet special credit "Reprinted from The Lancet, Vol. number, Author(s), Title of article, Pages No., Copyright (Year), with permission from Elsevier."

4. Reproduction of this material is confined to the purpose and/ or media for which permission is hereby given.

5. Altering/ Modifying Material: Not Permitted. However figures and illustrations may be altered/adapted minimally to serve your work. Any other abbreviations, additions, deletions and/ or any other alterations shall be made only with prior written authorization of Elsevier Ltd. (Please contact Elsevier at permissions@elsevier.com)

6. If the permission fee for the requested use of our material is waived in this instance, please be advised that your future requests for Elsevier materials may attract a fee.

7. Reservation of Rights: Publisher reserves all rights not specifically granted in the combination of (i) the license details provided by you and accepted in the course of this licensing transaction, (ii) these terms and conditions and (iii) CCC's Billing and Payment terms and conditions.

8. License Contingent Upon Payment: While you may exercise the rights licensed immediately upon issuance of the license at the end of the licensing process for the transaction, provided that you have disclosed complete and accurate details of your proposed use, no license is finally effective unless and until full payment is received from you (either by publisher or by CCC) as provided in CCC's Billing and Payment terms and conditions. If full payment is not received on a timely basis, then any license preliminarily granted shall be deemed automatically revoked and shall be void 
as if never granted. Further, in the event that you breach any of these terms and conditions or any of CCC's Billing and Payment terms and conditions, the license is automatically revoked and shall be void as if never granted. Use of materials as described in a revoked license, as well as any use of the materials beyond the scope of an unrevoked license, may constitute copyright infringement and publisher reserves the right to take any and all action to protect its copyright in the materials.

9. Warranties: Publisher makes no representations or warranties with respect to the licensed material.

10. Indemnity: You hereby indemnify and agree to hold harmless publisher and CCC, and their respective officers, directors, employees and agents, from and against any and all claims arising out of your use of the licensed material other than as specifically authorized pursuant to this license.

11. No Transfer of License: This license is personal to you and may not be sublicensed, assigned, or transferred by you to any other person without publisher's written permission.

12. No Amendment Except in Writing: This license may not be amended except in a writing signed by both parties (or, in the case of publisher, by CCC on publisher's behalf).

13. Objection to Contrary Terms: Publisher hereby objects to any terms contained in any purchase order, acknowledgment, check endorsement or other writing prepared by you, which terms are inconsistent with these terms and conditions or CCC's Billing and Payment terms and conditions. These terms and conditions, together with CCC's Billing and Payment terms and conditions (which are incorporated herein), comprise the entire agreement between you and publisher (and CCC) concerning this licensing transaction. In the event of any conflict between your obligations established by these terms and conditions and those established by CCC's Billing and Payment terms and conditions, these terms and conditions shall control. 
14. Revocation: Elsevier or Copyright Clearance Center may deny the permissions described in this License at their sole discretion, for any reason or no reason, with a full refund payable to you. Notice of such denial will be made using the contact information provided by you. Failure to receive such notice will not alter or invalidate the denial. In no event will Elsevier or Copyright Clearance Center be responsible or liable for any costs, expenses or damage incurred by you as a result of a denial of your permission request, other than a refund of the amount(s) paid by you to Elsevier and/ or Copyright Clearance Center for denied permissions.

\section{LIMITED LICENSE}

The following terms and conditions apply only to specific license types:

15. Translation: This permission is granted for non-exclusive world English rights only unless your license was granted for translation rights. If you licensed translation rights you may only translate this content into the languages you requested. A professional translator must perform all translations and reproduce the content word for word preserving the integrity of the article. If this license is to re-use 1 or 2 figures then permission is granted for non-exclusive world rights in all languages.

16. Posting licensed content on any Website: The following terms and conditions apply as follows: Licensing material from an Elsevier journal: All content posted to the web site must maintain the copyright information line on the bottom of each image; A hyper-text must be included to the Homepage of the journal from which you are licensing at http:// www.sciencedirect.com/science/journal/ xxxxx or the Elsevier homepage for books at http:// www.elsevier.com; Central Storage: This license does not include permission for a scanned version of the material to be stored in a central repository such as that provided by Heron/XanEdu. 
Licensing material from an Elsevier book: A hyper-text link must be included to the Elsevier homepage at http:/ / www.elsevier.com . All content posted to the web site must maintain the copyright information line on the bottom of each image.

Posting licensed content on Electronic reserve: In addition to the above the following clauses are applicable: The web site must be password-protected and made available only to bona fide students registered on a relevant course. This permission is granted for 1 year only. You may obtain a new license for future website posting.

For journal authors: the following clauses are applicable in addition to the above: Permission granted is limited to the author accepted manuscript version* of your paper.

*Accepted Author Manuscript (AAM) Definition: An accepted author manuscript (AAM) is the author's version of the manuscript of an article that has been accepted for publication and which may include any author-incorporated changes suggested through the processes of submission processing, peer review, and editor-author communications. AAMs do not include other publisher value-added contributions such as copy-editing, formatting, technical enhancements and (if relevant) pagination.

You are not allowed to download and post the published journal article (whether PDF or HTML, proof or final version), nor may you scan the printed edition to create an electronic version. A hyper-text must be included to the Homepage of the journal from which you are licensing at http:// www.sciencedirect.com/ science/journal/ xxxxx. As part of our normal production process, you will receive an e-mail notice when your article appears on Elsevier's online service ScienceDirect (www.sciencedirect.com). That e-mail will include the article's Digital Object Identifier (DOI). This number provides the electronic link to the published article and should be included in the posting of your personal version. We ask that you wait until you receive this e-mail and have the DOI to do any posting. 
Posting to a repository: Authors may post their AAM immediately to their employer's institutional repository for internal use only and may make their manuscript publically available after the journal-specific embargo period has ended.

Please also refer to Elsevier's Article Posting Policy for further information.

18. For book authors the following clauses are applicable in addition to the above: Authors are permitted to place a brief summary of their work online only.. You are not allowed to download and post the published electronic version of your chapter, nor may you scan the printed edition to create an electronic version. Posting to a repository: Authors are permitted to post a summary of their chapter only in their institution's repository.

20. Thesis/ Dissertation: If your license is for use in a thesis/ dissertation your thesis may be submitted to your institution in either print or electronic form. Should your thesis be published commercially, please reapply for permission. These requirements include permission for the Library and Archives of Canada to supply single copies, on demand, of the complete thesis and include permission for Proquest/ UMI to supply single copies, on demand, of the complete thesis. Should your thesis be published commercially, please reapply for permission.

Elsevier Open Access Terms and Conditions

Elsevier publishes Open Access articles in both its Open Access journals and via its Open Access articles option in subscription journals.

Authors publishing in an Open Access journal or who choose to make their article Open Access in an Elsevier subscription journal select one of the following Creative Commons user licenses, which define how a reader may reuse their work: Creative Commons Attribution License (CC BY), Creative Commons Attribution - Non 
Commercial - ShareAlike (CC BY NC SA) and Creative Commons Attribution - Non Commercial - No Derivatives (CC BY NC ND)

Terms \& Conditions applicable to all Elsevier Open Access articles:

Any reuse of the article must not represent the author as endorsing the adaptation of the article nor should the article be modified in such a way as to damage the author's honour or reputation.

The author(s) must be appropriately credited.

If any part of the material to be used (for example, figures) has appeared in our publication with credit or acknowledgement to another source it is the responsibility of the user to ensure their reuse complies with the terms and conditions determined by the rights holder.

Additional Terms \& Conditions applicable to each Creative Commons user license:

CC BY: You may distribute and copy the article, create extracts, abstracts, and other revised versions, adaptations or derivative works of or from an article (such as a translation), to include in a collective work (such as an anthology), to text or data mine the article, including for commercial purposes without permission from Elsevier

CC BY NC SA: For non-commercial purposes you may distribute and copy the article, create extracts, abstracts and other revised versions, adaptations or derivative works of or from an article (such as a translation), to include in a collective work (such as an anthology), to text and data mine the article and license new adaptations or creations under identical terms without permission from Elsevier

CC BY NC ND: For non-commercial purposes you may distribute and copy the article and include it in a collective work (such as an anthology), provided you do not alter or modify the article, without permission from Elsevier 
Any commercial reuse of Open Access articles published with a CC BY NC SA or CC BY NC ND license requires permission from Elsevier and will be subject to a fee.

Commercial reuse includes:

· $\quad$ Promotional purposes (advertising or marketing)

- $\quad$ Commercial exploitation ( e.g. a product for sale or loan)

- $\quad$ Systematic distribution (for a fee or free of charge)

Please refer to Elsevier's Open Access Policy for further information. 